Portland State University

PDXScholar

Winter 2-7-2018

\title{
Financial Strain and the Work-Home Interface: a Test of the Work-Home Resources Model from the Study for Employment Retention of Veterans (SERVe)
}

MacKenna Laine Perry

Portland State University

Follow this and additional works at: https://pdxscholar.library.pdx.edu/open_access_etds

Part of the Psychology Commons

Let us know how access to this document benefits you.

\section{Recommended Citation}

Perry, MacKenna Laine, "Financial Strain and the Work-Home Interface: a Test of the Work-Home Resources Model from the Study for Employment Retention of Veterans (SERVe)" (2018). Dissertations and Theses. Paper 4235.

https://doi.org/10.15760/etd.6119

This Dissertation is brought to you for free and open access. It has been accepted for inclusion in Dissertations and Theses by an authorized administrator of PDXScholar. Please contact us if we can make this document more accessible: pdxscholar@pdx.edu. 
Financial Strain and the Work-Home Interface: A Test of the Work-Home Resources Model from the Study for Employment Retention of Veterans (SERVe)

by

MacKenna Laine Perry

A dissertation submitted in partial fulfillment of the requirements for the degree of

Doctor of Philosophy

in

Applied Psychology

Dissertation Committee:

Leslie Hammer, Chair

Todd Bodner

Jennifer Dimoff

Kris Henning

Portland State University

2018 
(C) 2017 MacKenna Laine Perry 


\begin{abstract}
Money is consistently one of the most common and significant sources of stress in America. The American Psychological Association's annual Stress in America survey has found that money and work have been two of the top sources of "very" or “somewhat" significant stress for Americans since 2007, when the first report was released (American Psychological Association, 2017). Drawing upon the work-home resources model (ten Brummelhuis \& Bakker, 2012), this study examined the longitudinal effects of financial strain as a component of the work-home interface on a sample of 512 employed veterans from the post-9/11 era. The work-home resources model posits that contextual demands and contextual resources in one domain (i.e., work or non-work) influence outcomes in the opposite domain through losses and gains of personal resources. Lower scores on a measure of financial strain represent better ability to meet financial needs, and the ability to meet financial needs is argued to represent a personal capital resource that could serve as a mechanism in the work-home interface. Using three waves of data, the study examined longitudinal effects on both behavioral and attitudinal outcomes of importance to veterans and organizations alike. Results did not confirm the role financial strain plays in the interface between work and home domains, as hypotheses were generally unsupported. Implications for both theory and practice, as well as limitations of the study and future directions for research are discussed.
\end{abstract}




\section{Acknowledgements}

First and foremost, I would like to express my deepest gratitude to my advisor and chair, Dr. Leslie Hammer, for all she has done to guide, support, and teach me. Each year that I have known her, I feel as though I have learned about 5\% of the grand total of all she does for me and her other students. By that logic, I am now up to knowing $25 \%$ of all that she does for us, and even that small amount that I know about is enough to feel thoroughly overwhelming. Thank you for caring about us so deeply and doing all you can to foster our growth. I often joke that if anyone can help all of your dreams come true, it's Leslie, but it feels like the truth. Thank you for everything.

I would also like to thank my dissertation committee members, Dr. Todd Bodner, Dr. Jennifer Dimoff, and Dr. Kris Henning. Thank you for all of your time and guidance in helping me learn and grow through this project. I am so grateful to get to work with you all and learn from your expertise. To Dr. Todd Bodner in particular, thank you for the countless times you have encouraged and taught me throughout all of our work together. It continues to be an honor to work with you.

Next, I would like to express my utmost gratitude to my partner, family, and friends for their constant support and encouragement. To my partner and family, thank you for being my biggest fans and my endless source of support through every day of this degree (and the rest of my life, too). To Tori Crain - you are the best mentor there is, and to get to call you my friend, too? I am the luckiest! To Alexa Garcia, thank you for being on my side, and by my side, through every day.

Finally, I would like to acknowledge the research team and funding agency responsible for the data presented in this study. Data for the present study were collected 

as part of the Study for Employment Retention of Veterans (SERVe). The U.S. Army Medical Research Acquisition Activity, 820 Chandler Street, Fort Detrick MD 217025014 is the awarding and administering acquisition office. This work was supported by the Office of the Assistant Secretary of Defense for Health Affairs, through the USAMRMC Broad Agency Announcement under Award No. W81XWH-13-2-0020. Opinions, interpretations, conclusions and recommendations are those of the author and are not necessarily endorsed by the Department of Defense. 


\section{Table of Contents}

Abstract.......................................................... i

Acknowledgements.................................................... ii

List of Tables....................................................

List of Figures.................................................. vi

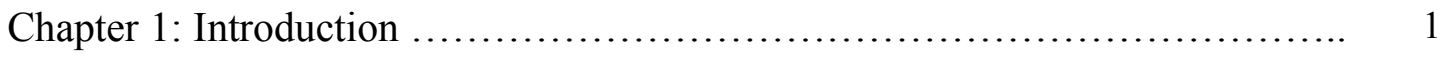

Chapter 2: Financial Strain......................................... 8

Chapter 3: The Work-Family Interface.................................... 14

Chapter 4: The Work-Home Resources Model........................... 24

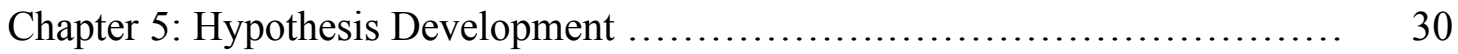

Chapter 6: Method ................................................ 44

Chapter 7: Analytic Approach ....................................... 54

Chapter 8: Results $\ldots \ldots \ldots \ldots \ldots \ldots \ldots \ldots \ldots \ldots \ldots \ldots \ldots \ldots \ldots \ldots \ldots \ldots \ldots \ldots \ldots ., 60$

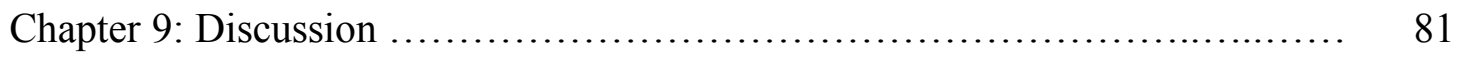

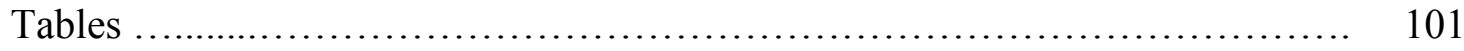

Figures......................................................... 110

References....................................................... 145 


\section{List of Tables}

Table 1. Items from Study Measures.................................. 101

Table 2. Means, Standard Deviations, and Intercorrelations................ 103

Table 3. Correlations of Financial Strain With Other Study Variables........... 109 


\section{List of Figures}

Figure 1. Conceptual model from the work-home resources model (ten

Brummelhuis \& Bakker, 2012)...................................... 110

Figure 2. Hypothesized model of the home-to-work process................. 111

Figure 3. Hypothesized model of the work-to-home process................ 112

Figure 4. Participants and conditions for the Study for Employment Retention

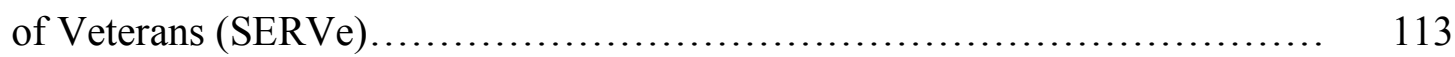

Figure 5. Standardized results for structural equation model $1 \ldots \ldots \ldots \ldots \ldots \ldots . . . \ldots 114$

Figure 6. Standardized results for structural equation model $2 \ldots \ldots \ldots \ldots \ldots \ldots . .115$

Figure 7. Standardized results for structural equation model $3 \ldots \ldots \ldots \ldots \ldots \ldots . .116$

Figure 8. Standardized results for structural equation model $4 \ldots \ldots \ldots \ldots \ldots \ldots . \quad 117$

Figure 9. Standardized results for structural equation model $5 \ldots \ldots \ldots \ldots \ldots \ldots \ldots . . . \ldots 118$

Figure 10. Standardized results for structural equation model $6 \ldots \ldots \ldots \ldots \ldots \ldots . . . . . .119$

Figure 11. Standardized results for structural equation model $7 \ldots \ldots \ldots \ldots \ldots \ldots . \quad 120$

Figure 12. Standardized results for structural equation model $8 \ldots \ldots \ldots \ldots \ldots \ldots . \quad 121$

Figure 13. Standardized results for structural equation model $9 \ldots \ldots \ldots \ldots \ldots \ldots . . \ldots 122$

Figure 14. Standardized results for structural equation model $10 \ldots \ldots \ldots \ldots \ldots \ldots \quad 123$

Figure 15. Standardized results for structural equation model $11 \ldots \ldots \ldots \ldots \ldots . \quad 124$

Figure 16. Standardized results for structural equation model $12 \ldots \ldots \ldots \ldots \ldots \ldots . \quad 125$

Figure 17. Standardized results for structural equation model $13 \ldots \ldots \ldots \ldots \ldots \ldots . \quad 126$

Figure 18. Standardized results for structural equation model $14 \ldots \ldots \ldots \ldots \ldots . \quad 127$

Figure 19. Standardized results for structural equation model $15 \ldots \ldots \ldots \ldots \ldots \ldots . \quad 128$ 
Figure 20. Standardized results for structural equation model $16 \ldots \ldots \ldots \ldots \ldots . .129$

Figure 21. Standardized results for structural equation model $17 \ldots \ldots \ldots \ldots \ldots . \quad 130$

Figure 22. Standardized results for structural equation model $18 \ldots \ldots \ldots \ldots \ldots \ldots . \quad 131$

Figure 23. Standardized results for structural equation model $19 \ldots \ldots \ldots \ldots \ldots . \quad 132$

Figure 24. Standardized results for structural equation model $20 \ldots \ldots \ldots \ldots \ldots . \quad 133$

Figure 25. Standardized results for structural equation model $21 \ldots \ldots \ldots \ldots \ldots . .134$

Figure 26. Standardized results for structural equation model $22 \ldots \ldots \ldots \ldots \ldots . .135$

Figure 27. Standardized results for structural equation model $23 \ldots \ldots \ldots \ldots \ldots \ldots . \quad 136$

Figure 28. Standardized results for structural equation model $24 \ldots \ldots \ldots \ldots \ldots \ldots . \quad 137$

Figure 29. Standardized results for structural equation model $25 \ldots \ldots \ldots \ldots \ldots \ldots . \quad 138$

Figure 30. Standardized results for structural equation model $26 \ldots \ldots \ldots \ldots \ldots . .139$

Figure 31. Standardized results for structural equation model $27 \ldots \ldots \ldots \ldots \ldots \ldots \quad 140$

Figure 32. Standardized results for structural equation model $28 \ldots \ldots \ldots \ldots \ldots \ldots . \quad 141$

Figure 33. Standardized results for structural equation model $29 \ldots \ldots \ldots \ldots \ldots . \quad 142$

Figure 34. Standardized results for structural equation model $30 \ldots \ldots \ldots \ldots \ldots . \quad 143$

Figure 35. Standardized results for structural equation model $31 \ldots \ldots \ldots \ldots \ldots . \quad 144$ 


\section{Chapter 1: Introduction}

As of April 2017, there were 7.1 million unemployed workers in the United States (Bureau of Labor Statistics, 2017a). Though unemployment rates have improved considerably over the last several years, there continue to be high rates of underemployed and marginally attached workers struggling to find jobs, as well. An additional 5.3 million workers are classified as involuntary part-time workers (i.e., workers who would prefer full-time employment), while 1.5 million workers are classified as marginally attached (i.e., individuals who searched for jobs within the past twelve months but were not counted as unemployed because they had not searched in the past four weeks). Even within employed individuals, financial stressors are common. In the most recent report of occupational wages, only two of the ten largest occupations in the United States showed an average wage above the U.S. mean of $\$ 49,630$; the two above-average wages were for registered nurses and for general and operations managers (Bureau of Labor Statistics, 2017b). Several of the remaining eight largest occupations fell substantially below the mean, including retail salespersons (i.e., \$27,180), cashiers (i.e., \$21,680), and food preparation and serving workers (i.e., \$20,460). Due to these and other wage issues, in combination with financial demands, many workers experience a discrepancy between income and financial needs that threatens their ability to meet demands.

Within the U.S. military service member population, financial stressors are of particular concern. As of September 2015, there were over 4.7 million United States veterans from the post-9/11 era (National Center for Veterans Analysis and Statistics, 2015). As veterans return from service and enter the civilian workforce, many face issues of civilian unemployment and underemployment, often while juggling National Guard or 
Reserve Component duties. Approximately 53\% of veterans in 2010 and 2011 faced a period of unemployment within 15 months of separation (Department of Veteran Affairs, 2015). Additionally, veteran status is linked with 50-65\% higher odds of unemployment when compared with civilians of similar characteristics, with even higher odds for female veterans (Kleykamp, 2013). A lack of employment stability during the transition to the civilian workforce likely contributes to stress experiences related to financial circumstances, especially as this lack of employment stability is often coupled with other reintegration challenges. For example, Adler and colleagues (2011) studied a sample of post-9/11 veterans, both employed and unemployed, and found that both alcohol/illicit drug use and psychiatric disorders, including major depressive disorder, posttraumatic stress disorder, and generalized anxiety disorder, were associated with several types of work impairment and productivity loss.

In addition to challenges of transitioning back to civilian employment, financial management is also known to be a challenge veterans face. One study by Elbogen and colleagues (2013) found, in a sample of over 1,000 veterans, that $30 \%$ reported "money mismanagement" (e.g., bouncing a check, going over credit limit), which was associated with increased likelihood of homelessness over the subsequent year. Another study found that veterans who did not have enough money to cover basic needs were more likely to experience criminal arrest, homelessness, substance abuse, suicidal behavior, aggression, and other adjustment issues (Elbogen, Johnson, Wagner, Newton, and Beckham, 2012). While veterans are not alone in facing money management challenges (e.g., the annual American Psychological Association's [2017] Stress in America survey showed that 61\% of Americans rated money as a very or somewhat significant source of stress), 
transitioning veterans face challenges that the average civilian does not encounter. Preventing financial stress experiences is important to preventing negative outcomes regardless of military status, but is particularly important for veterans, given the other challenges veterans already have to face as they transition back to civilian life.

To help determine how both organizations and society at large can better aid transitioning veterans, additional research on the role of financial stress experiences in both the work and home domains, as well as the interface between work and home, is needed. Greater knowledge of predictors that shape financial stress experiences will provide targets to actively try to improve financial stress experiences in veterans. Likewise, greater knowledge of outcomes from financial stress experiences will provide motives for organizations and governmental bodies to support this type of intervention work. To support these goals, the purpose of the current study was to determine the role of veterans' financial strain in the work-home interface over a period of nine months.

\section{Financial Stress Experiences}

Financial stress experiences come in many different forms. Conger and colleagues (1994) argue that financial stress experiences often span both objective and subjective conceptualizations, even within the same stressor. As a result, financial stressors have been defined as "aspects of economic life that are potential stressors for employees and their families and consist of both objective and subjective components reflecting the employment and income dimensions of the worker-earner role" (Probst, 2005, p. 268). Researchers thus explore financial stressors through both objective and subjective measures. Objective financial stressors include loss of income or duration of unemployment, while subjective financial stressors include worries about job loss or fears 
of ability to meet financial demands.

In existing research, which will be described in greater detail Chapter 2, financial stressors have been tied to psychological and physiological health outcomes. However, it is important to emphasize that individuals with similar incomes can still have vastly different experiences and outcomes, based on non-employment related factors (e.g., larger families for support or differing housing costs; Kahn \& Pearlin, 2006). While there is a separate body of evidence surrounding the relationship objective financial measures such as income share with health and well-being, the experience of individuals can still differ greatly beyond the effects of objective stressors alone, based on their subjective perceptions of their financial circumstances. Lazarus and Folkman (1984) argue that it is the perception of stress may be more important than the objective exposure to stress. Thus, the current study focuses on a more subjective stressor through examination of what has been termed financial strain in past literature. Financial strain represents perceptions of whether one's income is adequate to meet demands, such as having enough money to pay bills and to buy necessities (Angel, Frisco, Angel, \& Chiriboga, 2003; Son \& Wilson, 2015). Financial strain measures thus account for an individual's assessment of their needs and ability to meet those needs. Chapter 2 provides a more detailed discussion of this construct.

\section{Study Overview and Contributions}

The theoretical foundation for this study lies in the work-home resources model (ten Brummelhuis \& Bakker, 2012), proposed here as a framework within which to examine the role of financial strain in veterans' work-home experiences over time. The work-home resources model posits that contextual demands and contextual resources in 
one domain (i.e., work or non-work) influence outcomes in the opposite domain through losses and gains of personal resources. One category of personal resources proposed in the model is capital resources, which reflects the inclusion of financial resources as one potential personal resource of importance. Financial strain, as a measure of ability to meet financial needs, represents a personal capital resource that may serve as a key mechanism in the work-home interface. The current study thus focuses specifically on utilizing the work-home resources model to expand understanding of how work and home demands and resources impact veterans' health, well-being, and attitudes through levels of financial strain.

The study tests the influence of financial strain in both directions of the interface between domains: work to home, as well as home to work. Ten Brummelhuis and Bakker (2012) propose three types of outcomes, each found in both the work and home domains, in their model, including production, behavioral, and attitudinal. I focus on home and work outcomes in the behavioral and attitudinal areas in particular. Behavioral outcomes in the hypothesized models include health and safety behaviors, as well as job-search behaviors. Attitudinal outcomes in the hypothesized models include satisfaction, commitment, and turnover intentions. Furthermore, in assessing the role of contextual resources, the hypothesized models target social support resources from both home and work domains. Figure 1 depicts the conceptual model from the work-home resources model, and Figures 2 and 3 depict the hypothesized mediation models, all of which will be described in greater detail in the following chapters.

This study is built around providing several contributions to the current literature. First, the study tests the primary propositions of the work-home resources model, which 
is still relatively new to the literature and has not yet received substantial testing. The study focuses on the role of financial strain as a personal resource in the interface between the work and home domains. By expanding understanding of how a financial stressor can serve as a link between domains, this study contributes to untangling the role of financial stressors in order to find the best targets for interventions and provide support for why these interventions are important. This study also tests the work-home resources model by expanding upon previous financial strain models. While a variety of well-being outcomes have been explored in relation to financial stressors, several behavior and attitudinal outcomes have not been explored in relation to financial strain. For example, workplace safety has been largely ignored in the financial stress literature. Probst and Brubaker (2001) examined the effects of job insecurity on employee safety, but financial strain has been thus far left out of this relatively recent intersection of the financial stress and safety literatures.

Second, the current study utilized a longitudinal approach, integrating three waves of data over a period of nine months and specifically testing whether the particular organization a veteran works in affects veteran outcomes. Probst (2010) recommends the use of a multilevel approach when investigating relations between occupational stress and well-being, calling for increased use of multilevel methods that take into account the personal and contextual factors that align with most contemporary stress theories and models. Additionally, Bliese and Jex (2002) also note the importance of increased focus on multilevel perspectives in occupational health research. The addition of several social support resources to this literature is novel, while also helping to meet the call for multilevel conceptualizations. 
Finally, this study contributes to the current literature by focusing on an employed sample of veterans and service members. Financial stress has previously been examined more commonly in the context of job loss (e.g., Creed, Muller, \& Machin, 2001; Ullah, 1990), but perceptions of financial stress are much less commonly measured within employed samples, with the exception of the construct of job insecurity. Perceptions of financial stress that are not specific to unemployment or job insecurity are even less often measured in veteran samples. More research is needed to assess how financial stress influences employed individuals in general (Sinclair \& Cheung, 2016), and still more to assess how financial stress influences transitioning veterans. This study seeks to fill that gap and provide more research on veteran reintegration experiences. In general, past research on financial strain has focused on those populations considered to be at higher risk, such as elderly individuals (e.g., Angel et al., 2003) or clinical populations (e.g., Mattsson et al., 2008). By targeting a sample of employed veterans and service members, this study contributes new understanding that can be applied to both veterans and the broader employed population.

Because the current study bridges the financial stress and work-family literatures, which are not often integrated, the next two chapters focus on providing an overview of each as it pertains to the focal study variables and relationships. Subsequent chapters present descriptions of the theoretical model, the hypothesized models, the methods used in the study, the analysis strategy, and, finally, an outline and discussion of the results of the study. 


\section{Chapter 2: Financial Strain}

Financial stress represents "aspects of economic life that are potential stressors for individuals and families" (Voydanoff, 1990, p. 1102). Financial stress measures have been classified into four categories using the combination of two different criteria: employment versus income stressors and subjective versus objective stressors (Probst, 2005; Sinclair, Sears, Probst, \& Zajack, 2010; Voydanoff, 1990). Employment stressors are those related to maintaining employment status, while income stressors are based on ability to meet financial demands. Subjective stressors represent individuals' perceptual assessments of their situation, while objective stressors represent direct measures of employment or finances. Thus, the four categories are objective employment stressors (e.g., current employment status), subjective employment stressors (e.g., perceptions of job insecurity), objective income stressors (e.g., inability of income to meet financial need), and subjective income stressors (e.g., perceived adequacy of income, including financial strain, the focus of this study).

A recent review by Sinclair and Cheung (2016) covered the current state of the financial stress literature and supported a need for further development. Sinclair and Cheung highlight what is a striking lack of occupational health research focused on financial stress and note that the majority of the research that does exist has focused on employment stressors, such an unemployment and job insecurity. Because modern society depends upon money to meet basic life needs, and employment provides a source of money, finances are innately intertwined with work experiences. Thus, occupational health researchers are uniquely positioned to target this area of potential stress from the perspective of the worker in particular. Application of occupational health theories to 
financial stress experiences can add to the broader literature on financial stress, which spans numerous fields of study, and provides a unique and critical perspective. One primary criticism of this literature has been the lack of theoretical background, and occupational health is well positioned to improve upon this deficiency. The current study utilizes an occupational health theory - the work-home resources model (ten Brummelhuis \& Bakker, 2012) — to explore financial stress experiences.

\section{Subjective Income Stressors}

Falling into the subjective income category described above, financial strain represents a perception of ability to meet financial need (Son \& Wilson, 2015). While objective income measures can provide important information about an individual's experiences, the subjective sense of income adequacy cannot be directly observed (Angel et al., 2003), yet may be of even greater importance in understanding individual experiences and outcomes. Although objective income is related to subjective financial strain perceptions, they are not perfectly aligned and can differ by individual (Mirowsky \& Ross, 1999; Young \& Schieman, 2012). A study by Morra and colleagues (2008) found that objective student debt was weakly related to financial strain, but anticipated levels of future debt were more strongly related to financial strain, illustrating the differences between subjective and objective measurement and the importance of context and life circumstances. Various demands and lifestyle choices can substantially impact financial need and income adequacy (e.g., having children requires greater economic resources; Ross \& Huber, 1985), and these differences are better captured with subjective measures. 
One reason subjective measures provide key information is that they represent an assessment that can be used when considering the stressor-strain relationship. A stressor is "the particular relationship between the person and the environment that is appraised by the person as taxing or exceeding his or her resources and endangering his or her wellbeing" (Lazarus \& Folkman, 1984, p. 19). Stressors therefore require appraisal to be so defined. While a measure like objective income may also be a stressor, in that it leads to a strain (i.e., a negative consequence of stress; Koeske \& Koeske, 1993), that is only the case if the individual appraises it as a stressor. Financial strain and possible ways to reduce its effects are thus critical to understand because if financial strain continues over time, it becomes a chronic stressor, which can cause more negative outcomes over time than a discrete stressor (e.g., Kahn \& Pearlin, 2006; Thoits, 2010).

\section{Financial Stress and Well-Being}

Various financial stressors, including unemployment, job insecurity, and income inadequacy have been tied to psychological and physiological health (e.g., Catalano, Dooley, Wilson, \& Hough, 1993; Dooley, Prause, \& Ham-Rowbottom, 2000), social relationships and family functioning (e.g., Burke \& Greenglass, 2001; Vinokur, Price, \& Caplan, 1996), and job-specific outcomes (e.g., Rosenblatt, Talmud, \& Ruvio, 1999; Sverke, Hellgren, \& Näswall, 2002). Financial strain, in particular, can lead to decreased psychological well-being (Martin, Gruendahl, \& Martin, 2001), decreased trust in others (Krause, 1991), decreased life satisfaction (Dolan, Peasgood, \& White, 2008; Watson, Barber, \& Dziurawiec, 2015), increased depression (Kahn \& Pearlin, 2006), and decreased self-esteem (Pearlin et al., 1981). Further exploration of behavioral and attitudinal outcomes associated with financial strain, as were assessed in the current 
study, provide novel contributions to the financial strain literature and improve understanding of its effects. Behavioral work outcomes assessed include safety compliance and job search behaviors, while attitudinal work outcomes include job satisfaction, organizational commitment, and turnover intentions. Behavioral home outcomes include diet and exercise behaviors, while the focal attitudinal home outcome be life satisfaction. Empirical support for, or description of novelty of, each of the hypothesized relationships are described in Chapter 5.

\section{Frameworks of Financial Stress}

Sinclair and colleagues (2010) proposed a multilevel model of financial stress and employee well-being that integrates macroeconomic, organizational, and individual factors into a single, comprehensive model. The broader model considers antecedents, mechanisms, and outcomes across all three levels. The present study applies many of these relationships. Within a portion of this model, Sinclair and colleagues propose that individual financial stress perceptions are influenced by macroeconomic, organizational, and individual antecedents, as well as organizational strategies and individual moderators, and that financial stress perceptions are tied to individual healthrelationships that are all applicable to the hypothesized models.

An additional conceptualization of financial strain that provides important background for this study is that of financial strain in the resource context. Past researchers have conceptualized income adequacy as a resource (e.g., Lynch \& Kaplan, 2000). Adequate income provides access to not just the ability to meet basic needs, but also to a larger variety and better quality of goods and conditions, as well as ready access to the skills and labor of others. Thus, the income adequacy represented by low financial 
strain is a resource, and high financial strain represents a lack of resource in that income is perceived as insufficient to meet financial demands.

\section{Financial Stress in Veterans}

Financial stress is particularly important to study in veteran populations, both because existing issues have been documented and need to be further explored and because veterans already face so many other obstacles during and following reintegration to civilian life. Several studies have focused on the employment stressor side of the financial stress literature within veteran populations. One Department of Veteran Affairs report (2015) found that over 50\% of veterans in 2010 and 2011 were unemployed at some point within 15 months of separating from the military. Kleykamp (2013) found that veterans have substantially higher odds of unemployment compared to their civilian counterparts, with the highest odds for female veterans.

Other studies have focused on the income stressor side of financial stress in veterans. Elbogen and colleagues (2013) found that 30\% of veterans reported "money mismanagement”. Adler and colleagues (2011) found that, even among employed veterans, $12 \%$ reported they could not "make ends meet." This could be particularly problematic because Elbogen and colleagues (2012) found that veterans who could not cover basic needs with their existing income and financial resources were more likely to experience criminal arrest, homelessness, substance abuse, suicidal behavior, and aggression. Beyond obtaining enough income, studies have found that military families face other financial challenges. Oron (2006) and others have found that military families are particularly targeted by predatory lending practices, such as payday and car title loans. These factors, combined with the many other simultaneous challenges of 
reintegration, make financial stress an important aspect of reintegration to consider and study. 


\section{Chapter 3: The Work-Family Interface}

Scholars have long considered the interplay between work and nonwork aspects of life, but especially so over the last several decades (Veal, 2004). This area of study is commonly referred to as the work-family interface, despite how broadly the "family" domain can be defined, often encompassing traditional family roles (e.g., spousal, parental, eldercare) as well as roles related to friendships, communities, leisure activities, and the self (e.g., Kreiner, 2006). Although some studies measure specific nonwork roles (e.g., Boswell \& Olson-Buchanan, 2007; Butler, 2007), previous research has primarily either combined nonwork roles into a single measure or used single-role-specific measures that are not supported by strong evidence of construct validity (Wilson \& Baumann, 2015). While differentiating among nonwork roles provides a finer-grained analysis of the work-nonwork interface, the current study follows the tradition of the literature in referring the work-family interface more broadly. This distinction represents an important area for continued future research.

Throughout the development of society, the roles that people hold have evolved dramatically. Over the past 60 years, increased participation of women in the workforce has led to changes in the structure of work and family roles, increasing the percentage of dual-career couples and changing responsibilities within the family to meet childcare and household needs (Hammer \& Zimmerman, 2011). The aging of the workforce and the broader population has also changed the structure of nonwork life, with more individuals retiring later and more workers providing eldercare for aging family members — and often even simultaneously providing care for both children and elders (Neal \& Hammer, 2007). 
Developments in technology have helped workers meet these changing demands, allowing greater flexibility in both time and location of work, such as through remote and virtual work. Meta-analytic research has shown that flexible work arrangements are related to lower work interference with family life (Allen, Johnson, Kiburz, \& Shockley, 2013), making these organization-level policies very valuable to workers. However, national policies to support work-family needs have been slow to keep up. The United States, in particular, offers few national policies to support working families when compared with other countries that are at both similar and less advanced stages of development (Heymann \& McNeill, 2012; Winston, 2014). In spite of the lack of national support for work-family needs - or perhaps even because of the lack of national support, as Hammer and colleagues (2006) argued — organizations in the United States continue to develop their own policies. However, these policies are almost exclusively available to higher-wage workers and those in large organizations, leaving most low-wage workers with little support, even though they are often most in need (Hammer et al., 2013). Since the Family and Medical Leave Act (FMLA) was passed, states and cities have begun to implement their own policies and procedures, including some paid family and sick leave policies, as well as temporary disability insurance (Winston, 2014).

\section{Theoretical Models}

A wide selection of theories has been used to guide work-family research; however, Matthews and colleagues (2016) present four theories that have been most consistently relied upon in work-family research: role theory, systems theory, conservation of resources theory, and boundary theory. While all four theories have been 
important to the work-family field, the first three are particularly relevant to this study and will be described next.

The first relevant work-family theory is that of role theory (Kahn, Wolfe, Quinn, Snoek, \& Rosenthal, 1964), which is perhaps the most foundational. Role theory posits that roles are determined by others' expectations of appropriate behaviors. Furthermore, when the demands of one role are not compatible with the demands of another role, interrole conflict occurs, often leading to strain (Katz \& Kahn, 1978). In the work-family literature, Greenhaus \& Beutell (1985) define work-family conflict as "a form of interrole conflict in which the role pressures from the work and family domains are mutually incompatible in some respect" (p. 77). Work-family conflict is bi-directional (i.e., workto-family and family-to-work) and is thought to consist of three types: time-based, strainbased, and behavior-based conflict. Beyond creating conflict, engagement with multiple roles also has potential to benefit individuals, as roles help build self-definition, guide behavior, and create meaningfulness (Thoits, 1983; 1986). This positive view of the interaction between roles has given rise to the work-family enrichment literature, which argues that work and nonwork roles can be beneficial to each other (Edwards \& Rothbard, 2000).

Role theory thus contributes foundational support to the work-home resources model because the work-home resources model presents ideas about interactions between the work and home domains. The processes described in the model reflect conflict and enrichment processes (ten Brummelhuis \& Bakker, 2012), as demands in one domain are posited to lead to negative outcomes in the other domain through differences in personal 
resources (i.e., conflict), while resources in one domain are posited to lead to beneficial outcomes in the other domain through resource accumulation (i.e., enrichment).

A second relevant theory in work-family research is systems theory, which argues that two or more interrelated parts make up a system, and that there are four interrelated systems (Bronfenbrenner, 1977). A microsystem consists of an individual and their immediate situation. A mesosystem is made up of interactions between microsystems. An exosystem includes other social structures that influence behavior. Finally, a macrosystem is the broader, often society-level patterns that show the values of the culture. Hammer and Zimmerman (2011) developed an integrative work-family systems model that incorporates both role theory and systems theory and proposes that work and nonwork domains are microsystems within the mesosystem of the work-family interface. The model also includes the broader exosystem of community, organizational, and family factors, as well as the macrosystem of society, incorporating socioeconomic, legal, and political factors.

Systems theory is built into several aspects of the work-home resources model and thus provides support for the current study. First, contextual demands, contextual resources, personal resources, and key resources in the work-home resources model all reflect aspects of the microsystem and interactions between microsystems, in that the influence of several individual difference variables and the interactions between the individual's work and home domains are modeled. Second, macro resources in the workhome resources model reflect the inclusion of the exosystem and/or macrosystem.

A final foundational work-family theory — perhaps the most directly relevant — is that of conservation of resources theory (Hobfoll, 1989; 2002). Conservation of resources 
theory posits that individuals are motivated by the desire to obtain, maintain, and protect resources, and that threats to resources, loss of resources, and lack of resource gain following investment of resources all can lead to strain. Resources are very broadly defined within conservation of resources theory, consisting of objects, personal characteristics, conditions, or energies that the individual values or that can help the individual gain further resources. Conservation of resources theory has been criticized for this broad definition (e.g., Halbesleben, Neveu, Paustian-Underdahl, \& Westman, 2014), but recent work continues to refine and clarify the definition of resources. One such contribution is the work-home resources model, which categorizes resources based on dimensions of both source and transience. The work-home resources model is heavily based in conservation of resources theory, which will be discussed in Chapter 4 .

\section{Key Constructs}

The most common conceptualization of the interactions between work and nonwork domains distinguishes between work-family conflict and work-family enrichment. Work-family conflict occurs when the demands of one role interfere with the demands of another role (Greenhaus \& Beutell, 1985), while work-family enrichment occurs when involvement in one role benefits quality of life in another role (Edwards \& Rothbard, 2000). Conflict and enrichment can occur bidirectionally, with conflict or enrichment originating from the work domain and impacting the nonwork domain, or originating from the nonwork domain and impacting the work domain.

\section{Known Predictors and Outcomes}

A substantial body of research has been devoted to antecedents and consequences of both conflict and enrichment. The following review will highlight several key 
predictors and outcomes of both, distinguishing between work-to-family and family-towork processes when possible, as predictors and outcomes are different for each originating domain (e.g., Frone, Russell, \& Cooper, 1992). Additionally, the review will rely primarily on meta-analytic evidence to help summarize this large body of work.

Predictors of conflict. Across the work-family conflict literature, there is substantial evidence for unique antecedents for the two directions of conflict. Within the work domain, research suggests that elements of the work role are more strongly related to work-to-family conflict (WTFC) than to family-to-work conflict (FTWC) (Byron, 2005). For example, a meta-analysis by Michel and colleagues (2011a) found that work role stressors, such as role ambiguity, work involvement, workplace social support, and work characteristics like task variety and job autonomy all significantly predicted WTFC, with only a few of these work factors significantly predicting FTWC. Within the realm of workplace social support, a more finely grained meta-analysis conducted by Kossek and colleagues (2011) found that supervisor and organization support are more strongly related to employee WTFC when the support measured is specific to work-family needs rather than general support.

Elements of the family role are more mixed in their relationships with WTFC and FTWC, though the general trend holds that family factors relate more strongly with FTWC, aligning with the pattern that work factors relate more strongly with WTFC (Byron, 2005). Michel and colleagues (2011a) found that family stressors, family social support, and family climate predict FTWC and WTFC, with family role involvement also significantly predicting WTFC. Effects were generally larger for the paths from family factors to FTWC than to WTFC. Byron (2005) found that number of children 
significantly predicted both WTFC and FTWC, and income was related to WTFC but not FTWC.

Individual characteristics and other domain-unspecific factors are weakly related to both WTFC and FTWC, overall (Byron, 2005). Gender, for example, showed only mild effects on FTWC, though sex differences did appear when parenthood was considered, with mothers experiencing higher conflict than fathers (Byron, 2005). Negative affectivity/neuroticism, on the other hand, was one of the strongest predictors of WTFC in Michel and colleagues' (2011a) meta-analysis and also showed a moderate relationship to FTWC. Few consistent differences have been found across national contexts, with one meta-analysis finding no differences in WTFC in cultural, institutional, or economic national factors, though FTWC differed by collectivism, economic gender gap, and within (as opposed to outside of) the United States (Allen, French, Dumani, \& Shockley, 2015).

Predictors of enrichment. Largely because of its relative novelty to the workfamily literature, there is much less literature surrounding predictors of work-family enrichment. The research that does exist has generally found that work factors are more highly predictive of work-to-family enrichment (WTFE) than family-to-work enrichment (FTWE) (Crain \& Hammer, 2013). Some work factors linked to both WTFE and FTWE include burnout (Innstrand, Langballe, Espnes, Falkum, \& Aasland, 2008) and familysupportive supervisor behaviors (Hammer, Kossek, Yragui, Bodner, \& Hanson, 2009). Work factors that have so far been linked to WTFE include organizational citizenship behaviors (Kwan \& Mao, 2011), family-supportive organization perceptions (Wayne, 
Casper, Matthews, \& Allen, 2013), and schedule flexibility (Carlson, Grzywacz, \& Kacmar, 2010).

Turning to the family domain, nonwork factors have typically shown stronger relationships to FTWE than WTFE (Crain \& Hammer, 2013). Much of this research has focused on social support, though other relationship factors are also related to FTWE, such as relationship satisfaction (Stevens, Minnotte, Mannon, \& Kiger, 2007). Some individual, domain-unspecific constructs have also been tied to enrichment, with a metaanalysis by Michel and colleagues (2011b) finding that extraversion, agreeableness, conscientiousness, and openness to experience were positively related to enrichment. More research is needed to continue exploring antecedents of work-family enrichment across work, nonwork, and individual factors.

Conflict outcomes. Work-specific outcomes of work-family conflict are perhaps the most extensively studied. Earlier meta-analyses tied WTFC to decreased job satisfaction (Kossek \& Ozeki, 1998), increased turnover, turnover intentions, and absenteeism, and decreased organizational commitment and job performance (Allen et al., 2000). A more recent meta-analysis by Amstad and colleagues (2011) found that both WTFC and FTWC are significantly related to work-specific outcomes, such as organizational citizenship behaviors, work-related stress, career satisfaction, and burnout and exhaustion, though WTFC shows stronger relationships with work-specific outcomes in general.

Family-specific outcomes have also been widely tied to experiences of workfamily conflict. Kossek and Ozeki’s (1998) meta-analysis found WTFC and FTWC were related to decreased life satisfaction. Allen and colleagues (2000) showed that WTFC is 
also related to marital satisfaction and family satisfaction, in addition to life satisfaction. Amstad and colleagues' (2011) meta-analysis further found that WTFC and FTWC were significantly related to family-related stress and martial satisfaction, but stronger relationships were found with FTWC and family-specific outcomes than were found with WTFC.

Conflict has also been linked to several key health and well-being outcomes. Amstad and colleagues (2011) tied both WTFC and FTWC to general stress, while Allen and colleagues (2000) found relationships between WTFC and somatic and physical symptoms, as well as general psychological strain, burnout, and depression. Nohe, Meier, Sonntag, and Michel (2015) further explored the relationships WTFC and FTWC have with strain in a meta-analysis, finding that there are reciprocal relationships between both directions of conflict and strain that hold across a variety of potential moderators.

Enrichment outcomes. Within the work domain, a meta-analysis by McNall and colleagues (2010) tied both WTFE and FTWE to increased job satisfaction and affective organizational commitment and found that WTFE is more strongly related to work outcomes than is FTWE. A review by Crain and Hammer (2013) also found several studies that point to a negative relationship between WTFE and turnover intentions.

Within the family domain, WTFE and FTWE are both tied to increased family satisfaction (McNall et al., 2010). Shockley and Singla (2011) explored relationships between enrichment and satisfaction in different domains and found that WTFE was more strongly related to job satisfaction, while FTWE was more strongly related to family satisfaction, though both directions of enrichment were linked to satisfaction in both domains. 
Research has also tied enrichment to health and well-being outcomes. McNall and colleagues (2010) found that both WTFE and FTWE are positively related to mental and physical health. Other studies have suggested that work-family positive spillover, a construct closely related to enrichment, is associated with decreased odds of problem drinking (Gryzwacz \& Marks, 2000) and decreased depressive symptoms of both employees and their spouses (Hammer et al., 2005).

\section{The Work-Home Interface and Veterans}

Several studies have begun to explore the work-family experiences of veterans in particular, and this study seeks to build upon this research. Vinokur, Pierce, Lewandowski-Romps, Hobfoll, and Galea (2011) found that, in a sample of active duty, National Guard, and Reserves members, exposure to trauma, post-traumatic stress symptoms, and loss of resources as a result of deployment all led to increased workfamily conflict. Military service can have substantial impacts on spousal and child relationships, as well. One qualitative study of reservists who has deployed to Iraq found that family members all experienced "boundary ambiguity" (i.e., uncertainty around family membership and roles/tasks within the family) that lessened over time as the veteran reintegrated into civilian work (Faber, Willerton, Clymer, MacDermid, \& Weiss, 2008). Another study, using interviews and focus groups, found that decreased mental health of the non-deployed caregiver was linked with lower child well-being, such as anxiety and functioning at school (Chandra, Martin, Hawkins, \& Richardson, 2010). Many researchers (e.g., Sheppard, Malatras, \& Israel, 2010) discuss the need to better understand work-family experiences around military deployments and the transition times surrounding them, and the present study seeks to help meet this call. 


\section{Chapter 4: The Work-Home Resources Model}

As a whole, the financial stress literature is in need of better theoretical grounding (e.g., Sinclair \& Cheung, 2016). However, the work-family literature offers an important context and, consequently, a theoretical framework that situates financial stress experiences as a mechanism in the interface between work and home roles. Because veterans often face financial and employment instability following return from service (e.g., Elbogen et al., 2013; Kleykamp, 2013), it is particularly important to consider these relationships in a sample of veterans and service members. Veterans face numerous obstacles during the reintegration period, and research dedicated to better understanding how the work and home domains impact each other during this period has potential to provide key recommendations on how to better support transitioning veterans from both home and work perspectives.

At its root, the primary goal of employment is acquiring financial resources to maintain nonwork quality of life. For the clear majority of people living in society as it is structured today, it would be impossible to maintain quality of life without access to income derived from employment_or income that has come from past employment, such as during retirement. While there are certainly other potential benefits of employment and reasons to hold a job (e.g., meaningfulness, identity, social interaction), many people would not choose to hold a full-time job without the financial resources the job provides that allow them to survive, maintain, or even thrive outside of work (e.g., housing, transportation, food, supporting dependents, leisure activities). Thus, the income-acquiring process of work inherently crosses the work and nonwork domains; 
income is gained primarily through the work role and utilized primarily in the home $\operatorname{role}(\mathrm{s})$.

When income is not adequate to meet financial needs and wants, financial strain results. Consequently, financial strain represents a lack of resources or a perceived threat to financial resources. This study posits, broadly speaking, that financial strain is impacted by demands and resources in both the work and home domains and, furthermore, influences outcomes in both the work and home domains. Ten Brummelhuis and Bakker (2012) developed a particularly relevant theoretical model, called the workhome resources model, that provides a framework within which to conceptualize and test this process. The remainder of this chapter will discuss their theoretical propositions, and then the next chapter will describe my specific hypotheses, directly applying the workhome resources model to the context of interest.

The work-home resources model is grounded in conservation of resources theory, first proposed by Hobfoll in 1989. As described in Chapter 3, conservation of resources theory proposes that the desire to obtain, maintain, and protect resources is motivational and that strain can result from loss of resources, threat to resources, or failure to gain resource when expected. Conservation of resources theory has played a key role in our current understanding of stress processes, but it has also been increasingly criticized. The primary criticism of conservation of resources theory is that it defines "resources" very broadly. Hobfoll $(1988,1989)$ originally defined resources as things of value, including conditions, objects, personal characteristics, and energies, or that help attain other resources. Halbesleben and colleagues (2014), as well as other critics (e.g., Thompson \& Cooper, 2001) argue that, with previous applications of conservation of resources theory, 
"nearly anything good can be considered a resource" (p. 1337). The work-home resources model provides a more specific taxonomy of resources that, while not eliminating the concern that almost anything can be a resource, does help further classify what can be considered a resource.

Following Hobfoll (2002), the work-home resources model categorizes resources by source and by transience. The source dimension differentiates between contextual resources, which are found in contexts outside of the individual, such as social support, and personal resources, which are found within the individual, such as energies and personal traits. The transience dimension differentiates between volatile resources, which are either fleeting (i.e., once used, they cannot be repurposed, such as time) or temporal (i.e., resources that can be experienced multiple times, coming and going, such as moods). These two dimensions create a two-by-two grid of types of resources. Contextual structural resources are objects and conditions, such as marriage or a home. Contextual volatile resources consist of social support factors. Personal structural resources are constructive resources, such as knowledge or skills. Personal volatile resources are energies, such as mood or attention.

The work-home resources model represents a substantial and novel advancement in the development of work-family theory in part because, rather than measuring workfamily conflict and enrichment directly, the model views them as processes made up of antecedents, mechanisms, and outcomes (ten Brummelhuis \& Bakker, 2012). This approach encourages testing of specific underlying mechanisms related to interrole experiences. Specifically, the model proposes that personal resources are the linking mechanism between domains. Contextual resources in one domain are viewed as the 
beginning of the enrichment process, leading to beneficial outcomes in the opposite domain through increases in personal resources. Contextual demands, on the other hand, are viewed as the start of the conflict process, leading to detrimental outcomes in the other domain through decreases in personal resources. Contextual demands are those aspects of the social context that require effort to sustain (Demerouti, Bakker, Nachreiner, \& Schaufeli, 2001).

Ten Brummelhuis and Bakker (2012) further describe the components of the work-home resources model, breaking down each component (i.e., contextual demands, contextual resources, personal resources, and outcomes) into subtypes. Contextual demands are categorized into quantitative demands, emotional demands, physical demands, and cognitive demands. The present study focuses on quantitative demands, or overload. Contextual resources, on the other hand, are posited to include social support, autonomy, opportunities for development, and feedback. The present study focuses on the social support subtype of contextual resources. Personal resources in the work-home resources model are separated into physical, psychological, affective, intellectual, and capital resources. Capital resources, which are those instrumental resources that help an individual perform their role, are the focus of this study. Finally, outcomes in the workhome resources model are delineated using Cohen and Bailey's (1997) approach of production, behaviors, and attitudes. Behavioral outcomes, or those behaviors that indirectly influence other role outcomes, such as safety behaviors at work or health behaviors at home, are one focus of this study. The other focus is attitudinal outcomes, or those beliefs and feelings that a worker and those in the work and home domains (e.g., organizational leaders, spouse) value, such as job satisfaction or life satisfaction. 
The work-home resources model also considers two other categories of resources: key resources, which are stable personal traits that facilitate other resources, such as personality or social status, and macro resources, which are stable contextual characteristics from the broader economic, social, or cultural macrosystem, such as public policy or social equality. Key resources and macro resources are viewed as important moderators of the impacts of contextual resources and demands on personal resources. Ten Brummelhuis and Bakker posit that key resources are valuable in preventing conflict and fostering enrichment because they increase — or mitigate loss of - personal resources. People with more key resources are argued to be better situated to solve problems as they arise and cope with stress, as well as to use existing contextual resources. Macro resources are posited to similarly impact the conflict and enrichment process by moderating the relationship between antecedents (i.e., contextual demands and resources) and personal resources. Ten Brummelhuis and Bakker argue that macro resources, because they are characteristics of the broader environment, determine how much an individual must utilize other resources and how well those other resources can be used. While the current study does not incorporate key or macro resources, this addition represents an important direction for future research.

Finally, the propositions of the work-home resources model differentiate between short-term and long-term work-home processes. Temporal demands and volatile contextual resources in one domain are posited to impact outcomes in the other domain through differences in volatile personal resources, making up the short-term work-home process. In the long-term process, using the principle of loss and gain spirals from Hobfoll (2002), ten Brummelhuis and Bakker argue that chronic demands in one domain 
require repeated investment of personal resources, which leads to long-term outcomes in the other domain. Structural contextual resources in one domain, on the other hand, are argued to help increase personal resources over time, leading to positive long-term outcomes in the other domain. This study focuses on long-term work-home processes. 


\section{Chapter 5: Hypothesis Development}

In line with the work-home resources model (ten Brummelhuis \& Bakker, 2012), the current study posited that contextual demands and contextual resources impact outcomes across work and home domains, through the mediating effect of personal resources. Figure 1 depicts the broader conceptual model from the work-home resources model, while figures 2 and 3 reflect the specific hypotheses of this study. Below, I will outline each of the hypothesized relationships, including impacts of the work domain on behavioral and attitudinal outcomes in the home domain, as well as of behavioral and attitudinal outcomes in the home domain on the work domain, and the hypothesized mediating effects of financial strain.

In the present study, financial strain is conceptualized in the category of capital personal resources; financial strain represents a measure of individuals' perceptions of sufficiency of income to meet financial need. Greater financial strain thus represents a decrease in perceived personal capital resources. Conversely, and more in line with the language of the work-home resources model, decreased financial strain represents greater perceived personal capital resources.

\section{Contextual Demands in the Home Domain as Predictors of Work Outcomes}

Behavioral work outcomes. The work-home resources model posits that contextual demands in one domain will influence outcomes in the opposite domain through differences in personal resources. In the home-to-work direction, this study assesses how home demands, including family status and caretaking status, impact behavioral work outcomes, including safety compliance and job search behaviors. 
Home demands have not been specifically tied to safety compliance in the literature, but family-to-work conflict, which represents demands of the family role interfering with work, has been tied to decreased safety compliance (Cullen \& Hammer, 2007), and general work-family interference has been tied to increased risk of occupational injury (Smith \& DeJoy, 2012). Financial strain also has not yet been tied to safety behavior; however, Probst and Brubaker (2001) assessed job insecurity as a predictor of employee safety and found that job insecurity was negatively related to safety compliance, which was, in turn, negatively related to accidents and injuries. Thus, while similar relationships have been explored and provide some support for potential mediating effects of financial strain in the home demands to safety compliance relationship, hypotheses $1 \mathrm{a}$ and $2 \mathrm{a}$, reflecting the direct and indirect effects, respectively, of demands at home on safety compliance, represent novel contributions to the literature. One possible explanation for such relationships is that demands at home are likely to create more stress, which in turn would decrease attention paid to safety at work due to distraction or cognitive impairment. Financial strain could explain part of this relationship, as demands at home could lead to decreased personal resources, such as perceived ability to meet financial needs. For example, if an individual has a greater number of dependents, representing more home demands, greater financial need is likely. If individuals do not perceive they can meet financial needs, financial strain will occur, and this could similarly influence safety behavior.

Some constructs similar to demands at home and financial strain have also been tied to job search behaviors. For example, Blau (1994) tested a model of the effects of financial need on job search behaviors and found support for the relationship. While 
financial need is not a direct reflection of either demands at home or financial strain, it could be considered similar to both. Financial need likely stems in large part from increased home demands, providing preliminary evidence that home demands could predict job search behaviors. If, for example, an employee has greater home demands, they may seek a different job that provides resources that allow them to better meet demands, such as schedule flexibility or increased income. Additionally, while not precisely representative of the perceived ability to meet need that financial strain measures, financial need also represents a construct conceptually similar to financial strain. If workers have greater home demands, they are expected to experience greater financial strain, which may in turn lead to the desire to seek out different or additional employment to support family members or otherwise meet home demands. Hypotheses $1 \mathrm{~b}$ and $2 \mathrm{~b}$ thus reflect the direct and indirect effects, respectively, of home demands on job search behaviors.

Hypothesis 1: Demands at home will be related to subsequent behavioral work outcomes, such that demands will have a negative relationship with safety compliance $(H 1 a)$ and a positive relationship with job search behaviors $(H 1 b)$. Hypothesis 2: Financial strain will partially mediate the relationships between demands at home and the behavioral work outcomes of safety compliance $(H 2 a)$ and job search behaviors $(H 2 b)$.

Attitudinal work outcomes. This study also evaluates whether contextual demands at home impact attitudinal work outcomes, including job satisfaction, organizational commitment, and turnover intentions. Hypotheses $3 \mathrm{a}$ and $4 \mathrm{a}$ represent the direct and indirect effects, respectively, of home demands on job satisfaction. A meta- 
analysis by Kossek and Ozeki (1998) found that family-to-work conflict was negatively related to job satisfaction, indicating some evidence of a potential direct effect of home demands on job satisfaction, as family-to-work conflict is likely highly correlated with demands at home. Individuals could experience lower job satisfaction following higher home demands, as they may feel their inability to meet home demands stems in part from their work obligations, as is potentially represented by the relationship between familyto-work conflict and job satisfaction. On the other hand, financial strain has not yet, to my knowledge, been tied to many of the most common job-related attitudinal variables, including job satisfaction. However, there is evidence of similar relationships, such as higher salaries relating to increased job satisfaction (e.g., Beutell \& Wittig-Berman, 1999). As described in the previous discussion of behavioral work outcomes, home demands are expected to lead to increased financial strain, representing a reduction in personal resources, which may in turn lead to decrease job satisfaction because of the job's inability to provide resources to help the individual meet their financial needs.

Hypotheses $3 \mathrm{~b}$ and $4 \mathrm{~b}$ represent the direct and indirect effects of home demands on affective organizational commitment, or an individual's attitude toward the organization, including belief in and acceptance of organizational goals and desire to be involved in and continue being a member of the organization (e.g., Mowday, Steers, \& Porter, 1979). In their meta-analysis, Amstad and colleagues (2011) found that family-towork conflict was significantly, negatively related to organizational commitment. This represents preliminary evidence for the proposition that home demands predict organizational commitment. As in the case of job satisfaction, no research to my knowledge has tied financial strain to organizational commitment. Based on the work- 
home resources model, I hypothesize that home demands lead to increased financial strain, representing a decrease in personal resources, which then leads to decreased organizational commitment. For example, an individual may feel resentful toward the organization for not providing the resources needed to meet home and/or financial demands, and thus may feel less committed.

Finally, hypotheses $3 \mathrm{c}$ and $4 \mathrm{c}$ reflect the direct and indirect effects, respectively, of home demands on turnover intentions. Family-to-work conflict was found, in a metaanalysis by Amstad and colleagues, to predict higher turnover intentions. Furthermore, as additional meta-analysis Williams, McDaniel, and Nguyen (2006) found that pay satisfaction was significantly, negatively related to turnover intentions. These metaanalyses provide preliminary support for the hypothesized relationships.

Hypothesis 3: Demands at home will be related to subsequent attitudinal work outcomes, such that demands will have negative relationships with job satisfaction $(H 3 a)$ and organizational commitment $(H 3 b)$, as well as a positive relationship with turnover intentions $(\mathrm{H} 3 \mathrm{c})$.

Hypothesis 4: Financial strain will partially mediate the relationships between demands at home and the attitudinal work outcomes of job satisfaction $(\mathrm{H} 4 \mathrm{a})$, organizational commitment $(H 4 b)$, and turnover intentions $(H 4 c)$.

\section{Contextual Demands in the Work Domain as Predictors of Home Outcomes}

Behavioral home outcomes. In the work-to-home direction, the current study assesses whether work demands, including work hours and work schedule, impact behavioral home outcomes, including diet and exercise. Work demands have been tied to health outcomes quite consistently. For example, Payne, Jones, and Harris (2002) found 
that employees in high-strain jobs performed less exercise than employees in low-strain jobs. A study by Hellerstedt and Jeffery (1997) found that job demands were associated with higher fat intake and BMI. Financial strain has also been tied to health outcomes. For example, Martin, Gruendahl, and Martin (2001) found that financial strain was associated with decreased psychological well-being, while Kahn and Pearlin (2006) found that financial strain was tied to increased depression. Individuals experiencing greater financial strain are unlikely to have the financial resources to be able to pay for exercise and healthy food choices. Unfortunately, there is less evidence for the relationship between work-specific demands and financial strain. However, the workhome resources model offers suggestions toward this particular relationship, as well. Contextual work demands are posited to lead to home outcomes through differences in personal resources - in this case, through an increase in financial strain. This may occur, for example, when an individual must work longer hours than usual to meet job demands and must pay for additional childcare. Another example is if an individual is exhausted or experiencing symptoms of burnout, which disallow the individual from engaging in other paid jobs. Hypotheses 5 and 6 posit effects of demands at work on health behaviors through financial strain.

Hypothesis 5: Demands at work will be related to subsequent behavioral home outcomes, such that demands will have a negative relationship with healthy diet behaviors $(H 5 a)$, a positive relationship with unhealthy diet behaviors $(H 5 b)$, and a negative relationship with exercise behaviors $(\mathrm{H} 5 \mathrm{c})$. 
Hypothesis 6: Financial strain will partially mediate the relationships between demands at home and the behavioral home outcomes of healthy diet behaviors (H6a), unhealthy diet behaviors $(H 6 b)$, and exercise behaviors $(H 6 c)$.

Attitudinal home outcomes. This study also evaluates whether contextual demands at work impact attitudinal home outcomes, including life satisfaction. Some variables related to job demands have been tied to life satisfaction in past literature, including a meta-analysis where work-to-family conflict, which represents demands from the work role interfering with the home domain, was found to significantly, negatively predict life satisfaction (Amstad et al., 2011). Furthermore, financial strain has been linked to decreased life satisfaction by multiple studies (e.g., Dolan, Peasgood, \& Matthew, 2008; Watson, Barber, \& Dziurawiec, 2015).

Hypothesis 7: Demands at work will be related to subsequent attitudinal home outcomes, such that demands will have positive relationships with life satisfaction.

Hypothesis 8: Financial strain will partially mediate the relationships between demands at home and the attitudinal home outcome of life satisfaction.

\section{Contextual Resources in the Home Domain as Predictors of Work Outcomes}

Behavioral work outcomes. The work-home resources model also posits that contextual resources in one domain will influence outcomes in the opposite domain through differences in personal resources. In the home-to-work direction, the present study assesses how home resources, including social support from family and friends, impact behavioral work outcomes, including safety compliance and job search behaviors. There has been little research on how non-work social support relates to safety 
compliance, as is proposed in hypotheses 9a, 10a, 11a, and 12a. A substantial body of research (discussed in the home-to-work section below) supports the role of workspecific social support, including from both organizational leaders/supervisors and from team members/coworkers, in predicting safety compliance. Although support from friends and family has not yet been shown to predict workplace safety compliance and represents a more distal relationship than work-specific support, the relationships may function similarly. Home support reflects a contextual resource, which ten Brummelhuis and Bakker (2012) argue will benefit a variety of work outcomes. In the context of safety compliance, for example, workers who feel more supported by their friends and family may feel that others value their safety and thus may pay more careful attention to complying with safety procedures at work. Financial strain is expected to partially mediate this relationship, as social support at home can increase personal resources by decreasing financial strain, which would in turn allow workers to pay more careful attention to their safety at work, such as by reducing distraction and cognitive impairment.

Although safety compliance has not often been tested with non-work support as a predictor, there is much more evidence for the work-related behavioral outcome of job search behaviors. One particular meta-analysis, conducted by Kanfer, Wanberg, and Kantrowitz (2001), provides support for the hypothesized direct and indirect effects of social support on job search behaviors; however, the study targeted unemployment, so some extension is necessary. The authors found that social support was positively related to job search behavior in the unemployment context. However, I hypothesize that the relationship will be negative in the already-employed worker context. Social support 
serves as a contextual resource in the model, but it is important to note that there are alternative possibilities to the directionality of this particular direct effect. It may be that workers who feel more supported are less likely to seek another job, or it may be that workers who feel more supported think they can more easily find a new job. By targeting financial strain as a personal resource in the relationship between social support and job search behaviors, I can study a particular mechanism by which the relationship may function. In the same meta-analysis, Kanfer and colleagues found that financial need-a variable closely related to financial strain—was positively associated with job search behaviors. Thus, it is likely that social support predicts job search behavior through differences in financial strain. If workers feel more supported, they are expected to feel less concern about their ability to meet financial needs, perhaps due to knowing they can rely on others in a time of need or can discuss the stressful situation with others-and may even be able to share the burden of improving ability to meet financial need, such as with a spouse. In turn, with less financial strain, representing increased personal resources, workers are likely less inclined to need an additional or new job, resulting in decreased job search behaviors. Hypotheses $9 \mathrm{~b}, 10 \mathrm{~b}, 11 \mathrm{~b}$, and 12b cover the hypothesized direct and indirect effects of social support resources on job search behaviors.

Hypothesis 9: Social support from friends will be related to subsequent behavioral work outcomes, such that support will have a positive relationship with safety compliance $(H 9 a)$ and a negative relationship with job search behaviors $(H 9 b)$. Hypothesis 10: Financial strain will partially mediate the relationships between social support from friends and the behavioral work outcomes of safety compliance $(H 1 O a)$ and job search behaviors $(H 1 O b)$. 
Hypothesis 11: Social support from family will be related to subsequent behavioral work outcomes, such that support will have a positive relationship with safety compliance (H1la) and a negative relationship with job search behaviors $(H 11 b)$.

Hypothesis 12: Financial strain will partially mediate the relationships between social support from family and the behavioral work outcomes of safety compliance (H12a) and job search behaviors (H12b).

Attitudinal work outcomes. The current study also assesses how home resources, including social support from family and friends, impact attitudinal work outcomes, including job satisfaction, organizational commitment, and turnover intentions. A meta-analysis by Viswesvaran, Sanchez, and Fisher (1999) began to assess several of the hypothesized relationships between home social support resources and attitudinal work outcomes. The authors found that social support, using a variety of social support sources including coworkers, supervisors, and family and friends, was a substantial predictor of work strain, including significant effects on job satisfaction and withdrawal intentions, which are approximately representative of turnover intentions. These relationships provide evidence of the direct effects in hypotheses 13a, 13c, 15a, and 15c. Few substantial differences were found between sources of support. No such comprehensive study exists for the effects of organizational commitment, but there is little reason to suspect the direct effects in hypotheses $13 \mathrm{~b}$ and $15 \mathrm{~b}$ would not reflect similar processes to the other work attitudes.

Hypotheses 14 and 16 reflect the hypothesized indirect effects of contextual home social support resources on attitudinal work outcomes through the personal resource of 
financial strain. As proposed in the work-home resources model, contextual resources of home social support are expected to increase personal resources. In this case, social support is expected to reduce financial strain, as described in the behavioral work outcomes section above. Decreased financial strain is then, in turn, expected to benefit work outcomes. Although little to no research has yet measured the effects of financial strain on work outcomes, this effect could occur, for example, through attribution of increased resources (i.e., decreased financial strain) to participation in the work role. If home social support increases personal resources by reducing perceptions of financial strain, the lack of financial strain may then lead individuals to be more satisfied with their jobs, such as in hypotheses $14 \mathrm{a}$ and 16a, more committed to their organizations, such as in hypotheses $14 \mathrm{~b}$ and $16 \mathrm{~b}$, and less likely to turn over or leave the organization, as in hypotheses $14 \mathrm{c}$ and $16 \mathrm{c}$.

Hypothesis 13: Social support from friends will be related to subsequent attitudinal work outcomes, such that support will have positive relationships with job satisfaction $(H 13 a)$ and organizational commitment $(H 13 b)$, as well as a negative relationship with turnover intentions $(H 13 c)$.

Hypothesis 14: Financial strain will partially mediate the relationships between social support from friends and the attitudinal work outcomes of job satisfaction (H14a), organizational commitment $(H 14 b)$, and turnover intentions $(H 14 c)$.

Hypothesis 15: Social support from family will be related to subsequent attitudinal work outcomes, such that support will have positive relationships with job satisfaction $(H 15 a)$ and organizational commitment $(H 15 b)$, as well as a negative relationship with turnover intentions $(H 15 c)$. 
Hypothesis 16: Financial strain will partially mediate the relationships between social support from family and the attitudinal work outcomes of job satisfaction (H16a), organizational commitment (H16b), and turnover intentions $(H 16 c)$.

\section{Contextual Resources in the Work Domain as Predictors of Home Outcomes}

Behavioral home outcomes. In the work-to-home direction, this study assesses whether work resources, including social support from supervisors and coworkers, impact behavioral home outcomes, including diet and exercise behaviors. Work-specific social support has been tied to worker health, such as in the intervention tested by Hammer, Kossek, Anger, Bodner, and Zimmerman (2011). Following a training to increase supportive supervisor behaviors, results reflected positive effects of the intervention on physical health for those workers with high family-to-work conflict. Evidence of effects of workplace social support on health outcomes provides preliminary support for the hypotheses targeting direct effects of social support on diet and exercise behaviors. Financial strain and other closely related measures have also been tied to health outcomes. For example, Catalano and colleagues (1993) found effects related to alcohol consumption behaviors. Additionally, Kahn and Pearlin (2006) found effects of financial stress experiences on depression. The current study extends previous findings to include diet and exercise, focusing particularly on the mediating effects of financial strain in the relationships between work social support and health outcomes. For example, workplace social support is expected to lead to increased personal resources - decreased financial strain, in this case. In turn, decreased financial strain, is expected to be related to subsequent health behaviors. One example of how the hypothesized mediational process might unfold is that individuals who feel more supported by their supervisors and 
coworkers may feel they can turn to supervisors or coworkers in times of financial need, such as picking up a shift or asking for a raise. This perceived support may reduce how stressful fears of inability to meet financial demands are, leaving more time, energy, and money for eating well and exercising. Hypotheses 18 and 20 outline the proposed indirect effects.

Hypothesis 17: Social support from supervisors will be related to subsequent behavioral home outcomes, such that support will have a positive relationship with healthy diet behaviors $(H 17 a)$, a negative relationship with unhealthy diet behaviors $(H 17 b)$, and a positive relationship with exercise behaviors $(H 17 c)$. Hypothesis 18: Financial strain will partially mediate the relationships between social support from supervisors and the behavioral home outcomes of healthy diet behaviors $(H 18 a)$, unhealthy diet behaviors $(H 18 b)$, and exercise behaviors $(H 18 c)$.

Hypothesis 19: Social support from coworkers will be related to subsequent behavioral home outcomes, such that support will have a positive relationship with healthy diet behaviors $(H 19 a)$, a negative relationship with unhealthy diet behaviors $(H 19 b)$, and a positive relationship with exercise behaviors $(H 19 c)$. Hypothesis 20: Financial strain will partially mediate the relationships between social support from coworkers and the behavioral home outcomes of healthy diet behaviors $(H 20 a)$, unhealthy diet behaviors $(H 20 b)$, and exercise behaviors $(H 20 c)$.

Attitudinal home outcomes. Finally, this study evaluates whether contextual resources at work impact attitudinal home outcomes, including life satisfaction. A meta- 
analysis by Ford, Heinen, and Langkamer (2007) found that support from supervisors and from coworkers were both positively related to family satisfaction, which incorporated broader non-work satisfaction measures. Financial strain is also known to be related to life satisfaction. Watson and colleagues (2015) found that higher financial strain was related to subsequently lower life satisfaction. Hypotheses 21 and 23 propose the direct effects of workplace social support on life satisfaction, while hypotheses 22 and 24 propose the indirect effects through financial strain. One way the mediational effects could occur is that, if workers feel more supported by their supervisors and coworkers, they may, for example, feel more confident they could turn to supervisors to ask for additional financial support or to coworkers to pick up an extra shift or ask for financial advice. This support would reduce financial strain, increasing personal resources, which would then lead to greater satisfaction with one's life due to decreased perceptions of stressful experiences and increased perceptions of ability to meet financial demands.

Hypothesis 21: Social support from supervisors will be related to subsequent attitudinal home outcomes, such that support will have a positive relationship with life satisfaction.

Hypothesis 22: Financial strain will partially mediate the relationship between social support from supervisors and life satisfaction.

Hypothesis 23: Social support from coworkers will be related to subsequent attitudinal home outcomes, such that support will have a positive relationship with life satisfaction.

Hypothesis 24: Financial strain will partially mediate the relationship between social support from coworkers and life satisfaction. 


\section{Chapter 6: Method}

\section{Participants and Procedures}

Data for this study were collected as part of the Study for Employment Retention of Veterans (SERVe), a study built around changing the work environment to improve veterans' health and well-being, relationship and family experiences, job-related attitudes, and job retention. Detailed information about the study can be found in Hammer, Wan, Brockwood, Mohr, and Carlson (in press). All participants $(N=509)$ were post-9/11 veterans or service members in or around Oregon who were employed at least 20 hours per week in organizations that had agreed to participate in the SERVe study. Based on their current status or the last branch of the military in which they served, approximately $48 \%$ of participants were separated from active duty, $34 \%$ were separated from the National Guard and Reserves, and 18\% remained active in the National Guard and Reserves. The sample was $84 \%$ male and $83 \%$ white, with an average age of 39 . Of the sample, $82 \%$ were in a committed relationship, and $59 \%$ had one or more children living in the home at least three days per week. Almost $6 \%$ had a high school diploma or GED as their highest level of education, while $27 \%$ had completed some college or technical school, 49\% had completed college or technical school, and 19\% were completing or had completed graduate study. The sample contained employees from both public organizations (61\%) and private organizations (39\%), and participants worked in a variety of different industries and job types. The largest industry was government work (39\%), followed by education and healthcare (14\%), manufacturing (13\%), and professional or business services $(12 \%)$. The sample is largely representative of the broader population of interest, though some differences do exist. For example, the sample 
for the present study is substantially less racially diverse and holds higher education status than the broader post-9/11 veteran population (e.g., National Center for Veterans Analysis and Statistics, 2016). These differences are likely attributable to the geographic region, as Oregon is $87 \%$ White, with $31 \%$ holding a bachelor's degree or higher (U.S. Census Bureau, 2017).

Participants were recruited through two primary strategies. First, members of the study team attended veteran-focused events in the community and obtained the names of qualifying veterans' employers, with the intention of attempting to recruit these organizations for the study. This strategy helped guarantee that the recruited organization employed at least one qualifying veteran. Later on, the study team began recruiting organizations by contacting them directly, then conducting internal recruiting to seek out qualifying veterans once the organization had already agreed to participate.

Survey data collection occurred in three waves: baseline, three months following baseline, and finally nine months following baseline. Participants received $\$ 25$ on a reloadable gift card for each time they completed one of the three surveys. The SERVe intervention, called the Veteran-Supportive Supervisor Training (VSST), was implemented in intervention group organizations between the baseline and three-month time points. The VSST consisted of a computer-based training and subsequent behaviortracking exercise for supervisors at the participating organizations. Because the hypothesized models do not focus on effects of the intervention, potential impacts of these aspects of the larger study on the analyses will be discussed in Chapter 7, which outlines the analyses. 
Following completion of baseline data collection, 512 veterans and service members had completed the baseline survey. Three were taken out of the final sample because there were no participating supervisors at their organization. The final baseline sample was thus made up of 509 veterans and service members. These participants were employed at 36 different organizations, randomized into intervention and control conditions. Of the 509 baseline participants, 435 (85.5\%) completed the three-month follow-up survey and 392 (77.0\%) completed the nine-month follow-up survey. Complete data (i.e., baseline, three-month, and nine-month surveys) are available for a total of $364(71.5 \%)$ participants. Figure 4 presents details on eligibility, response rates, and sample sizes of each condition.

\section{Measures}

Home role demands. The measure of home role demands was constructed as an additive index of caretaking demands - particularly those that are likely to be linked to financial need - including (1) number of dependent children living in the home at least three days per week, (2) whether any dependent children have a developmental disability, physical health problem, or long-term serious mental health problem, and (3) whether the participant was providing care for one or more elderly or adult dependents at least three hours per week. Similar additive indices have been constructed in past research to create composite measures that represent multiple demands. This practice has been most common in the financial stress literature. For example, George and Brief (1990) computed an index of financial requirements that accounted for marital status, whether the participant's partner was employed, and number of dependent children. Doran, Stone, Brief, and George (1991) used a similar measure, adapted from the previous study. Shaw 
and Gupta (2001) also created a composite of financial need based on marital status, number of children in the household, income sources, and employment status of household members.

In line with the work-home resources model, the composite measure for the current study was constructed to allow for a focus on contextual demands specific to the home role while increasing model parsimony (i.e., as compared with several models examining separate demands). George and Brief (1990) found that their composite measure moderated the relationship between pay satisfaction and life satisfaction. They argued that, although other factors can also contribute to demands/need, their objective composite measure likely provided an underestimate of the moderating effect. Doran and colleagues (1991) argue that George and Brief's statistically significant results, despite the likely underestimation, supports the construct validity of the composite measure.

This study's composite measure largely follows the example set by previous studies, with one primary exception. In previous studies, relationship status was accounted for by combining relationship status with spouse/partner's employment status, such that both single participants and married participants whose spouses worked fulltime were viewed as having decreased home demands, when compared with participants whose spouses did not work or worked part-time. This is potentially problematic for both practical and theoretical reasons. In the sample analyzed for this study, spouse/partner employment status was not collected from veteran participants, but rather was collected only directly from spouses who participated in the dyadic data collection. Because not all veteran participants' spouses participated in the study, there is a prohibitive amount of missing data on the spouse employment variable. From a theoretical perspective, it is not 
clear how spousal employment status may influence contextual home demands, both within and beyond financial need. It may be that participants who are in committed relationships with a spouse/partner who is employed full-time face greater childcare demands in both time and finances. For these reasons, relationship status is not included in the computation of the composite measure.

To compute the index, a score of 1 was added for each dependent child living in the home at least three days per week. Second, a score of 1 was added if the participant indicated that one or more of their children had a developmental disability, physical health problem, or long-term serious mental health problem. Finally, a score of 1 was added if the participant indicated that they provided care for one or more elderly or adult dependents at least three hours per week. Scores ranged from 1 to 7 , with an average of 1.58. Higher scores indicated greater home contextual demands.

Work role demands. Work role demands were measured with items focused on work hours and schedule type. The work hours item was "How many hours do you work in an average week at all of your jobs put together, including your primary job?" The schedule type item asked participants to select all that applied to them from the following schedule types: variable schedule, regular daytime shift, regular evening shift, regular night shift, rotating shift, split shift, and other. Schedule type was coded dichotomously, with a score of 1 given to all participants who worked a regular shift (i.e., evening, night, or daytime) and a score of 0 given to all participants who did not work a regular shift (i.e., variable, rotating, split, or other shift) to reflect the demands of an irregular shift. Work hours and schedule type were evaluated as individual predictors in the models. 
Home social support resources. Support from friends was measured with a seven-item measure by Procidano and Heller (1983). A sample item is, "I rely on my friends for emotional support." Response options ranged from (1) strongly disagree to (5) strongly agree. Scores were coded such that a higher score represents more perceived support. The baseline Cronbach's alpha value was .92. Support from family was measured with a seven-item measure also by Procidano and Heller (1983). A sample item is, "Members of my family are good at helping me solve problems." Response options ranged from (1) strongly disagree to (5) strongly agree. Scores were coded such that a higher score represented more perceived support. The baseline Cronbach's alpha value was .91 .

Work social support resources. Supervisor support was measured with a threeitem measure by Yoon and Lim (1999). A sample item is, "My supervisor is willing to listen to my job-related problems." Response options ranged from (1) strongly disagree to (5) strongly agree. Scores were coded such that a higher score represented more perceived support. The baseline Cronbach's alpha value was .74. Coworker support was measured with a four-item measure by Caplan and colleagues (1975). A sample item is, "How much can your coworkers be relied on when things get tough at work?" Response options ranged from (1) not at all to (5) very much. Scores were coded such that a higher score represented more perceived support. The baseline Cronbach's alpha value was .84.

Financial strain. Financial strain was measured with a three-item scale from Vinokur, Price, and Caplan (1996). The first item asked, "How difficult is it for you to live on your total household income right now?" Response options ranged from (1) not at all difficult to (5) extremely difficult. The second and third items, "How much do you 
anticipate that you and your family will experience actual hardships such as inadequate housing, food, or medical attention?" and "How much do you anticipate having to reduce your standard of living to the bare necessities in life?", ranged from (1) not at all to (4) a great deal. The second and third items were rescaled to a 5-point scale prior to averaging items to create scale scores. All scores were coded such that a higher score represented more perceived strain. The baseline Cronbach's alpha value was .84.

Safety compliance. This construct was measured with a four-item scale by Neal, Griffin, and Hart (2000). A sample item is, "I carry out my work in a safe manner." Response options ranged from (1) strongly disagree to (5) strongly agree, with an additional option for participants to select that an item was not applicable. Scores were coded such that a higher score represented more safety compliance. The baseline Cronbach's alpha value was .94.

Job search behaviors. Job search behaviors were measured with a four-item measure by Kopelman, Rovenpor, and Millsap (1992). A sample item is, "In the past 30 days, I looked for a new job in the newspaper or on the web." Response options ranged from (1) never to (5) nearly every day. Scores were coded such that a higher score represented more frequent job search behaviors. The baseline Cronbach's alpha coefficient was .85 .

Job satisfaction. Job satisfaction was measured with the three-item Michigan Organizational Assessment Questionnaire Job Satisfaction Subscale (Cammann, Fichman, Jenkins, \& Klesh, 1983). A sample item is, "In general, you like working at your job." Response options ranged from (1) strongly disagree to (5) strongly agree. 
Scores were coded such that a higher score represented higher job satisfaction. The baseline Cronbach's alpha value was .89 .

Turnover intentions. Turnover intentions were measured with two items by Boroff and Lewin (1997). The first item read, "I am seriously considering quitting this company for an alternate employer." The second item was, "During the next year, I will probably look for a new job outside this firm.” Response options ranged from (1) strongly disagree to (5) strongly agree. Scores were coded such that a higher score represented greater intention to turn over. The baseline Spearman-Brown coefficient was 93.

Organizational Commitment. Organizational commitment was measured with a four-item measure of affective organizational commitment written by Meyer, Allen, and Smith (1993). A sample item is, "I feel a strong sense of 'belonging' to my organization." Response options ranged from (1) strongly disagree to (5) strongly agree. Scores were coded such that a higher score represented higher commitment. The baseline Cronbach's alpha value was .95 .

Diet behaviors. Diet behaviors were measured with a ten-item measure of food and beverage consumption. The measure was written by the U.S. Department of Defense (2011), and response options ranged from (1) rarely or never to (6) three or more times per day. Scores were coded such that a higher score represented more frequent consumption of each food. Because these items had previously, to my knowledge, been analyzed only as single items, an exploratory factor analysis (EFA) was conducted to identify underlying dimensions of variability in the diet behaviors. Oblique rotation was 
selected using the oblimin procedure to aid in interpretation of the factors and allow for correlations between factors if present.

Results of the factor analysis revealed two underlying dimensions of variability, as indicated by using Kaiser's criterion for Eigenvalues and examining the Scree Plot. Nine items loaded adequately and cleanly onto one of the two factors, with the smallest loading of these nine being .44 and the largest being .78. One item (i.e., caffeinated drinks) did not load sufficiently onto either factor and was subsequently excluded from the measure. The first factor included five items: fruit, vegetables, whole grains, dairy, and lean protein. All of these items represent healthier food choices ("healthy diet" factor), when compared with items in the second factor. The second factor included four items: snack foods, sweets, sugary drinks, and fried foods. The second factor thus represents less healthy food choices ("unhealthy diet" factor). Collectively, these two factors accounted for over half (56\%) of the covariability between all pairs of items. The two factors were only very slightly correlated at -.08. The baseline Cronbach's alpha value for the healthy diet measure was .78 , while the value for the unhealthy diet measure was .69.

Exercise behaviors. Exercise behaviors were measured with a four-item measure of exercise behaviors computed based on eight original items (i.e., a frequency item and a duration item each for mild, moderate, vigorous, and strength exercise). The measure was written by the U.S. Department of Defense (2011). For the exercise frequency items, response options ranged from (0) not at all in the past 30 days to (5) about every day per week, while the exercise duration response options ranged from (0) never in the past 30 days to (4) 60 or more minutes per session. Frequency of each type of exercise (i.e., mild, 
moderate, vigorous, and strength) was multiplied by duration of that type to obtain a total amount of each type of exercise per week. To create scale scores, all types of exercise were then summed to provide a single, comprehensive measure of total time spent exercising per week. Scores were coded such that higher scores represented more exercise. The baseline Cronbach's alpha coefficient for the four frequency-by-duration items (i.e., one item each for mild, moderate, vigorous, and strength) was .79.

Life satisfaction. Life satisfaction was measured with a five-item measure by Diener, Emmons, Larsen, and Griffin (1985). A sample item is, "In most ways my life is close to my ideal.” Response options ranged from (1) strongly disagree to (5) strongly agree. Scores were coded such that a higher score represented higher satisfaction. The baseline Cronbach's alpha value was .90 . 


\section{Chapter 7: Analytic Approach}

\section{Preliminary Analyses}

Before hypothesis testing, data were examined for abnormal scores that fall beyond acceptable values. All scores were determined to fall within plausible ranges, and no outliers were removed prior to analysis. Second, a series of confirmatory factor analyses were conducted on each of the baseline measures that contained three or more items to assess unidimensionality (e.g., Tabachnick \& Fidell, 2013). All measures showed acceptable or marginally acceptable model fit according to Hu and Bentler's (1999) criteria of Comparative Fit Index (CFI) > .95, Standardized Root Mean Residual $(\mathrm{SRMR})<.08$, and Root Mean Square Error of Approximation $(\mathrm{RMSEA})<.06$. Table 1 presents a list of items from each measure. Cronbach's alpha coefficients, means, and standard deviations for all three time points are presented in Table 2, in addition to intercorrelation estimates among all study variables.

Assumptions of univariate and multivariate normality were then examined by first assessing univariate skewness and kurtosis using West, Finch, and Curran's (1995) recommendations of skewness less than 2 and kurtosis less than 7. All variables met these criteria, so Mardia's multivariate skewness and kurtosis tests were performed using the SPSS macros from DeCarlo (1997) and based on Bentler and Wu's (2002) recommendation of normalized estimates less than 3 . All study variables met multivariate skewness criteria, but several variables exceeded a value of 3 in their multivariate kurtosis estimates. Of the variables with estimates above 3 , most exceeded the cutoff by a relatively small amount, but some key study variables had estimates above 4 . To account for this nonnormality, a maximum likelihood adjusted estimation method with robust 
standard errors was selected (i.e., MLR in MPlus version 7). This method allows for testing of multi-level models and provides estimates that are robust to nonnormality.

Finally, missingness was assessed to determine whether additional strategies are required, such as a different estimation approach or an imputation method like that presented by Graham and Hofer (2000). While the amount of missing data was not deemed substantively problematic, there were at least some missing data for many of the study variables. The MLR estimator in Mplus, which was chosen to account for multivariate nonnormality in the data, also accounts for missingness and is expected to be able to reduce potential bias (Schafer \& Graham, 2002).

Levels of analysis. Data for the current study contain two potential levels of analysis: organization (Level 2) and worker (Level 1). To assess the appropriateness of accounting for heterogeneity among organizations and supervisors, aggregation indices for the outcome variables were examined. The ICC1 (e.g., Bliese, 2000) for each outcome was less than .075 , with most falling below .04, indicating that only $7.5 \%$ of variance in each outcome represented an organization-by-organization difference. A multi-level analysis strategy was therefore deemed unnecessary.

Intervention. Because the data for the study come from a larger study in which an intervention was conducted, it is important to consider potential implications that intervention participation may have for the analyses. The intervention, as described in Chapter 6, was intended to influence workers' experiences through changes in the support they received from supervisors. As such, and because supervisor support is explicitly contained in one of the hypothesized models, intervention group membership 
was included as a control variable to account for potential effects of the intervention on the hypothesized relationships.

\section{Hypothesis Testing}

Mediation. Mediation testing reflects the hypothesis that, within a predictive relationship between two variables, there is an intervening mechanism - that is, the focal independent variable, often referred to as $X$, leads to the dependent variable $Y$, through a mediator variable $M$ (e.g., Baron \& Kenny, 1986). The indirect effect of $X$ on $Y$ is the product of the regression coefficient of $Y$ regressed on $M$ and the regression coefficient of $M$ regressed on $X$. The mediation model reflects several assumptions (MacKinnon, 2012). One is that of temporal precedence. The mediation model assumes that, in a spectrum of time, $X$ comes before $M$, which comes before $Y$. Another is that of the appropriateness of measurement timing. The measurement of variables in the mediation model should match the timing of the relationships in their natural occurrence. A third assumption is that of causality. Within the basic mediation model, there is an implication that $X$ causes $M$, which causes $Y$. However, when there is no random assignment within the study design, one cannot be as confident that it is, in fact, a causal chain of variables, reflecting a more descriptive purpose to mediational analysis. Other assumptions include normal distribution of all variables and that there are no other variables influencing the relationships, which is highly unlikely to be met by a single study alone, especially in a non-experimental design.

Measuring the mediation model variables over multiple time points affords several advantages (MacKinnon, 2012). Longitudinal data allow assessment of change both within and between persons, allow analysts to specify a model that reflects temporal 
precedence and assesses change over time, and remove many concerns about extraneous variables because each individual acts as their own control. Because the archival data analyzed in the current study contain three waves of data, I focus on one primary method for assessing three or more waves of data: autoregressive models. These models offer several advantages, such as the ability to assess both longitudinal and cross-sectional mediational effects and the ability to estimate confidence intervals around the mediation effects using standard errors; however, there are several disadvantages to this method as well, such as potential inaccuracy of the cross-lagged relations, if modeled (MacKinnon, 2012).

When assessing mediation longitudinally, stability, stationarity, and equilibrium are key concepts (Cole \& Maxwell, 2003; Kenny, 1979; MacKinnon 2012). Stability can refer to whether the mean changes over time points, but can also refer to the strength of the correlation between the same variable at two time points. Stationarity represents whether the relationships among variables change over time. Finally, equilibrium reflects that there is lack of change in cross-sectional variances and covariances across time points. Assessment of the presence of stability, stationarity, and equilibrium allows the analyst to be more confident that estimates of relationships among variables are not based on the time of measurement, and longitudinal data afford an opportunity to examine these.

Autoregressive models. Cole and Maxwell (2003) described the basic autoregressive mediation model, upon which the models for the current study were based. This method includes the predictor, mediator, and outcome variables at all three time points and specifies relationships among the predictor, mediator, and outcome at adjacent 
time points using only the longitudinal relationships indicated by the hypothesized model. MacKinnon (2012) presents three different variations on this model. The simplest model was chosen as a starting point, with potential to build upon it further following initial hypothesis testing. In the example model MacKinnon provides, all relations are specified one time point apart. To test the direct effects hypotheses specific to this study, one direct path was added that bridged wave 1 to wave 3 , from the predictor variable at time $1(X 1)$ to the outcome variable at time $3(Y 3)$. The model MacKinnon provides is advantageous in part because it accounts for stability of each variable over time with autoregressive specifications. Additionally, the model includes covariances among all three variables variables at time 1 , as well as covariances among the residuals of all variables at all time points. Intervention condition was added as a control variable in all models.

The choice of autoregressive models reflects a focus on measuring levels of the study variables over time (i.e., across the three waves of data). This is in opposition to a focus on change in one variable leading to change in other variables, as would be reflected in a growth curve model that assessed how change in the predictor impacted the growth trajectory of the mediator, and how, in turn, the growth trajectory of the mediator impacted the growth trajectory of the outcome (MacKinnon, 2012).

There are several ways to build upon the basic autoregressive mediation model used in the current study (MacKinnon, 2012). One method is to specify cross-sectional relationships among the variables in the hypothesized model, in addition to the adjacent longitudinal relationships. Another method is to furthermore add to the cross-sectional and adjacent longitudinal relationships by specifying cross-lagged relationships among all variables and freeing all directions of relationships to vary. This method allows for the 
temporal precedence assumption to be violated, but has other advantages, such as the ability to look for cross-lagged relationships. Regardless of the specification selected, parameter estimation and calculation of standard errors can be performed using structural equation modeling, and confidence intervals can be computed. All analyses were performed in Mplus, Version 7 (Muthén \& Muthén, 2012).

Model fit. The chi-square value will be reported for all models throughout the results section below. The chi-square value represents "discrepancy between the sample and fitted covariance matrices" (Hu \& Bentler, 1999, p. 2), and the null model under assessment is that the model and data are consistent — thus, a nonsignificant chi-square is desirable as evidence of good model fit. However, due to the sensitivity of chi-square values to larger sample sizes, number of variables, and distribution of variables, chisquare can often be significant for an otherwise well-fitting model, indicating what would traditionally be considered poor model fit. Additional fit indices of (RMSEA), (CFI), and (SRMR) will be reported, using guidelines suggested by Hu and Bentler (1999) of RMSEA less than .06, SRMR less than .08, and CFI greater than .95 . 


\section{Chapter 8: Results}

\section{Work and Home Context}

To further explore the work and home contexts and how they relate to financial strain, some descriptive/exploratory analyses were conducted in SPSS (version 24). The sample of 509 veterans was found to be $84 \%$ male and $83 \%$ white, with an average age of 39. Almost $6 \%$ had a high school diploma or GED as their highest level of education, while $27 \%$ had completed some college or technical school, $49 \%$ had completed college or technical school, and 19\% were completing or had completed graduate study. At baseline measurement, education was negatively related to financial strain, with a oneunit increase in education level $(1=$ high school diploma or GED, 2 = some college or technical school, 3 = completed college or technical school, 4 = graduate study in progress or completed) associated with a .17 decrease in financial strain on a 1 to 5 scale $(b=-.17, S E=.051, p<.01)$. Age was also negatively related to financial strain at baseline, with a one-year increase in age tied to an average of a .02 decrease in financial strain $(b=-.02, S E=.004, p<.001)$.

Relevant to the work context, service members came from 36 different organizations, with $61 \%$ of participants employed in a public organization. Participants were employed in a wide variety of industries, with the largest proportions employed government work (39\%), education and healthcare (14\%), manufacturing (13\%), and professional or business services $(12 \%)$. Total number of work hours was not significantly related to financial strain at baseline $(b=-.01, S E=.007, n s)$, but tenure was significantly and negatively related $(b=-.03, S E=.007, p<.001)$, with a one-year increase in tenure linked to a .03 decrease in financial strain. 
Specific to the home context, $82 \%$ of participants were in a committed

relationship, and 59\% had one or more children living in the home at least three days per week. A one-way analysis of variance conducted to evaluate the relationship between relationship status and financial strain showed a significant difference between groups, $F(2,504)=3.65, p<.05$. Further exploration with post-hoc tests showed that the only significant difference between groups was between those in a committed relationship (i.e., in a relationship, cohabitating, married, or civil union) and those who were separated (i.e., divorced, separated, or widowed), with the separated group $(M=2.17)$ showing significantly higher financial strain at baseline than the committed relationship group $(M=1.79)$. Many of those in committed relationships were partnered with employed spouses, with $49 \%$ of paired veteran and spouse dyads containing a full-time employed spouse and an additional $15 \%$ of dyads containing a part-time employed spouse. Number of dependent children living in the home at least three days per week also was significantly related to financial strain at baseline, with each additional child tied to an average of a .09 increase in financial strain $(b=.09, S E=.033, p<.01)$. Providing three or more hours of eldercare per week, on the other hand, was not significantly related to financial strain at baseline $(b=-.03, S E=.208, n s)$. Time since separation from military service was not significantly related to financial strain at baseline $(b=-.02, S E=$ $.013, n s)$.

\section{Correlations}

Table 2 presents full intercorrelation estimates among all study variables, and Table 3 presents a subset of these results focused on only the relationships between financial strain and the other focal variables, within and across time points. The vast 
majority of significant correlations were in the expected directions. Most of the predictor variables were significantly correlated with financial strain at all three time points.

Correlations between predictor variables and financial strain. In the contextual demands section of predictor variables, home demands was positively and significantly correlated with financial strain at all three time points, but work hours and schedule type were not significantly correlated with financial strain at any time point. In the resources section of predictor variables, social support from both friends and family were positively related to financial strain at all three time points, with family support being the more strongly related of the two. Supervisor and coworker support were also significantly related, though weakly, to financial strain, but only at some time points (i.e., time 1 and time 3 for supervisor support; time 1 for coworker support).

Correlations between financial strain and outcome variables. In the work domain, financial strain was not significantly correlated with safety compliance but was significantly related in the expected directions to job search behaviors (positive correlations), job satisfaction (negative correlations), turnover intentions (positive correlations), and organizational commitment (negative correlations). The correlations were generally strongest between financial strain and the variables of job search behaviors and turnover intentions, which are conceptually the two most financially oriented outcome variables. In the home domain, financial strain was significantly related to all outcome variables at all time points in the expected directions, including healthy diet behaviors (negative correlations), unhealthy diet behaviors (positive correlations), exercise behaviors (negative correlations), and life satisfaction (negative correlations). Of 
all correlations between financial strain and outcome variables, life satisfaction held the strongest correlations consistently across time points.

Correlations of predictor variables with outcome variables. Generally, the correlation patterns between hypothesized predictor variables and outcome variables were consistent with the expected patterns, with one clear exception: the correlations between demands predictor variables and almost all outcome variables. These correlations were often in the opposite direction of the expected relationships, with baseline home demands positively related to job satisfaction at time 1 and time 2, negatively related to turnover intention at time 1 , positively related to organizational commitment at time 1 , time 2 , and time 3 , and positively related to life satisfaction at time 1 and time 2. The relationships between home demands and exercise behaviors were in the expected direction, with positive correlations at time 1 and time 2 . Baseline work hours were not significantly related to most outcome variables, with the exception of a positive correlation with exercise behaviors at all three time points and with healthy diet behaviors at time 3 (i.e., opposite of expected direction). Baseline schedule type was not significantly correlated with any outcome variables.

The patterns with support predictor variables, unlike the demands predictor variables, were in the expected directions and were much more consistent. Correlations were particularly strong within each domain, with work-specific social support most strongly related to work-specific outcomes and home-specific social support most strongly related to home-specific outcomes.

In the home domain, baseline social support from friends was positively correlated with safety compliance (time 1 and time 3 ), positively correlated with job 
satisfaction (all time points), negatively correlated with turnover intentions (time 1 and

time 2), positively correlated with organizational commitment (all time points), positively correlated with healthy diet behaviors (all time points), positively correlated with exercise behaviors (time 1), and positively correlated with life satisfaction (all time points). Baseline social support from family was positively correlated with safety compliance (time 2), negatively correlated with job search behaviors (time 1), positively correlated with job satisfaction (time 1 and time 2), negatively correlated with turnover intentions (all time points), positively correlated with organizational commitment (all time points), positively correlated with healthy diet behaviors (all time points), and positively correlated with life satisfaction (all time points).

In the work domain, baseline supervisor support was positively correlated with safety compliance (time 1 and time 2), negatively correlated with job search behaviors (all time points), positively correlated with job satisfaction (all time points), negatively correlated with turnover intentions (all time points), positively correlated with organizational commitment (all time points), and positively correlated with life satisfaction (time 1 and time 3). Baseline coworker support mirrored these effects with even stronger correlations, including being positively correlated with safety compliance (all time points), negatively correlated with job search behaviors (all time points), positively correlated with job satisfaction (all time points), negatively correlated with turnover intentions (all time points), positively correlated with organizational commitment (all time points), and positively correlated with life satisfaction (all time points).

\section{Home Demands Predicting Work Outcomes}


Behavioral work outcomes. Hypotheses 1 and 2 posited that home demands would be negatively related to safety compliance $(\mathrm{Hla})$ and positively related to job search behaviors $(H 1 b)$, and that financial strain would partially mediate these relationships ( $H 2 a$ for safety compliance and $H 2 b$ for job search behaviors). Figure 5 depicts results of the model including safety compliance as an outcome, while Figure 6 depicts results of the model focused on job search behavior outcomes. Although the chisquare for the model including safety compliance as the outcome was significant, $\chi^{2}(20)$ $=76.234, p<.01$, alternative fit indices indicated a good fit to the data, $\operatorname{RMSEA}=.074$, $\mathrm{CFI}=.970, \mathrm{SRMR}=.044$. When the full model constraints were included, home demands at time 1 was not significantly related to safety compliance at time $2, \beta=.001$, $S E=.041, n s$, or at time $3, \beta=.001, S E=.128, n s$. The path from time 1 home demands to time 2 financial strain was also not significant, $\beta=.022, S E=.039, n s$. The indirect effect of home demands on safety compliance through financial strain was not significant, $\beta=.000, S E=.001, n s$. The model predicting job search behaviors, though the chi-square was significant, $\chi^{2}(20)=66.476, p<.01$, also fit the data well according to alternative fit indices, $\mathrm{RMSEA}=.068, \mathrm{CFI}=.976, \mathrm{SRMR}=.051$. When all model constraints were included, home demands at time 1 was not significantly related to job search behaviors at time $2, \beta=-.039, S E=.038, n s$, or at time $3, \beta=.059, S E=.197, n s$. The path from time 1 home demands to time 2 financial strain was not significant, $\beta=$ $.022, S E=.039, n s$. The indirect effect of home demands on safety compliance through financial strain was not significant in the full model, $\beta=.002, S E=.003, n s$. These results fail to support hypothesis 1 or hypothesis 2 . 
Attitudinal work outcomes. Hypothesis 3 posited that home demands would be negatively related to job satisfaction $(H 3 a)$ and organizational commitment $(H 3 b)$ and positively related to turnover intentions $(\mathrm{H} 3 \mathrm{c})$. Hypothesis 4 stated that financial strain would partially mediate these relationships ( $H 4 a$ for job satisfaction, $H 4 b$ for organizational commitment, and $H 4 c$ for turnover intentions). Figure 7 depicts results of the model including job satisfaction as an outcome, while Figure 8 depicts results of the model focused on organizational commitment outcomes. Figure 9 depicts results of the model with turnover intentions as the outcome of interest. Although the chi-square for the model including job satisfaction as the outcome was significant, $\chi^{2}(20)=77.731, p<.01$, alternative fit indices indicated a good fit to the data, RMSEA $=.075, \mathrm{CFI}=.974, \mathrm{SRMR}$ $=.045$. When the full model constraints were included, home demands at time 1 was not significantly related to job satisfaction at time $2, \beta=.022, S E=.023, n s$, or at time $3, \beta=$ $-.024, S E=.105, n s$. The path from time 1 home demands to time 2 financial strain was not significant in the model, $\beta=.024, S E=.027, n s$. The indirect effect of home demands on job satisfaction through financial strain was also not significant in the full model, $\beta=$ $.001, S E=.001, n s$. Turning to the model predicting organizational commitment, the chisquare for the model was significant, $\chi^{2}(20)=72.028, p<.01$, but alternative fit indices indicated a good fit to the data, $\mathrm{RMSEA}=.071, \mathrm{CFI}=.976, \mathrm{SRMR}=.041$. Home demands at time 1 was not significantly related to commitment at time 2 with all model constraints included, $\beta=.050, S E=.032, n s$, or at time $3, \beta=-.186, S E=.184, n s$. The path from time 1 home demands to time 2 financial strain in the full model was not significant, $\beta=.022, S E=.039, n s$. The indirect effect of home demands on safety compliance through financial strain was also not significant in the model, $\beta=-.001, S E=$ 
$.003, n s$. Finally, for the model including turnover intentions as an outcome, the chisquare for the was significant, $\chi^{2}(20)=80.268, p<.01$, but alternative fit indices indicated a good fit to the data, RMSEA $=.077, \mathrm{CFI}=.972, \mathrm{SRMR}=.052$. In the full model, home demands at time 1 was not significantly related to turnover intentions at time $2, \beta=.022, S E=.037, n s$, or at time $3, \beta=.269, S E=.173, n s$. The path from time 1 home demands to time 2 financial strain was not significant, $\beta=.023, S E=.039$, ns. The indirect effect of home demands on turnover intentions through financial strain was also not significant, $\beta=.000, S E=.001, n s$. These results fail to support hypotheses 3 and 4 .

\section{Work Demands Predicting Home Outcomes}

Behavioral home outcomes. Hypothesis 5 stated that demands at work would have a negative relationship with healthy diet behaviors $(H 5 a)$, a positive relationship with unhealthy diet behaviors $(H 5 b)$, and a negative relationship with exercise behaviors $(H 5 c)$. Hypothesis 6 stated that financial strain would partially mediate these relationships ( $H 6 a$ for healthy diet behaviors, $H 6 b$ for unhealthy diet behaviors, and $H 6 c$ for exercise behaviors). Beginning with models that included work hours as the predictor, Figure 10 depicts results of the model including healthy diet behaviors as an outcome, while Figure 11 depicts results of the model focused on unhealthy diet behaviors as an outcome. Figure 12 depicts results of the model with exercise behaviors as the outcome of interest. Although the chi-square for the model including healthy diet behaviors as the outcome was significant, $\chi^{2}(20)=88.978, p<.01$, alternative fit indices indicated a good to marginally good fit to the data, $\mathrm{RMSEA}=.082, \mathrm{CFI}=.903, \mathrm{SRMR}=.050$. In the full model, total work hours at time 1 was not significantly related to healthy diet at time $2, \beta$ $=.048, S E=.043, n s$, or at time $3, \beta=.099, S E=.037, n s$. The path from time 1 work 
hours to time 2 financial strain was not significant, $\beta=-.008, S E=.032, n s$. The indirect effect of work hours on healthy diet through financial strain was also not significant, $\beta=$ $.000, S E=.000, n s$. Turning to the model predicting unhealthy diet behaviors, the chisquare for the model was significant, $\chi^{2}(20)=100.746, p<.01$, but alternative fit indices indicated a marginally acceptable fit to the data, $\mathrm{RMSEA}=.089, \mathrm{CFI}=.883, \mathrm{SRMR}=$ .052. With all model constraints included, work hours at time 1 was not significantly related to unhealthy diet at time $2, \beta=.002, S E=.033, n s$, or at time $3, \beta=-.003, S E=$ $.048, n s$. The path from time 1 work hours to time 2 financial strain was not significant, $\beta$ $=-.008, S E=.032, n s$. The indirect effect of work hours on unhealthy diet through financial strain was also not significant in the context of the full model, $\beta=.000, S E=$ $.001, n s$. Finally, for the model including exercise behaviors as an outcome, the chisquare for the model was significant, $\chi^{2}(20)=92.158, p<.01$, but alternative fit indices indicated a marginally acceptable fit to the data, $\mathrm{RMSEA}=.084, \mathrm{CFI}=.887, \mathrm{SRMR}=$ .051. With all model constraints included, work hours at time 1 was not significantly related to exercise behaviors at time $2, \beta=.022, S E=.037, n s$, but it was significantly related to exercise behaviors at time $3, \beta=.133, S E=.043, p<.01$. However, this direct effect was in the opposite direction as expected. The path from time 1 work hours to time 2 financial strain was not significant in the model, $\beta=-.008, S E=.032, n s$. The indirect effect of work hours on exercise behaviors through financial strain was also not significant in the full model, $\beta=.001, S E=.003, n s$. These results indicate a failure to support hypotheses 5 and 6.

Similar models were also assessed with schedule type as a predictor instead of work hours to test another form of work demands. Figure 13 depicts results of the model 
including healthy diet behaviors as an outcome, while Figure 14 depicts results of the model focused on unhealthy diet behaviors as an outcome. Figure 15 depicts results of the model with exercise behaviors as the outcome of interest. Although the chi-square for the model including healthy diet behaviors as the outcome was significant, $\chi^{2}(20)=$ $88.978, p<.01$, alternative fit indices indicated a marginally acceptable fit to the data, $\mathrm{RMSEA}=.093, \mathrm{CFI}=.908, \mathrm{SRMR}=.050$. Schedule type at time 1 was not significantly related to healthy diet at time 2 in the context of the full model, $\beta=-.018, S E=.035, n s$, or at time $3, \beta=-.053, S E=.046, n s$. The path from time 1 schedule type to time 2 financial strain was not significant in the model, $\beta=.030, S E=.028, n s$. The indirect effect of work hours on healthy diet through financial strain was also not significant, $\beta=$ $.000, S E=.001, n s$. Turning to the model predicting unhealthy diet behaviors, the chisquare for the model was significant, $\chi^{2}(20)=114.624, p<.01$, but alternative fit indices indicated a marginally acceptable fit to the data, RMSEA $=.096, \mathrm{CFI}=.894, \mathrm{SRMR}=$ .050. When the full model constraints were included, schedule type at time 1 was not significantly related to unhealthy diet at time $2, \beta=-.050, S E=.039, n s$, or at time $3, \beta=$ $.007, S E=.038, n s$. The path from time 1 schedule type to time 2 financial strain was not significant in the model, $\beta=.030, S E=.028, n s$. The indirect effect of schedule type on unhealthy diet through financial strain was not significant, $\beta=.001, S E=.002, n s$. Finally, for the model including exercise behaviors as an outcome, the chi-square for the model was significant, $\chi^{2}(20)=102.744, p<.01$, but alternative fit indices indicated a marginally acceptable fit to the data, $\mathrm{RMSEA}=.090, \mathrm{CFI}=.897, \mathrm{SRMR}=.049$. Schedule type at time 1 was not significantly related to exercise behaviors at time 2 when all model constraints were included, $\beta=-.009, S E=.039, n s$, or time $3, \beta=.015, S E=$ 
$.051, n s$. The path from time 1 work hours to time 2 financial strain was not significant, $\beta$ $=-.008, S E=.032, n s$. The indirect effect of work hours on exercise behaviors through financial strain was also not significant in the model, $\beta=.030, S E=.028, n s$. These results also indicate a failure to support hypotheses 5 and 6 .

Attitudinal home outcomes. Hypothesis 7 stated that demands at work would be positively related to subsequent life satisfaction, and hypothesis 8 posited that financial strain would partially mediate this relationship. Figure 16 depicts results of the model with life satisfaction as the outcome of interest. Although the chi-square for the model predicting life satisfaction from total work hours was significant, $\chi^{2}(20)=116.106, p<$ .01 , alternative fit indices indicated a marginally acceptable fit to the data, RMSEA $=$ $.097, \mathrm{CFI}=.897, \mathrm{SRMR}=.068$. When the full model constraints were included, total work hours at time 1 was not significantly related to life satisfaction at time $2, \beta=.013$, $S E=.029, n s$, or at time $3, \beta=.013, S E=.036, n s$. The path from time 1 work hours to time 2 financial strain was not significant in the model, $\beta=-.007, S E=.032, n s$. The indirect effect of work hours on healthy diet through financial strain was also not significant, $\beta=.001, S E=.003, n s$. Turning to the model predicting life satisfaction from schedule type, depicted in Figure 17, the chi-square was significant, $\chi^{2}(20)=127.416, p<$ .01 , but alternative fit indices indicated a marginally acceptable fit to the data, RMSEA $=$ $.103, \mathrm{CFI}=.909, \mathrm{SRMR}=.062$. Schedule type at time 1 was not significantly related to exercise behaviors at time 2 when all model constraints were included, $\beta=-.022, S E=$ $.029, n s$, or time $3, \beta=-.023, S E=.034, n s$. The path from time 1 work hours to time 2 financial strain was not significant, $\beta=.030, S E=.028, n s$. The indirect effect of work 
hours on exercise behaviors through financial strain was also not significant in the full model, $\beta=-.003, S E=.003, n s$. Results failed to support hypotheses 7 and 8 .

\section{Home Resources Predicting Work Outcomes}

Behavioral work outcomes. Hypothesis 9 posited that social support from

friends would be positively related to subsequent safety compliance ( $H 9 a)$ and negatively related to job search behaviors $(H 9 b)$, while hypothesis 10 stated that financial strain would partially mediate these relationships ( $H 10 a$ for safety compliance and $H 10 b$ for job search behaviors). Hypotheses 11 and 12 reflected the same relationships, but with social support from family instead of from friends ( $H 11$ la for direct effect on safety compliance, $H 11 b$ for direct effect on job search behaviors, $H 12 a$ for mediated effect on safety compliance, and $H 12 b$ for mediated effect on job search behaviors).

Beginning with the models focused on support from friends as a predictor, Figure 18 depicts results of the model including safety compliance as an outcome, while Figure 19 depicts results of the model focused on job search behaviors as an outcome. Although the chi-square for the model including safety compliance as the outcome was significant, $\chi^{2}(20)=84.734, p<.01$, alternative fit indices indicated a marginally good fit to the data, RMSEA $=.080, \mathrm{CFI}=.932, \mathrm{SRMR}=.055$. When the full model constraints were included, support from friends at time 1 was not significantly related to safety compliance at time $2, \beta=.004, S E=.042, n s$, or at time $3, \beta=-.023, S E=.065, n s$. The path from time 1 support from friends to time 2 financial strain was not significant in the model, $\beta=$ $-.055, S E=.040, n s$. The indirect effect of support from friends on safety compliance through financial strain was not significant, $\beta=-.003, S E=.003, n s$. The model predicting job search behaviors, though the chi-square was significant, $\chi^{2}(20)=79.423, p$ 
$<.01$, also fit marginally well to the data according to alternative fit indices, RMSEA $=$ $.076, \mathrm{CFI}=.945, \mathrm{SRMR}=.063$. Support from friends at time 1 was not significantly related to job search behaviors at time 2 when all model constraints were included, $\beta=-$ $.023, S E=.039, n s$, or at time $3, \beta=-.033, S E=.068, n s$. The path from time 1 support from friends to time 2 financial strain was not significant, $\beta=-.055, S E=.041, n s$. The indirect effect of support from friends on safety compliance through financial strain was also not significant in the model, $\beta=-.004, S E=.004, n s$. These results failed to support hypotheses 9 or 10 .

Turning to results of the models with support from family as the predictor, Figure 20 depicts results of the model including safety compliance as an outcome, while Figure 21 depicts results of the model focused on job search behaviors as an outcome. The chisquare for the model including safety compliance as the outcome was significant, $\chi^{2}(20)$ $=188.573, p<.01$, and alternative fit indices indicated a poor fit to the data, RMSEA $=$ $.129, \mathrm{CFI}=.843, \mathrm{SRMR}=.065$. Support from family at time 1 was significantly related to safety compliance at time 2 in the full model with all constraints included, $\beta=.109, S E$ $=.055, p<.05$, but not at time $3, \beta=-.037, S E=.074, n s$. The path from time 1 support from family to time 2 financial strain was not significant in the model, $\beta=-.044, S E=$ $.040, n s$. The indirect effect of support from family on safety compliance through financial strain was also not significant, $\beta=-.001, S E=.002, n s$. For the model predicting job search behaviors, the chi-square was significant, $\chi^{2}(20)=161.969, p<.01$, and the model fit poorly to the data according to alternative fit indices, RMSEA $=.118$, $\mathrm{CFI}=.883, \mathrm{SRMR}=.068$. Support from family at time 1 was not significantly related to job search behaviors at time 2 in the full model, $\beta=.019, S E=.038, n s$, but was 
significantly related at time $3, \beta=.202, S E=.078, p<.01$, though this was in the opposite direct of the expected relationship. The path from time 1 support from family to time 2 financial strain was not significant, $\beta=-.045, S E=.040, n s$. The indirect effect of support from family on safety compliance through financial strain was also not significant in the full model, $\beta=-.003, S E=.004, n s$. These results fail to support hypothesis 11 or hypothesis 12 , with the exception of partial support for hypothesis $11 \mathrm{a}$ - the direct effect of support from family on safety compliance (time 2 supported; no support for time 3).

Attitudinal work outcomes. Hypothesis 13 stated that social support from friends would be positively related to job satisfaction $(H 13 a)$ and organizational commitment $(H 13 b)$, as well as negatively related to turnover intentions $(H 13 c)$. Hypothesis 14 reflected the proposition that financial strain would partially mediate these relationships ( $H 14 a$ for job satisfaction, $H 14 b$ for organizational commitment, and $H 14 c$ for turnover intentions). Hypotheses 15 and 16 reflected the same relationships, but with social support from family instead of from friends ( $H 15 a$ for direct effect on job satisfaction, $H 15 b$ for direct effect on organizational commitment, $H 15 c$ for direct effect on turnover intentions, $H 16 a$ for mediated effect on job satisfaction, and $H 16 b$ for mediated effect on organizational commitment, and $H 16 c$ for mediated effect on turnover intentions).

Beginning with the models focused on support from friends, Figure 22 depicts results of the model including job satisfaction as an outcome, while Figure 23 depicts results of the model focused on organizational commitment outcomes. Figure 24 depicts results of the model with turnover intentions as the outcome of interest. Although the chi- 
square for the model including job satisfaction as the outcome was significant, $\chi^{2}(20)=$ $85.034, p<.01$, alternative fit indices indicated a good fit to the data, RMSEA $=.080$, $\mathrm{CFI}=.945, \mathrm{SRMR}=.063$. When the full model constraints were included, support from friends at time 1 was not significantly related to job satisfaction at time $2, \beta=-.011, S E=$ $.035, n s$, or at time $3, \beta=-.027, S E=.058, n s$. The path from time 1 support from friends to time 2 financial strain was not significant in the full model, $\beta=-.055, S E=.041, n s$. The indirect effect of support from friends on job satisfaction through financial strain was also not significant, $\beta=-.001, S E=.003, n s$. Turning to the model predicting organizational commitment, the chi-square for the model was significant, $\chi^{2}(20)=$ 93.207, $p<.01$, but alternative fit indices indicated a marginally good fit to the data, $\mathrm{RMSEA}=.085, \mathrm{CFI}=.942, \mathrm{SRMR}=.064$. Support from friends at time 1 was not significantly related to commitment at time 2 when all model constraints were included, $\beta$ $=.004, S E=.035, n s$, or at time 3, $\beta=-.076, S E=.055, n s$. The path from time 1 support from friends to time 2 financial strain was not significant, $\beta=-.055, S E=.040, n s$. The indirect effect of support from friends on safety compliance through financial strain was not significant in the model, $\beta=.002, S E=.003, n s$. Finally, for the model including turnover intentions as an outcome, the chi-square for the was significant, $\chi^{2}(20)=93.062$, $p<.01$, but alternative fit indices indicated a marginally acceptable fit to the data, $\mathrm{RMSEA}=.085, \mathrm{CFI}=.940, \mathrm{SRMR}=.068$. Support from friends at time 1 was not significantly related to turnover intentions at time $2, \beta=-.006, S E=.032, n s$, or at time 3 , $\beta=-.004, S E=.057, n s$. The path from time 1 support from friends to time 2 financial strain was not significant in the full model, $\beta=-.055, S E=.040, n s$. The indirect effect of support from friends on turnover intentions through financial strain was also not 
significant in the model, $\beta=.002, S E=.003, n s$. These results fail to support hypotheses 13 and 14.

For the models focused on support from family, Figure 25 depicts results of the model including job satisfaction as an outcome, while Figure 26 depicts results of the model focused on organizational commitment outcomes. Figure 27 depicts results of the model with turnover intentions as the outcome of interest. The chi-square for the model including job satisfaction as the outcome was significant, $\chi^{2}(20)=165.402, p<.01$, and alternative fit indices indicated a marginally acceptable fit to the data, $\mathrm{RMSEA}=.120$, $\mathrm{CFI}=.888, \mathrm{SRMR}=.062$. When the full model constraints were included, support from family at time 1 was not significantly related to job satisfaction at time $2, \beta=.031, S E=$ $.037, n s$, or at time $3, \beta=-.097, S E=.074, n s$. The path from time 1 support from family to time 2 financial strain was not significant, $\beta=-.044, S E=.040, n s$. The indirect effect of support from family on job satisfaction through financial strain was also not significant in the full model, $\beta=.000, S E=.002, n s$. Turning to the model predicting organizational commitment, the chi-square for the model was significant, $\chi^{2}(20)=160.736, p<.01$, but alternative fit indices indicated a marginally acceptable fit to the data, $\mathrm{RMSEA}=.118$, $\mathrm{CFI}=.894, \mathrm{SRMR}=.065$. Support from family at time 1 was significantly related to commitment at time 2 when all constraints were included, $\beta=.104, S E=.036, p<.01$, but not at time $3, \beta=-.047, S E=.072, n s$. The path from time 1 support from family to time 2 financial strain was not significant, $\beta=-.044, S E=.040, n s$. The indirect effect of support from family on safety compliance through financial strain was not significant in the model, $\beta=.002, S E=.003, n s$. Finally, for the model including turnover intentions as an outcome, the chi-square for the was significant, $\chi^{2}(20)=168.398, p<.01$, but 
alternative fit indices indicated a good fit to the data, RMSEA $=.121, \mathrm{CFI}=.887$, SRMR $=.068$. When the full model constraints were included, support from family at time 1 was not significantly related to turnover intentions at time $2, \beta=-.022, S E=.034, n s$, or at time $3, \beta=.125, S E=.079, n s$. The path from time 1 support from family to time 2 financial strain was not significant in the model, $\beta=-.044, S E=.261, n s$. The indirect effect of support from family on turnover intentions through financial strain was also not significant, $\beta=.002, S E=.003, n s$. These results fail to support hypotheses 15 and 16 , with the exception of partial support for hypothesis $15 \mathrm{~b}$ predicting the direct effect of support from family on organizational commitment (time 2 only; time 3 not supported).

\section{Work Resources Predicting Home Outcomes}

Behavioral home outcomes. Hypothesis 17 stated that social support from supervisors would be positively related to healthy diet behaviors $(H 17 a)$, negatively related to unhealthy diet behaviors $(H 17 b)$, and positively related to exercise behaviors $(H 17 c)$. Hypothesis 18 reflected the proposition that financial strain would partially mediate these relationships ( $H 18 a$ for healthy diet behaviors, $H 18 b$ for unhealthy diet behaviors, and $H 18 c$ for exercise behaviors). Hypotheses 19 and 20 reflected the same relationships, but with social support from coworkers instead of from supervisors ( $\mathrm{H} 19 \mathrm{a}$ for direct effect on healthy diet behaviors, $H 19 b$ for direct effect on unhealthy diet behaviors, $H 19 \mathrm{c}$ for direct effect on exercise behaviors, $H 20 a$ for mediated effect on healthy diet behaviors, and $H 20 \mathrm{~b}$ for mediated effect on unhealthy diet behaviors, and $H 20 c$ for mediated effect on exercise behaviors).

Beginning with models that included social support from supervisors as the predictor, Figure 28 depicts results of the model including healthy diet behaviors as an 
outcome, while Figure 29 depicts results of the model focused on unhealthy diet behaviors as an outcome. Figure 30 depicts results of the model with exercise behaviors as the outcome of interest. Although the chi-square for the model including healthy diet behaviors as the outcome was significant, $\chi^{2}(20)=108.281, p<.01$, alternative fit indices indicated a marginally good fit to the data, $\mathrm{RMSEA}=.093, \mathrm{CFI}=.918, \mathrm{SRMR}=.054$. When the full model constraints were included, supervisor support at time 1 was significantly related to healthy diet at time $2, \beta=-.080, S E=.034, p<.05$, and at time 3 , $\beta=-.105, S E=.054, p=.05$, although both of these relationships were in the opposite direction of the expected pattern. The path from time 1 supervisor support to time 2 financial strain was not significant in the model, $\beta=-.029, S E=.043, n s$. The indirect effect of supervisor support on healthy diet through financial strain was also not significant, $\beta=.000, S E=.001, n s$. Turning to the model predicting unhealthy diet behaviors, the chi-square for the model was significant, $\chi^{2}(20)=115.017, p<.01$, but alternative fit indices indicated a marginally acceptable fit to the data, RMSEA $=.097$, $\mathrm{CFI}=.905, \mathrm{SRMR}=.058$. Supervisor support at time 1 was not significantly related to unhealthy diet in the full model, both at time $2, \beta=-.025, S E=.042, n s$, and at time $3, \beta$ $=.055, S E=.054, n s$. The path from time 1 supervisor support to time 2 financial strain was not significant, $\beta=-.029, S E=.043, n s$. The indirect effect of supervisor support on unhealthy diet through financial strain was not significant in the model, $\beta=-.001, S E=$ .002 , ns. Finally, for the model including exercise behaviors as an outcome, the chisquare for the model was significant, $\chi^{2}(20)=102.193, p<.01$, but alternative fit indices indicated a marginally acceptable fit to the data, $\mathrm{RMSEA}=.090, \mathrm{CFI}=.910, \mathrm{SRMR}=$ .055. When the full model constraints were included, supervisor support at time 1 was 
significantly related to exercise behaviors at time $2, \beta=-.086, S E=.043, p<.05$, and at time $3, \beta=.146, S E=.054, p<.01$. The effect on exercise behaviors was in the hypothesized direction for time 3 , but not for time 2 . The path from time 1 supervisor support to time 2 financial strain was not significant in the model, $\beta=-.029, S E=.043$, $n s$. The indirect effect of supervisor support on exercise behaviors through financial strain was also not significant in the model, $\beta=.002, S E=.003, n s$. These results indicate a failure to support hypotheses 17 and 18, except for partial support for hypothesis $17 \mathrm{c}$, which predicted a positive direct effect of supervisor support on exercise behaviors (time 3 supported; time 2 failed to support).

Turning to the models that included social support from coworkers as the predictor, Figure 31 depicts results of the model including healthy diet behaviors as an outcome, while Figure 32 depicts results of the model focused on unhealthy diet behaviors as an outcome. Figure 33 depicts results of the model with exercise behaviors as the outcome of interest. Although the chi-square for the model including healthy diet behaviors as the outcome was significant, $\chi^{2}(20)=106.210, p<.01$, alternative fit indices indicated a marginally good fit to the data, $\mathrm{RMSEA}=.092, \mathrm{CFI}=.925, \mathrm{SRMR}=.059$. When the full model constraints were included, coworker support at time 1 was not significantly related to healthy diet at time $2, \beta=-.014, S E=.040, n s$, or at time $3, \beta=-$ $.111, S E=.058, n s$. The path from time 1 coworker support to time 2 financial strain was not significant in the model, $\beta=-.018, S E=.037, n s$. The indirect effect of coworker support on healthy diet through financial strain was also not significant, $\beta=-.000, S E=$ $.001, n s$. Turning to the model predicting unhealthy diet behaviors, the chi-square for the model was significant, $\chi^{2}(20)=110.199, p<.01$, but alternative fit indices indicated a 
marginally acceptable fit to the data, $\mathrm{RMSEA}=.094, \mathrm{CFI}=.915, \mathrm{SRMR}=.054$.

Coworker support at time 1 was not significantly related to unhealthy diet at time 2 in the context of the full model, $\beta=.002, S E=.036, n s$, or at time $3, \beta=-.005, S E=.049, n s$. The path from time 1 coworker support to time 2 financial strain was not significant in the model, $\beta=-.018, S E=.037$. The indirect effect of coworker support on unhealthy diet through financial strain was also not significant, $\beta=-.001, S E=.002$, $n s$. Finally, for the model including exercise behaviors as an outcome, the chi-square for the model was significant, $\chi^{2}(20)=102.406, p<.01$, but alternative fit indices indicated a marginally acceptable fit to the data, $\mathrm{RMSEA}=.090, \mathrm{CFI}=.916, \mathrm{SRMR}=.054$. Coworker support at time 1 was not significantly related to exercise behaviors at time 2 when the full model constraints were included, $\beta=-.025, S E=.045, n s$, or time $3, \beta=-.037, S E=.060, n s$. The path from time 1 coworker support to time 2 financial strain was not significant, $\beta=$ $.018, S E=.037, n s$. The indirect effect of coworker support on exercise behaviors through financial strain was also not significant in the model, $\beta=.002, S E=.003, n s$. These results indicate a failure to support hypotheses 19 and 20.

Attitudinal home outcomes. Hypothesis 21 stated that social support from supervisors would be positively related to life satisfaction, while hypothesis 22 stated that financial strain would partially mediate this relationship. Hypothesis 23 stated that social support from coworkers would also be positively related to life satisfaction, while hypothesis 24 stated that financial strain would partially mediate the relationship. Figure 34 depicts results of the model with life satisfaction as the outcome of interest. Although the chi-square for the model predicting life satisfaction from supervisor support was significant, $\chi^{2}(20)=135.992, p<.01$, alternative fit indices indicated a marginally 
acceptable to poor fit to the data, $\mathrm{RMSEA}=.107, \mathrm{CFI}=.913, \mathrm{SRMR}=.082$. Supervisor support at time 1 was not significantly related to life satisfaction at time 2 when the full model constraints were included, $\beta=-.040, S E=.029, n s$, or at time $3, \beta=.041, S E=$ $.040, n s$. The path from time 1 supervisor support to time 2 financial strain was not significant in the model, $\beta=-.029, S E=.043, n s$. The indirect effect of supervisor support on healthy diet through financial strain was also not significant, $\beta=.003, S E=$ $.004, n s$. These results failed to support hypotheses 21 and 22 .

Turning to the model predicting life satisfaction from coworker support, depicted in Figure 35, the chi-square was significant, $\chi^{2}(20)=132.884, p<.01$, and alternative fit indices indicated a marginally acceptable to poor fit to the data, $\mathrm{RMSEA}=.105, \mathrm{CFI}=$ $.918, \mathrm{SRMR}=.081$. When the full model constraints were included, coworker support at time 1 was not significantly related to exercise behaviors at time $2, \beta=.015, S E=.035$, $n s$, or time $3, \beta=.054, S E=.049, n s$. The path from time 1 coworker support to time 2 financial strain was not significant in the model, $\beta=-.018, S E=.037, n s$. The indirect effect of coworker support on exercise behaviors through financial strain was also not significant, $\beta=.002, S E=.003, n s$. Results failed to support hypotheses 23 and 24 . 


\section{Chapter 9: Discussion}

\section{Overview and Summary of Results}

Overall, the current study sought to test the work-home resources model (ten Brummelhuis \& Bakker, 2012) by exploring the role of financial strain in the relationships that veterans' different demands and resources have with behavioral and attitudinal outcomes over time. As suggested by the larger work-home resources model, the study tested these relationships in two directions: from the work domain to the home domain, as well as from the home domain to the work domain. In the contextual demands area, hypotheses focused on the effects of several objective demands - at work, veterans' work hours and schedule types, and at home, veterans' family statuses and caretaking statuses. In the contextual resources area, hypotheses focused on social support, including support from supervisors and coworkers at work and support from family and friends at home.

In general, results failed to support the hypothesized relationships. The results did provide evidence of several direct effects within the contexts of the larger models. These results included significant positive direct effects of support from family on safety compliance, of support from family on organizational commitment, and of supervisor support on exercise behaviors. Social support has been previously tied to many positive work and home outcomes, though sometimes inconsistently and much less often from a cross-domain perspective (e.g., Nahrgang, Morgeson, \& Hoffman, 2011; Ng \& Sorenson, 2008; Park et al., 2013). These results are thus not surprising but do help build further evidence for the less-studied cross-domain benefits of social support. 
Three other direct effects were also significant in the full models, but in the opposite direction of the expected relationships: total work hours were positively related to exercise behaviors, support from family was positively related to job search behaviors, and supervisor support was negatively related to healthy diet behaviors. The effect of supervisor support on exercise behaviors in the larger models was mixed, with a negative effect on exercise behaviors at time 2 but a positive effect on exercise behaviors at time 3. These unexpected results are contrary to previous findings in the literature. For example, longer work hours have been commonly found to be linked to lower exercise (e.g., Sparks, Cooper, Fried, \& Shirom, 1997), but the opposite effect was found in this study, both in the larger model of work hours predicting exercise behaviors through financial strain and in the correlational results. More exploration is needed to determine if this result is specific to the context of veterans and service members employed in civilian organizations or is unique to this sample.

Regarding the unexpected positive relationship between support from family and job search behaviors that was found in only the larger model (i.e., not the correlational results), it may be that the link between financial need and the desire to find a new job to better support that need causes the relationship to look different when financial strain is accounted for in the model. Perhaps veterans who feel more supported by their families feel like it is more acceptable or encouraged to take the risk of finding a new job to better support family financial need, or perhaps veterans with more family support are more motivated to find a job to better meet family financial need as a sort of psychological contract or social exchange. 
The last unexpected result was that baseline supervisor support was negatively related to healthy diet behaviors in the larger model positing that supervisor support would be linked to healthy diet through financial strain. Other studies have not found support for the direct relationship of supervisor support and healthy diet behaviors (e.g., Buxton et al., 2009). However, Cohen (1988) made the argument that social influence could result in either positive or negative effects of social support on health behaviors. It may be, for example, that supportive supervisors in the sample are also sometimes providing opportunities to eat less-healthy foods, such as snacks during meetings or the chance to eat out at a less-healthy restaurant for a meal during the work day. More research is needed to untangle these possibilities.

Correlational evidence was found to support many of the other hypothesized relationships, so it may be that the relationships hold up individually but not when couched in the larger autoregressive mediation models that account for the predictor, mediator, and outcomes variables at three separate time points and interrelationships among many of those variables. Implications of these results, as well as limitations of the present study and future directions for this research area, are outlined below.

\section{Theoretical Implications}

This study provided a test of the work-home resources model in a sample of veterans who have transitioned to civilian employment. The work-home resources model remains quite new to the occupational health literature and has thus far been tested only on a limited basis (e.g., Hammer et al., 2016) and has not yet been extended to include financial stress experiences. Although the results of the study failed to confirm the role of financial strain in the interface between the work and home domains, the results have 
several potential implications for theory and the work-home resources model in particular.

Broadly speaking, the study failed to support the work-home resources model, specifically with regard to financial strain. Financial strain, which was argued to reflect a lack of personal capital resources, did not exhibit significant mediating effects in the relationship between home demands and subsequent work behaviors and attitudes (i.e., home-to-work effects) or between work demands and subsequent home behaviors and attitudes (i.e., work-to-home effects). The study did not explore any production-related outcomes, so this remains an area for future research.

One issue may lie in the argument supporting financial strain as a resource, or, in fact, in the definition of resources itself. Although lower financial strain represents increased ability to meet financial needs, perhaps this does not adequately meet the definition of a personal resource and thus does not fulfill the requirements for positioning as a central mechanism between the work and home domains. ten Brummelhuis and Bakker (2012) argue that one type of personal resources is capital resources, which they say "are instrumental resources that facilitate role performance, such as money and time" (p. 550). Perhaps lower financial strain does not sufficiently "facilitate role performance" but instead better represents an attitudinal outcome. Money is clearly stated as meeting the definition of a capital resource, but this may refer specifically to an objective income measure. Financial strain, on the other hand, is a subjective income measure. It would be informative to compare models with financial strain as the personal resource to models with income as the personal resource (or another objective measure that is moneyrelated). 
There has been much debate over the definition of resources in general, notwithstanding the specific types of resource categories brought up in the work-home resources model. Further conceptual and theoretical development to more precisely define resources would allow for better determination of the role that financial strain —or any other construct - may play in the work-home interface. Conservation of resources theory, which the work-home resources model is largely based upon, has been widely criticized for its broad definition of resources (e.g., Halbesleben et al., 2014). ten Brummelhuis and Bakker (2012) built upon this definition by creating categories of resources that provide much better specificity, but many issues still remain. For example, Halbesleben and colleagues (2014) raise the point that existing conceptualizations of resources do not define the value part of the resources definition well. They differentiate between two ways to approach resource value: universal value of resources (nomothetic approaches) and idiosyncratic value of resources (idiographic approaches). It is likely that some measures in the financial stress literature could fall into either category. However, it seems that one could fairly safely assume that ability to meet basic needs is universally valued. The financial strain measure used in this study focuses primarily on these basic needs, with items focused on difficulty living on current income, anticipation of inadequate housing, food, or medical attention, and reducing standard of living to the bare necessities. The measure focuses little, if any, on lifestyle wants, which would likely have more potential for idiosyncratic value - perhaps there are substantial individual differences in how much people value ability to achieve lifestyle wants and, thus, the extent to which various income measures represent resources. As both the definition of resources and the measurement of financial stress constructs continue to be refined, 
researchers should continue to build upon this issue of whether lower financial strain represents a resource.

Yet another potential theoretical issue pertinent to the hypothesized models is that the work-home resources model focuses entirely on cross-domain effects. In a metaanalysis of 33 studies focused on how work interference with family, as well as family interference with work, impact strain outcomes at work and at home, Nohe and colleagues (2015) did not find support for cross-domain effects of interference on strain over time, but rather only for effects within the same domain as the origin of the interference. That is, work interference with family predicted work strain more strongly than family interference with work predicted work strain over time. This idea, called the "matching hypothesis" is not reflected in the work-home resources model. The workhome resources model posits cross-domain effects only, through changes in personal resources. The work-home resources model explicitly models the work-to-home and home-to-work conflict (i.e., cross-domain) processes, so exclusion of same-domain effects in the work-home resources model is warranted theoretically. However, future research may further explore within-domain effects, perhaps from a different theoretical perspective, such as the broader conservation of resources theory, upon which the workhome resources model was largely based.

Although the results of this study did not support the work-home resources model, the main goal of applying this theoretical model to the financial stress literature was to begin to explore how money-related constructs may act as a mechanism connecting aspects of the work and home domains. Employment remains our society's primary means of meeting basic needs and acquiring lifestyle wants, yet — arguably — the vast 
majority of the benefits of meeting those needs and achieving those wants resides outside of the work role, in the home role, in our ability to have a place to live, food to eat, and medical care when needed, but also to achieve non-work goals that provide additional meaning to our lives, such as traveling or buying gifts for loved ones or not having to worry about whether we will be able to retire someday. Research examining the role that financial stress and financial resources play in that interface has great potential to better our understanding of how to support employees' needs, and future research can continue to pursue this line of exploration. I will next discuss practical implications of the results of this study.

\section{Practical Implications}

In general, although the main study hypotheses were largely not supported when considered in the context of the full study models, financial strain was independently linked to many different predictors and outcomes at several different time points across a period of nine months. Results of the correlational analyses showed that financial strain was consistently linked across all three time points with home demands, work and home social support, and nearly all hypothesized outcomes at both work and home, including job search behaviors, job satisfaction, turnover intentions, organizational commitment, diet behaviors, exercise behaviors, and life satisfaction. These results point to the importance of financial strain from both a work and home perspective and provides several important practical implications for organizations to consider.

Social support. One key practical consideration based on the hypothesized models of the current study lies in the role of social support. Although the results did not show evidence of social support directly predicting financial strain in the larger models, 
four different types of social support were all significantly and negatively correlated with financial strain across multiple time points. Social support from family showed the strongest correlations with financial strain, but support from friends, supervisors, and coworkers were all also significantly and negatively correlated with financial strain during at least one of the time points. These correlations indicate that, despite the lack of significant effects detected in the comprehensive mediation models, social support could still be a target to improve financial strain.

Although the correlational results suggest that home-specific support (i.e., support from friends and family) is more strongly related to financial strain experiences than work-specific support is, it is also likely that there is simply a lack of attention paid to workplace social support around financial strain experiences. The social support workers receive from their supervisors and coworkers is likely focused more on other topics outside of financial strain but could be expanded to better incorporate and target financial strain experiences. Previous research has shown a plethora of evidence surrounding the benefits of social support for improving other aspects of employees' health and wellbeing. For example, a meta-analysis by Viswesvaran and colleagues (1999) found support for three different effects of social support on the stressor-strain relationship at work, including a direct effect of support on strain, a mitigating effect of support on perceived stressors, and a moderating effect of social support on the stressor-strain relationship. Despite testing several potential moderators of these effects, including the type of stressor, type of strain, type of support, and source of support, only marginal moderating effects were found, meaning the results generalized across a wide variety of contexts. There are also several specific examples of social support benefitting health and 
well-being, such as one study that found that employees whose supervisors were less open and creative in managing employee work-family needs slept significantly less and were more than twice as likely to have two or more cardiovascular disease risk factors (Berkman, Buxton, Ertel, \& Okechukwu, 2010). Another study found that higher levels of work-specific social support were linked to lower risk of type 2 diabetes and acted as a protective factor (Toker, Shirom, Melamed, \& Armon, 2012).

Increasing support at work and/or home is thus one way to improve employee health and well-being more broadly, and, although the models tested in the current study indicate this effect does not appear to occur through reductions in financial strain, there may also be other financial stress experiences that social support more directly impacts, such as job insecurity. The correlational results, though not supported by the larger hypothesized models, suggest that social support does have some link to financial strain that is worth further investigation. Regardless of whether existing social support interventions, such as the training offered as part of the larger Study for Employment Retention of Veterans (SERVe) Study, directly impact financial strain, organizations can focus resources on providing training to give more support to employees, as increased social support can help alleviate negative effects of a wide variety of stressors. Though more research is needed to determine what type of interventions could be designed to help specifically with financial strain, it is likely that interventions like the SERVe Veteran-Supportive Supervisor Training improve strain outcomes nonetheless, primarily through improvement in access to resources and decreases in demands. A review by Hammer, Demsky, Kossek, and Bray (2015) examined existing work-family 
interventions and found that, as a whole, most effects on work-family outcomes have been positive.

Veterans and the civilian workforce. Another important implication of this study's results rests in understanding of veteran experiences of financial stress. The mean level of financial strain was quite low in this sample (averages ranged from 1.67 to 1.83 across time points on a 1 to 5 scale, with higher scores indicating higher perceived financial strain). Although veterans have often historically experienced higher rates of unemployment than non-veterans (e.g., Kleykamp, 2013), the most recent Employment Situation of Veterans Summary from the Bureau of Labor Statistics (2017c) indicates that, among post-9/11 veterans, the unemployment rates of veterans and non-veterans were not significantly different, with the exception of a higher rate in male veterans aged 25 to 34 (i.e., $4.8 \%$ for non-veterans and 6.6 for veterans). The report also showed that post-9/11 veterans were more than twice as likely to be employed in the public sector as non-veterans. While unemployment statistics do not necessarily equate to financial strain experiences because financial strain is a subjective experience that can be perceived by individuals at any income level, money is most readily acquired through employment and is the most efficient way to increase ability to meet financial demands. It is thus likely that unemployment statistics mirror patterns of other financial stress experiences; with lower percentages of unemployment, there are likely lower levels of financial stress.

One of the inclusion criteria for participation in the study was to be employed at least 20 hours per week outside of military service, and the mean number of total work hours for the sample was 42.5 at baseline. The sample is therefore already limited to a generally well-employed group. It may simply be that employed post-9/11 veterans, or at 
least employed post-9/11 veterans who meet the inclusion criteria for this study, are not currently facing the same economic challenges of the past. The higher rate at which post9/11 veterans are employed in public-sector positions may also have influenced the results, as public-sector jobs often feature higher levels of job security and more comprehensive benefits that may help mitigate effects of income level. Future research should thus consider the hypothesized models in samples without the same employment inclusion criteria, as well as in non-veteran samples to determine whether different patterns of results exist in other contexts.

Despite the lack of significant findings, this study's focus on the work-home interface specifically within a military population also contributes to the work-family literature by building toward answering several calls in the literature to study workfamily models that account for the diversity of the workforce (e.g., Spector et al., 2004; Swanberg, 2005). MacDermid Wadsworth and Southwell (2011) argue, "Given the 'extreme work' these service members and their families volunteered to perform on behalf of our country, it is reasonable to consider the need for 'extreme work-family' support" (p. 180). While the results of this study failed to provide evidence for the vast majority of hypothesized relationships, continuing to study veteran and military samples to work toward finding the most meaningful and impactful intervention targets is essential to helping support veterans as they return from military service and reintegrate into civilian work and home domains.

\section{Limitations and Additional Future Directions}

One potential limitation of the present study is that of statistical power. While the sample size was relatively large $(N=509)$, the models tested are complex and contain a 
large number of constraints. The complexity of the models affords a number of advantages, as they account for the stability of the measures over time (autoregressive effects) and test for the longitudinal mediation effect while accounting for levels of the predictor, mediator, and outcome variables at all three time points. Additionally, the models include covariances among the variables at baseline and covariances among residuals at each time point to reflect the possibility of alternative causality orders (MacKinnon, 2012). The models account for bias from multiple measurements of the same variables. However, the complexity also provides a conservative test of the hypothesized effects. Because the models account for all three variables at all three time points, as well as interrelations among these variables and time points, a large number of parameters are estimated in each model. Many of the hypothesized effects may be small in magnitude, limiting power to detect the effects without an even larger sample size. An additional potential source of bias in the analytical approach and resulting parameter estimates is the large number of hypotheses tested. Although I did not adjust for the number of hypotheses, some of the surprising correlations and effects may be attributed to the inflate Type I error rate.

A second limitation of the current study is a limitation of the broader financial strain literature as a whole — that of measurement. Sinclair and Cheung (2016) describe subjective evaluations of financial stress through four considerations: cognitive evaluations and affective reactions, absolute standards and relative comparisons, needs and wants, and temporal considerations. Vinokur, Price, and Caplan's (1996) measure (i.e., the financial strain measure used in this study), while both concise and commonly used in past literature, conflates some of these issues together into a single measure. For 
example, the measure asks questions about both current experiences and expectations of the future. Additionally, the measure explicitly measures ability to meet needs (i.e., asking about "inadequate housing, food, or medical attention"), but also assesses lifestyle wants (i.e., asking about needing to "reduce your standard of living to the bare necessities in life"). Distinguishing among these differences within measures of financial strain will allow for more finely-grained research questions and could reduce measurement error substantially.

To address one way of accounting for flaws in the financial strain measure, the same models were tested using only a single item of the financial strain scale (i.e., item 1; "How difficult is it for you to live on your total household income right now?"). This item was chosen because it effectively removes both the conflation of needs and lifestyle wants, as well as the conflation of current experiences and expectations of the future. No substantial differences were found in the results, so those models are not reported here. However, future research can continue to address this issue through development and utilization of measures that are more specific and do not combine different ways to assess financial strain into one measure.

An additional potential issue with the financial strain measure is that the mean and variance of reported financial strain was quite low. Mean reported financial strain ranged from 1.67 to 1.83 across time points on a 1 to 5 scale, with higher scores indicating higher perceived financial strain. The standard deviation of the financial strain measure ranged from .84 to .93 across time points. The low mean and variance likely reflect the items of the measure, which tend toward relatively extreme conditions, like "inadequate housing, food, or medical attention." Because the sample is made up of 
employed veterans, inability to meet at least basic needs is likely quite rare, as reflected in the lower mean and variance. The items of the measure may simply not reflect the dayto-day experiences of the sampled veterans and service members. Even though use of a single item that did not specifically refer to such extreme conditions did not produce substantially different results, future research replicating these models with a different measure that references less extreme circumstances would be informative and would address this issue. An additional advantage of utilizing a measure with increased variance is that it would allow for more covariance with other study variables - an issue that likely limited the ability to detect effects in the current study. The vast improvements in economic conditions in the United States over recent years (e.g., Mandel \& Seydl, 2016) may also have played a part in the low mean and variance of reported financial strain and, thus, the lack of significant findings; the role of current economic conditions should be considered in future studies.

This measurement issue ties in directly to the generalizability of the study results, which is an additional limitation that must be considered. The financial strain measure captures a narrow perspective of potential economic stressors, which represents a set of relatively extreme circumstances that characterize the realistic experiences of only some individuals both within and outside the veteran population. While many Americans, civilian and veteran alike, do struggle with providing bare necessities, the results of this study must be considered within that context of what we might call financial "distress" instead of merely financial "strain"_-reflecting an "unpleasant subjective state" (Mirowsky \& Ross, 2003). It seems likely that a different measure or construct within the economic stress literature may function differently as a mediator between, on the one 
hand, work and home demands and resources, and on the other hand, work and home outcomes.

In addition to considering whether the financial strain measure used in this study was the most appropriate choice, it is also important to consider whether financial strain itself represents a resource at all. As discussed in the theoretical implications section above, objective measures of economic stress, whether income- or employment-specific, may better reflect ten Brummelhuis and Bakker's (2012) definition of a personal resource, and this should be explored further in future studies.

Beyond expanding the measurement of financial strain, there are several other potential measurement issues that may have interfered with the results of the study and thus present questions for future research. One such issue is in the measurement of home and work demands. Correlations between the demands variables and subsequent financial strain and home and work outcomes, which were examined prior to testing of the hypothesized models, were generally quite weak. These weak relationships indicate that the demands variables, though objective, may not align well with veterans' perceptions of these objective factors as "demanding". Additionally, the home demands measure was particularly stable across time. This constructed measure is based largely on stable variables that do not have a high frequency of change, such as number of children, which may not adequately capture the experience of day-to-day demands and may reflect a tendency to adapt to and accommodate stable stressors over time. It is likely that perceptual, subjective measures of demands would be more closely related to subsequent home and work outcomes. Future research should determine whether subjective demands 
have stronger relationships with subsequent financial strain and work and home outcomes.

Alternatively, on the social support resources side of the conceptual and hypothesized models, it may be that social support could actually be very beneficial for improving financial strain, but only social support related specifically to financial experiences. For coworkers and supervisors, at work, and for friends and family, outside of work, it could be a matter of veteran employees being surrounded by others who have similar financial stress experiences who can help the veteran feel less alone. On the other hand, it may also be that having coworkers or friends who are financially secure and are not experiencing financial strain themselves could help set a positive example to begin to better tackle financial difficulties and build better financial management strategies. This would be an interesting question for future research. Furthermore, supervisors, at work, and family members, outside of work are in unique positions of control over veteran employees' financial experiences. Supervisors can often directly influence income levels by offering or helping the veteran employee work toward pay raises, bonuses, and alternative work hours or schedules. Because finances are typically a complex topic to navigate in relationships_-but particularly so in workplace relationships, and relationships with a power imbalance on top of that - future research to explore the best way for supervisors and employees to approach financial discussions beyond negotiating pay would be very valuable. Outside of work, family members are likely to have the most direct effects on financial strain, due to close entanglement of finances from both a financial need perspective and a financial resources perspective. This could make finance-specific social support from families particularly valuable. For 
example, families can provide support by working together to build and follow a budget, to cut spending, or to obtain income streams.

Furthermore, it may be that some of the direct paths modeled from the predictors (i.e., work and home demands and resources) to the mediator (i.e., financial strain) do not adequately reflect the causal assumptions of a mediational model. Many of the demands and resources considered in this study may not lead to substantial changes in financial strain. On the demands side of the tested models, the specific work demands considered in this study may not be causally tied to financial strain at all, as total work hours and schedule type are unlikely to have a direct impact on ability to meet financial demands, with the exception of a potentially beneficial effect of additional work hours for those participants who are paid hourly wages. On the support side of the tested models, the support resources considered in this study primarily represented emotional support, which may not directly impact financial strain — or at least not to the extent that a different type of support might, such as instrumental support.

A related area for future research relates to intervention targets. There has been remarkably little intervention work done in the area of financial stress. Sinclair, Sears, Probst, and Zajack (2010) describe a framework for financial stress interventions, incorporating primary, secondary, and tertiary interventions at both the government and organization level of implementation. The authors focus on three areas of intervention, including financial education and counseling, alternate staffing strategies, and public policy interventions. While these represent important potential ways to target financial stress, it is likely that there are other ways organizations could help. This study contributes to one idea by examining impacts of social support on financial strain, but 
future research should aim to explore this issue in greater depth, perhaps beginning with some qualitative research to uncover what employees think may be helpful. The results of the current study did not show evidence for the role of general social support in predicting financial strain, so it may be that more specific, targeted support is needed, or there may be other intervention strategies besides increasing social support that could be more beneficial for managing financial strain in particular. These intervention strategies, whether social support-related or stemming from Sinclair and colleagues' ideas, may overlap with other efforts to reduce stress or could be incorporated into a broader wellbeing initiative, perhaps within the Total Worker Health framework (e.g., Bradley, Grossman, Hubbard, Ortega, \& Curry, 2016). For example, a financial education program could be integrated with other areas of well-being and built into a comprehensive worker well-being initiative. Several frameworks already include financial stress, such as the Gallup-Healthways Well-Being 5 framework (Healthways, 2015), which includes five areas of purpose, social, financial, community, and physical well-being. These frameworks could be used to build workplace interventions.

Another area to consider for future research is that of potential moderators of the relationships in this study. While the main effects of demands and social support on financial strain were not supported, there may be conditions under which these relationships are meaningful. Ten Brummelhuis and Bakker's (2012) work-home resources model proposes two primary categories of moderators for both the contextual demands to personal resources relationship and the contextual resources to personal resources relationship: macro resources and key resources. Macro resources are characteristics of the broader system a person is surrounded by, such as economic or 
cultural considerations, including public policies or community wealth levels. Ten Brummelhuis and Bakker argue that macro resources determine to what extent other resources are needed and/or can be used. Key resources, on the other hand, are resources that facilitate use or effectiveness of other resources. Examples of key resources are selfefficacy and social positions of power. Future research should explore whether such macro or key resources present conditions under which the hypothesized relationships may exist. For example, it may be that coworker support is a key way to reduce financial strain perceptions, but only in individuals who feel a strong sense of belonging to their work group.

Finally, although the sample of veterans and service members contributes to the literature in its own right, it is important to study financial stress experiences in a variety of contexts. A growing body of work has focused on unemployment, but much less is known about experiences of financial stress in employed populations, with the exception of job insecurity. Even though experiences of financial stress can impact individuals at any income level due to the subjective nature of many components of financial stress and the variety of demands individuals face, there is also a general lack of research in the occupational health and industrial-organizational psychology literatures on low-wage workers. Because low-wage workers are those most likely to experience inability to meet basic needs, research focused on their financial stress experiences has potential to make a very importance difference. One area that can be better integrated into occupational health and industrial-organizational psychology is that of living wage research (e.g., Carr, Parker, Arrowsmith, \& Watters, 2016). Future research can continue to integrate diverse 
areas of study and samples in an effort to reduce financial stress of the broader population and better society at large.

\section{Conclusion}

In summary, the goal of this study was to determine the role of veterans' financial strain in the work-home interface over a period of nine months. Although the results of the current study largely failed to support the hypothesized models, and thus failed to support the work-home resources model, several important directions for future research and reflections upon theory and organizational practices can be taken away from this work. This study further adds to the body of research seeking to aid veterans as they transition from military service to the civilian workforce - a goal that is worthy of continued effort to show support for the great service of our military and to help improve the lives of veterans and service members across the country. 
Table 1

Tables

Items from Study Measures

Home Demands (additive index constructed from items below)

1. How many dependent children do you have living in the home at least 3 days per week?

2. Do you have any children living at home who have a developmental disability, physical health problem, or long-term serious mental health problem?

3 . Are you currently providing care for one or more elderly or adult dependents at least 3 hours per week? (Caregiving activities include providing transportation, doing yard work, managing money, etc.)

Total Work Hours

1. How many hours do you work in an average week at all of your jobs put together, including your primary job?

Schedule Type

1. Which of the following best describes your work schedule at your primary job?

Friends Support

1. My friends give me the moral support I need.

2. My friends enjoy hearing about what I think.

3. I rely on my friends for emotional support.

4. There is a friend I could go to if I were just feeling down, without feeling funny about it later.

5. My friends are sensitive to my personal needs.

6. My friends are good at helping me solve problems.

7. I've recently gotten a good idea about how to do something from a friend.

Family Support

1. My family gives me the moral support I need.

2. My family enjoys hearing about what I think.

3. I rely on my family for emotional support.

4. There is a member of my family I could go to if I were just feeling down, without feeling funny about it later.

5. My family is sensitive to my personal needs.

6. Members of my family are good at helping me solve problems.

7. I don't have a relationship with a member of my family that is as close as other people's relationships with family members.

Supervisor Support

1. My supervisor can be relied upon when things get tough on my job.

2. My supervisor is willing to listen to my job-related problems.

3. My supervisor really does not care about my well-being. (Reverse-coded item)

Coworker Support

1. How much do your coworkers go out of their way to do things to make your work life easier for you?

2. How much can your coworkers be relied on when things get tough at work?

3 . How much are your coworkers willing to listen to your personal problems?

4. How easy is it to talk to your coworkers?

Financial Strain

1. How difficult is it for you to live on your total household income RIGHT NOW?

2. How much do you anticipate that you and your family will experience actual hardships such as inadequate housing, food, or medical attention?

3. How much do you anticipate having to reduce your standard of living to the bare necessities in life?

Safety Compliance

1. I carry out my work in a safe manner.

2. I use all the necessary safety equipment to do my job.

3. I use the correct safety procedures for carrying out my job.

4. I ensure the highest levels of safety when I carry out my job. 
Table 1, Cont.

Items from Study Measures

Job Search Behaviors

1. In the past 30 days, I have thought about applying for a new job

2. In the past 30 days, I have looked for a new job in the newspaper or on the web

3 . In the past 30 days, I have talked to a prospective employer about a new job

4. In the past 30 days, I have applied for a new job

Job Satisfaction

1. In general, you like working at your job.

2. In general, you are satisfied with your job.

3. You are generally satisfied with the kind of work you do in this job.

Turnover Intentions

1. I am seriously considering quitting this company for an alternate employer.

2. During the next year, I will probably look for a new job outside this firm.

Organizational Commitment

1. I feel a strong sense of "belonging" to my organization.

2. I feel "emotionally attached" to this organization.

3. I feel like "part of the family" at my organization.

4. This organization has a great deal of personal meaning for me.

Healthy Diet Behaviors

1. In a typical week, how often do you eat or drink fruit?

2. In a typical week, how often do you eat or drink vegetables?

3. In a typical week, how often do you eat or drink whole grains?

4. In a typical week, how often do you eat or drink dairy?

5. In a typical week, how often do you eat or drink lean protein?

Unhealthy Diet Behaviors

1. In a typical week, how often do you eat or drink snack foods?

2. In a typical week, how often do you eat or drink sweets?

3. In a typical week, how often do you drink sugary drinks?

4. In a typical week, how often do you eat fried foods?

Exercise Behaviors

1. Thinking of the past 30 days, how often did you do light/mild physical activity (slight increase in breathing and heart rate, can easily hold a conversation)?

2. On the days you did light/mild physical activity, how long per day did you typically do it?

3. Thinking of the past 30 days, how often did you do moderate physical activity (exertion that raises heart rate and breathing, but you should be able to carry on a conversation comfortably during the activity)?

4. On the days you did moderate physical activity, how long per day did you typically do it?

5. Thinking of the past 30 days, how often did you do vigorous physical activity (exertion that is high enough that you would find it difficult to carry on a conversation during the activity)?

6. On the days you did vigorous physical activity, how long per day did you typically do it?

7. Thinking of the past 30 days, how often did you do strength training (including using weights or resistance training to increase muscle strength)?

8. On the days you did strength training, how long per day did you typically do it?
Life Satisfaction
1. In most ways my life is close to my ideal.
2. The conditions of my life are excellent.
3. So far, I have gotten the important things I want in my life.
4. If I could live my life over, I would change almost nothing.
5. I am satisfied with my life. 
Table 2

Means, Standard Deviations, and Intercorrelations of Study Variables

\begin{tabular}{|c|c|c|c|c|c|c|c|c|c|c|c|c|c|}
\hline Variable & $M$ & $S D$ & 1 & 2 & 3 & 4 & 5 & 6 & 7 & 8 & 9 & 10 & 11 \\
\hline 1. Home Demands (T1) & 1.31 & 1.38 & - & & & & & & & & & & \\
\hline 2. Total Work Hours (T1) & 42.51 & 7.76 & .02 & - & & & & & & & & & \\
\hline 3. Schedule Type (T1) & 0.88 & 0.33 & .03 & -.03 & - & & & & & & & & \\
\hline 4. Friends Support (T1) & 3.45 & 0.82 & -.08 & -.03 & .01 & $(.92)$ & & & & & & & \\
\hline 5. Family Support (T1) & 3.75 & 0.94 & $.09^{*}$ & .01 & .03 & $.35 * *$ & $(.93)$ & & & & & & \\
\hline 6. Supervisor Support (T1) & 4.04 & 0.86 & -.01 & -.02 & .05 & $.14 * *$ & $.09 *$ & $(.73)$ & & & & & \\
\hline 7. Coworker Support (T1) & 3.01 & 0.73 & .03 & $-.13 * *$ & .02 & $.36^{* *}$ & $.31 * *$ & $.37 * *$ & $(.85)$ & & & & \\
\hline 8. Financial Strain (T1) & 1.83 & 0.93 & $.14 * *$ & -.06 & .04 & $-.17 * *$ & $-.24 * *$ & $-.09 *$ & $-.14 * *$ & $(.85)$ & & & \\
\hline 9. Safety Compliance (T1) & 4.55 & 0.59 & -.01 & -.08 & .07 & $.18 * *$ & .09 & $.18 * *$ & $.30 * *$ & .02 & $(.94)$ & & \\
\hline 10. Job Search Beh. (T1) & 1.76 & 0.90 & -.05 & .02 & -.04 & -.07 & $-.14 * *$ & $-.36 * *$ & $-.37 * *$ & $.25 * *$ & -.05 & $(.85)$ & \\
\hline 11. Job Satisfaction (T1) & 4.03 & 0.89 & $.11 *$ & -.01 & .02 & $.19 * *$ & $.18 * *$ & $.34 * *$ & $.48 * *$ & $-.12 * *$ & $.16^{* *}$ & $-.54 * *$ & $(.89)$ \\
\hline 12. Turnover Intentions (T1) & 2.22 & 1.28 & $-.10 *$ & .04 & -.07 & $-.14 * *$ & $-.15 * *$ & $-.42 * *$ & $-.41 * *$ & $.25 * *$ & $-.11 *$ & $.74 * *$ & $-.65 * *$ \\
\hline 13. Org. Commitment (T1) & 3.33 & 1.10 & $.10^{*}$ & -.06 & .02 & $.30 * *$ & $.18 * *$ & $.40 * *$ & $.52 * *$ & $-.09 *$ & $.19 * *$ & $-.47 * *$ & $.64 * *$ \\
\hline 14. Healthy Diet Beh. (T1) & 3.63 & 1.00 & .01 & .01 & -.05 & $.18 * *$ & $.17 * *$ & .03 & .08 & $-.12 * *$ & -.01 & .03 & .03 \\
\hline 15. Unhealthy Diet Beh. (T1) & 2.63 & 0.94 & .08 & -.05 & -.04 & -.04 & -.06 & .03 & -.02 & $.13 * *$ & .02 & .04 & -.02 \\
\hline 16. Exercise Beh. (T1) & 20.14 & 15.58 & $-.11 *$ & $.09 *$ & -.04 & $.11 *$ & .06 & -.01 & -.04 & $-.16 * *$ & -.03 & $.14 * *$ & -.02 \\
\hline 17. Life Satisfaction (T1) & 3.31 & 0.90 & $.11 *$ & .03 & -.01 & $.45^{* *}$ & $.48 * *$ & $.14 * *$ & $.34 * *$ & $-.40 * *$ & $.12 * *$ & $-.25 * *$ & $.38 * *$ \\
\hline 18. Home Demands (T2) & 1.38 & 1.38 & $.97 * *$ & .02 & .02 & -.04 & $.12 *$ & .01 & .08 & $.17 * *$ & .03 & -.09 & $.13^{* *}$ \\
\hline 19. Total Work Hours (T2) & 42.84 & 7.20 & .09 & $.50 * *$ & -.03 & -.06 & -.01 & .01 & -.05 & -.01 & -.08 & -.02 & -.02 \\
\hline 20. Schedule Type (T2) & 0.89 & 0.32 & .07 & .00 & $.53 * *$ & -.02 & .02 & .04 & -.07 & .00 & .02 & .03 & -.06 \\
\hline 21. Friends Support (T2) & 3.45 & 0.80 & -.07 & -.01 & -.04 & $.66^{* *}$ & $.28 * *$ & $.12 *$ & $.28 * *$ & $-.10 *$ & $.13 * *$ & .00 & $.20 * *$ \\
\hline 22. Family Support (T2) & 3.72 & 0.87 & .08 & .06 & -.00 & $.28 * *$ & $.70 * *$ & .07 & $.26^{* *}$ & $-.18 * *$ & $.10^{*}$ & -.04 & .09 \\
\hline 23. Supervisor Support (T2) & 3.92 & 0.87 & -.06 & -.03 & .04 & $.11 *$ & $.14^{* *}$ & $.58 * *$ & $.34 * *$ & -.08 & $.14^{* *}$ & $-.28 * *$ & $.34 * *$ \\
\hline 24. Coworker Support (T2) & 2.93 & 0.74 & .07 & -.08 & -.01 & $.33 * *$ & $.29 * *$ & $.15^{* *}$ & $.68 * *$ & $-.11 *$ & $.26 * *$ & $-.25 * *$ & $.40 * *$ \\
\hline 25. Financial Strain (T2) & 1.79 & 0.92 & $.15 * *$ & -.05 & .05 & $-.14 * *$ & $-.19 * *$ & -.08 & -.09 & $.70 * *$ & .03 & $.23 * *$ & $-.14 * *$ \\
\hline
\end{tabular}

Note. * indicates $p<.05 ; * *$ indicates $p<.01 . M$ and $S D$ are used to represent mean and standard deviation, respectively. Cronbach's alpha coefficients are presented on the diagonal for all measures with three items or more. Ns range from 298 to 509 due to missing data and attrition rates. Beh. $=$ Behaviors. Org. = Organizational. T1 = time 1 (i.e., baseline). T2 = time 2 (i.e., 3 months following baseline). T3= time 3 (i.e., 9 months following baseline). 
Table 2, Cont.

Means, Standard Deviations, and Intercorrelations of Study Variables

\begin{tabular}{|c|c|c|c|c|c|c|c|c|c|c|c|c|c|}
\hline Variable & $M$ & $S D$ & 1 & 2 & 3 & 4 & 5 & 6 & 7 & 8 & 9 & 10 & 11 \\
\hline 26. Safety Compliance (T2) & 4.53 & 0.62 & .00 & .01 & -.03 & .09 & $.15^{* *}$ & $.20 * *$ & $.17^{* *}$ & .03 & $.57 * *$ & -.08 & $.21 * *$ \\
\hline 27. Job Search Beh. (T2) & 1.79 & 0.91 & -.07 & .05 & -.05 & -.08 & -.09 & $-.30 * *$ & $-.33 * *$ & $.25^{* *}$ & -.05 & $.72 * *$ & $-.42 * *$ \\
\hline 28. Job Satisfaction (T2) & 3.95 & 0.93 & $.10^{*}$ & .03 & .02 & $.16^{* *}$ & $.18^{* *}$ & $.33 * *$ & $.45^{* *}$ & $-.14 * *$ & $.21 * *$ & $-.48 * *$ & $.75^{* *}$ \\
\hline 29. Turnover Intentions (T2) & 2.29 & 1.31 & -.04 & .00 & -.05 & $-.12 *$ & $-.17 * *$ & $-.33 * *$ & $-.36 * *$ & $.28 * *$ & $-.13 *$ & $.58 * *$ & $-.54 * *$ \\
\hline 30. Org. Commitment (T2) & 3.30 & 1.10 & $.13 * *$ & -.02 & -.02 & $.23 * *$ & $.24 * *$ & $.28 * *$ & $.47 * *$ & -.07 & $.20 * *$ & $-.39 * *$ & $.58 * *$ \\
\hline 31. Healthy Diet Beh. (T2) & 3.64 & 1.07 & -.01 & .07 & -.05 & $.15^{* *}$ & $.19 * *$ & -.05 & .06 & $-.12 *$ & .00 & $.10^{*}$ & -.01 \\
\hline 32. Unhealthy Diet Beh. (T2) & 2.50 & 0.93 & .06 & -.03 & -.08 & -.00 & -.01 & .00 & -.01 & $.10^{*}$ & -.03 & .01 & .00 \\
\hline 33. Exercise Beh. (T2) & 20.13 & 15.53 & $-.20 * *$ & $.13^{* *}$ & -.05 & .07 & .08 & -.07 & -.05 & -.07 & -.00 & .08 & -.05 \\
\hline 34. Life Satisfaction (T2) & 3.33 & 0.89 & $.10^{*}$ & .03 & -.03 & $.32 * *$ & $.47 * *$ & .08 & $.30 * *$ & $-.35 * *$ & $.12 *$ & $-.24 * *$ & $.34 * *$ \\
\hline 35. Home Demands (T3) & 1.41 & 1.42 & $.95 * *$ & .04 & -.02 & -.08 & $.11 *$ & .05 & $.12 *$ & $.18^{* *}$ & .00 & -.06 & $.12 *$ \\
\hline 36. Total Work Hours (T3) & 41.30 & 9.31 & .07 & $.29 * *$ & .01 & -.02 & .09 & .03 & -.01 & -.08 & .00 & -.06 & -.03 \\
\hline 37. Schedule Type (T3) & 0.88 & 0.32 & .02 & -.03 & $.40 * *$ & -.06 & .01 & .01 & .03 & -.01 & -.00 & -.08 & .05 \\
\hline 38. Friends Support (T3) & 3.49 & 0.82 & -.05 & -.03 & -.03 & $.59 * *$ & $.28 * *$ & .06 & $.32 * *$ & $-.15 * *$ & $.16^{* *}$ & $-.13 * *$ & $.21 * *$ \\
\hline 39. Family Support (T3) & 3.77 & 0.85 & $.10^{*}$ & .01 & .01 & $.27 * *$ & $.77 * *$ & .04 & $.28 * *$ & $-.20 * *$ & $.11 *$ & $-.12 *$ & $.10^{*}$ \\
\hline 40. Supervisor Support (T3) & 3.93 & 0.85 & .03 & -.02 & .00 & $.12 *$ & $.13^{*}$ & $.43^{* *}$ & $.30 * *$ & $-.19 * *$ & $.14^{*}$ & $-.29 * *$ & $.29 * *$ \\
\hline 41. Coworker Support (T3) & 3.01 & 0.69 & .02 & -.04 & -.01 & $.26^{* *}$ & $.20 * *$ & $.12 *$ & $.49 * *$ & $-.12 *$ & $.18 * *$ & $-.16^{* *}$ & $.25 * *$ \\
\hline 42. Financial Strain (T3) & 1.67 & 0.84 & $.15 * *$ & -.01 & -.03 & $-.16 * *$ & $-.20 * *$ & $-.14 * *$ & -.08 & $.59 * *$ & .04 & $.28 * *$ & $-.12 *$ \\
\hline 43. Safety Compliance (T3) & 4.52 & 0.63 & .11 & -.07 & .02 & $.15^{* *}$ & .08 & .07 & $.20 * *$ & .05 & $.57 * *$ & -.08 & $.22 * *$ \\
\hline 44. Job Search Beh. (T3) & 1.80 & 0.91 & -.00 & .08 & -.00 & -.10 & -.03 & $-.26 * *$ & $-.23 * *$ & $.29 * *$ & -.05 & $.54 * *$ & $-.30 * *$ \\
\hline 45. Job Satisfaction (T3) & 3.96 & 0.87 & .10 & -.02 & -.02 & $.15^{* *}$ & .08 & $.27 * *$ & $.31 * *$ & $-.14 * *$ & $.14 * *$ & $-.33 * *$ & $.57 * *$ \\
\hline 46. Turnover Intentions (T3) & 2.29 & 1.27 & -.07 & .06 & .01 & -.09 & $-.10 *$ & $-.27 * *$ & $-.29 * *$ & $.25 * *$ & $-.12 *$ & $.48 * *$ & $-.41 * *$ \\
\hline 47. Org. Commitment (T3) & 3.32 & 1.01 & $.12 *$ & .04 & -.01 & $.15^{* *}$ & $.16^{* *}$ & $.30 * *$ & $.40 * *$ & $-.10^{*}$ & $.14 * *$ & $-.34 * *$ & $.50 * *$ \\
\hline 48. Healthy Diet Beh. (T3) & 3.71 & 0.98 & .01 & $.11^{*}$ & -.07 & $.13 *$ & $.21 * *$ & -.09 & .05 & -.05 & -.00 & $.11 *$ & .00 \\
\hline 49. Unhealthy Diet Beh. (T3) & 2.54 & 0.94 & .04 & -.00 & .00 & -.02 & -.03 & .03 & .03 & $.13^{* *}$ & .03 & .05 & -.06 \\
\hline 50. Exercise Beh. (T3) & 18.88 & 14.95 & -.08 & $.21 * *$ & -.04 & .06 & .06 & .01 & -.07 & -.03 & -.03 & .06 & .01 \\
\hline 51. Life Satisfaction (T3) & 3.44 & 0.87 & .07 & .01 & -.00 & $.31 * *$ & $.40 * *$ & $.15^{* *}$ & $.30 * *$ & $-.29 * *$ & $.14 * *$ & $-.22 * *$ & $.28 * *$ \\
\hline
\end{tabular}

Note. * indicates $p<.05 ; * *$ indicates $p<.01 . M$ and $S D$ are used to represent mean and standard deviation, respectively. Cronbach's alpha coefficients are presented on the diagonal for all measures with three items or more. Ns range from 298 to 509 due to missing data and attrition rates. Beh. $=$ Behaviors. Org. = Organizational. T1 = time 1 (i.e., baseline). T2 = time 2 (i.e., 3 months following baseline). T3= time 3 (i.e., 9 months following baseline). 
Table 2, Cont.

Means, Standard Deviations, and Intercorrelations of Study Variables

\begin{tabular}{|c|c|c|c|c|c|c|c|c|c|c|c|c|c|}
\hline Variable & 12 & 13 & 14 & 15 & 16 & 17 & 18 & 19 & 20 & 21 & 22 & 23 & 24 \\
\hline \multicolumn{14}{|l|}{ 1. Home Demands (T1) } \\
\hline \multicolumn{14}{|l|}{ 2. Total Work Hours (T1) } \\
\hline \multicolumn{14}{|l|}{ 3. Schedule Type (T1) } \\
\hline \multicolumn{14}{|l|}{ 4. Friends Support (T1) } \\
\hline \multicolumn{14}{|l|}{ 5. Family Support (T1) } \\
\hline \multicolumn{14}{|l|}{ 6. Supervisor Support (T1) } \\
\hline \multicolumn{14}{|l|}{ 7. Coworker Support (T1) } \\
\hline \multicolumn{14}{|l|}{ 8. Financial Strain (T1) } \\
\hline \multicolumn{14}{|l|}{ 9. Safety Compliance (T1) } \\
\hline \multicolumn{14}{|l|}{ 10. Job Search Beh. (T1) } \\
\hline \multicolumn{14}{|l|}{ 11. Job Satisfaction (T1) } \\
\hline 12. Turnover Intentions (T1) & - & & & & & & & & & & & & \\
\hline 13. Org. Commitment (T1) & $-.60 * *$ & $(.95)$ & & & & & & & & & & & \\
\hline 14. Healthy Diet Beh. (T1) & -.00 & .04 & $(.78)$ & & & & & & & & & & \\
\hline 15. Unhealthy Diet Beh. (T1) & .06 & -.00 & -.06 & $(.69)$ & & & & & & & & & \\
\hline 16. Exercise Beh. (T1) & .04 & -.04 & $.26^{* *}$ & $-.17 * *$ & $(.79)$ & & & & & & & & \\
\hline 17. Life Satisfaction (T1) & $-.34 * *$ & $.37 * *$ & $.28 * *$ & $-.13 * *$ & $.15 * *$ & $(.90)$ & & & & & & & \\
\hline 18. Home Demands (T2) & $-.14 * *$ & $.15 * *$ & .02 & $.10^{*}$ & -.09 & $.14 * *$ & - & & & & & & \\
\hline 19. Total Work Hours (T2) & -.02 & -.00 & -.05 & .00 & $.16^{* *}$ & .03 & $.10^{*}$ & - & & & & & \\
\hline 20. Schedule Type (T2) & -.01 & -.04 & -.03 & -.02 & -.03 & .01 & .06 & .07 & - & & & & \\
\hline 21. Friends Support (T2) & $-.11 *$ & $.28 * *$ & $.22 * *$ & -.05 & .08 & $.32 * *$ & -.06 & -.04 & .04 & $(.93)$ & & & \\
\hline 22. Family Support (T2) & $-.11 *$ & $.17 * *$ & $.16^{* *}$ & .03 & .07 & $.39 * *$ & .09 & .07 & .03 & $.36 * *$ & $(.91)$ & & \\
\hline 23. Supervisor Support (T2) & $-.36 * *$ & $.38 * *$ & .01 & -.03 & .03 & $.16^{* *}$ & -.06 & -.03 & .05 & $.18 * *$ & $.15^{* *}$ & $(.68)$ & \\
\hline 24. Coworker Support (T2) & $-.36 * *$ & $.47 * *$ & $.14^{* *}$ & .02 & -.07 & $.36 * *$ & .09 & -.06 & -.02 & $.40 * *$ & $.32 * *$ & $.31 * *$ & $(.80)$ \\
\hline 25. Financial Strain (T2) & $.24 * *$ & $-.11 *$ & $-.16^{* *}$ & $.10^{*}$ & $-.15 * *$ & $-.36 * *$ & $.15^{* *}$ & -.01 & -.01 & $-.17 * *$ & $-.23 * *$ & -.08 & $-.19 * *$ \\
\hline
\end{tabular}

Note. * indicates $p<.05 ; * *$ indicates $p<.01 . M$ and $S D$ are used to represent mean and standard deviation, respectively. Cronbach's alpha coefficients are presented on the diagonal for all measures with three items or more. Ns range from 298 to 509 due to missing data and attrition rates. Beh. $=$ Behaviors. Org. = Organizational. T1 = time 1 (i.e., baseline). T2 = time 2 (i.e., 3 months following baseline). T3= time 3 (i.e., 9 months following baseline). 
Table 2, Cont.

Means, Standard Deviations, and Intercorrelations of Study Variables

\begin{tabular}{|c|c|c|c|c|c|c|c|c|c|c|c|c|c|}
\hline Variable & 12 & 13 & 14 & 15 & 16 & 17 & 18 & 19 & 20 & 21 & 22 & 23 & 24 \\
\hline 26. Safety Compliance (T2) & $-.17 * *$ & $.22 * *$ & -.06 & -.05 & -.00 & $.12 *$ & -.01 & -.06 & .01 & $.12 *$ & $.23 * *$ & $.27 * *$ & $.28 * *$ \\
\hline 27. Job Search Beh. (T2) & $.64 * *$ & $-.37 * *$ & .02 & -.00 & $.14^{* *}$ & $-.25 * *$ & -.08 & .04 & -.03 & -.04 & -.07 & $-.32 * *$ & $-.29 * *$ \\
\hline 28. Job Satisfaction (T2) & $-.60 * *$ & $.59 * *$ & .03 & -.01 & -.06 & $.38 * *$ & $.12 *$ & -.02 & -.01 & $.23 * *$ & $.16^{* *}$ & $.38 * *$ & $.45 * *$ \\
\hline 29. Turnover Intentions (T2) & $.76^{* *}$ & $-.51 * *$ & -.05 & .03 & .05 & $-.30 * *$ & -.06 & -.00 & -.05 & $-.18 * *$ & $-.16 * *$ & $-.39 * *$ & $-.39 * *$ \\
\hline 30. Org. Commitment (T2) & $-.53 * *$ & $.78 * *$ & .07 & .00 & -.05 & $.36 * *$ & $.15 * *$ & -.02 & -.01 & $.33 * *$ & $.26^{* *}$ & $.41 * *$ & $.57 * *$ \\
\hline 31. Healthy Diet Beh. (T2) & .02 & -.00 & $.65 * *$ & -.07 & $.25 * *$ & $.22 * *$ & .00 & -.05 & -.04 & $.20 * *$ & $.16^{* *}$ & -.02 & $.12 *$ \\
\hline 32. Unhealthy Diet Beh. (T2) & .03 & .05 & -.02 & $.64 * *$ & $-.13 * *$ & $-.13 * *$ & .07 & -.00 & .01 & .04 & .03 & -.04 & .05 \\
\hline 33. Exercise Beh. (T2) & .06 & $-.11 *$ & $.20 * *$ & $-.19 * *$ & $.57 * *$ & $.11 *$ & $-.18 * *$ & $.15 * *$ & .02 & $.15 * *$ & $.14 * *$ & .02 & -.04 \\
\hline 34. Life Satisfaction (T2) & $-.32 * *$ & $.37 * *$ & $.20 * *$ & $-.11 *$ & $.12 *$ & $.78 * *$ & $.11 *$ & .03 & .02 & $.41 * *$ & $.48 * *$ & $.16^{* *}$ & $.38 * *$ \\
\hline 35. Home Demands (T3) & -.10 & $.14 * *$ & .00 & .08 & -.07 & $.12 *$ & $.96 * *$ & $.13 *$ & .06 & -.08 & .09 & -.03 & .09 \\
\hline 36. Total Work Hours (T3) & -.05 & .05 & -.04 & -.10 & .06 & .10 & .09 & $.31 * *$ & -.04 & -.06 & .10 & .04 & .01 \\
\hline 37. Schedule Type (T3) & -.07 & .03 & -.06 & -.02 & -.07 & .00 & .01 & .08 & $.42 * *$ & -.00 & .02 & .02 & .05 \\
\hline 38. Friends Support (T3) & $-.19 * *$ & $.24 * *$ & $.21 * *$ & $-.11 *$ & $.14 * *$ & $.40 * *$ & -.01 & -.07 & .05 & $.74 * *$ & $.28 * *$ & $.13 *$ & $.36 * *$ \\
\hline 39. Family Support (T3) & $-.15 * *$ & $.18 * *$ & $.15^{* *}$ & -.07 & .10 & $.44 * *$ & $.13 *$ & .02 & -.03 & $.26 * *$ & $.75 * *$ & $.18 * *$ & $.29 * *$ \\
\hline 40. Supervisor Support (T3) & $-.32 * *$ & $.34 * *$ & .08 & -.02 & .01 & $.24 * *$ & .02 & -.09 & -.03 & $.15 * *$ & $.13^{*}$ & $.49 * *$ & $.27 * *$ \\
\hline 41. Coworker Support (T3) & $-.21 * *$ & $.33 * *$ & $.18 * *$ & -.05 & .03 & $.31 * *$ & .04 & $-.13 *$ & -.03 & $.28 * *$ & $.19 * *$ & $.23 * *$ & $.60 * *$ \\
\hline 42. Financial Strain (T3) & $.27 * *$ & $-.12 *$ & $-.13 * *$ & $.14 * *$ & -.09 & $-.31 * *$ & $.14 * *$ & .07 & -.02 & $-.13 *$ & $-.13 *$ & $-.11 *$ & $-.10^{*}$ \\
\hline 43. Safety Compliance (T3) & $-.14^{*}$ & $.20 * *$ & -.04 & $-.14 * *$ & -.04 & $.14 * *$ & $.13^{*}$ & $-.13 *$ & -.00 & $.17 * *$ & .09 & $.15^{* *}$ & $.26 * *$ \\
\hline 44. Job Search Beh. (T3) & $.51 * *$ & $-.28 * *$ & -.03 & .06 & .04 & $-.23 * *$ & -.02 & .08 & .06 & -.07 & -.04 & $-.23 * *$ & $-.16 * *$ \\
\hline 45. Job Satisfaction (T3) & $-.42 * *$ & $.45^{* *}$ & .01 & -.07 & .02 & $.36 * *$ & $.11 *$ & -.09 & .00 & $.20 * *$ & .04 & $.31 * *$ & $.28 * *$ \\
\hline 46. Turnover Intentions (T3) & $.59 * *$ & $-.36 * *$ & -.01 & .03 & -.04 & $-.26 * *$ & $-.11 *$ & .09 & -.01 & $-.11 *$ & $-.12 *$ & $-.30 * *$ & $-.21 * *$ \\
\hline 47. Org. Commitment (T3) & $-.43 * *$ & $.65 * *$ & .04 & -.05 & .07 & $.33 * *$ & $.16^{* *}$ & -.02 & .06 & $.24 * *$ & $.13^{*}$ & $.37 * *$ & $.42 * *$ \\
\hline 48. Healthy Diet Beh. (T3) & -.01 & -.02 & $.64 * *$ & -.09 & $.16^{* *}$ & $.25 * *$ & .02 & -.04 & -.03 & $.20 * *$ & $.18 * *$ & -.01 & $.19 * *$ \\
\hline 49. Unhealthy Diet Beh. (T3) & .03 & -.06 & $-.16 * *$ & $.63 * *$ & $-.22 * *$ & $-.17 * *$ & .05 & .03 & .10 & -.01 & .03 & -.06 & .03 \\
\hline 50. Exercise Beh. (T3) & -.04 & -.02 & $.28 * *$ & $-.16 * *$ & $.58 * *$ & $.13 * *$ & -.06 & $.17 * *$ & -.04 & $.12 *$ & .05 & -.02 & -.02 \\
\hline 51. Life Satisfaction (T3) & $-.32 * *$ & $.32 * *$ & $.23 * *$ & $-.21 * *$ & $.18 * *$ & $.73 * *$ & .09 & -.00 & .02 & $.33 * *$ & $.36 * *$ & $.19 * *$ & $.32 * *$ \\
\hline
\end{tabular}

Note. $*$ indicates $p<.05 ; * *$ indicates $p<.01 . M$ and $S D$ are used to represent mean and standard deviation, respectively. Cronbach's alpha coefficients are presented on the diagonal for all measures with three items or more. Ns range from 298 to 509 due to missing data and attrition rates. Beh. $=$ Behaviors. Org. = Organizational. T1 = time 1 (i.e., baseline). T2 = time 2 (i.e., 3 months following baseline). T3= time 3 (i.e., 9 months following baseline). 
Table 2, Cont.

Means, Standard Deviations, and Intercorrelations of Study Variables

\begin{tabular}{|c|c|c|c|c|c|c|c|c|c|c|c|c|c|}
\hline Variable & 25 & 26 & 27 & 28 & 29 & 30 & 31 & 32 & 33 & 34 & 35 & 36 & 37 \\
\hline 25. Financial Strain (T2) & $(.85)$ & & & & & & & & & & & & \\
\hline 26. Safety Compliance (T2) & -.04 & $(.96)$ & & & & & & & & & & & \\
\hline 27. Job Search Beh. (T2) & $.30 * *$ & $-.11 *$ & $(.85)$ & & & & & & & & & & \\
\hline 28. Job Satisfaction (T2) & $-.22 * *$ & $.25 * *$ & $-.52 * *$ & $(.91)$ & & & & & & & & & \\
\hline 29. Turnover Intentions (T2) & $.33 * *$ & $-.17 * *$ & $.72 * *$ & $-.64 * *$ & - & & & & & & & & \\
\hline 30. Org. Commitment (T2) & $-.15^{* *}$ & $.28 * *$ & $-.41 * *$ & $.67 * *$ & $-.57 * *$ & $(.95)$ & & & & & & & \\
\hline 31. Healthy Diet Beh. (T2) & $-.17 * *$ & -.05 & .03 & .03 & -.07 & .07 & $(.71)$ & & & & & & \\
\hline 32. Unhealthy Diet Beh. (T2) & $.10^{*}$ & -.08 & .01 & .00 & -.01 & .04 & .06 & $(.72)$ & & & & & \\
\hline 33. Exercise Beh. (T2) & $-.11 *$ & .01 & .06 & .01 & .01 & -.04 & $.27 * *$ & -.08 & $(.78)$ & & & & \\
\hline 34. Life Satisfaction (T2) & $-.41 * *$ & $.17^{* *}$ & $-.24 * *$ & $.43 * *$ & $-.35 * *$ & $.43 * *$ & $20 * *$ & $-.10^{*}$ & $.19 * *$ & $(.91)$ & & & \\
\hline 35. Home Demands (T3) & $.14 * *$ & -.02 & -.07 & .10 & -.05 & $.14^{* *}$ & -.02 & .05 & $-.14^{*}$ & .10 & - & & \\
\hline 36. Total Work Hours (T3) & -.06 & .05 & -.06 & .04 & -.06 & .02 & -.04 & -.10 & $.11^{*}$ & $.14^{*}$ & .08 & - & \\
\hline 37. Schedule Type (T3) & .03 & -.07 & -.02 & .03 & -.04 & -.01 & -.10 & .00 & -.06 & .02 & .01 & .06 & - \\
\hline 38. Friends Support (T3) & $-.22 * *$ & .11 & $-.19 * *$ & $.23 * *$ & $-.26 * *$ & $.27 * *$ & $.17 * *$ & -.06 & $.15^{* *}$ & $.41 * *$ & -.02 & -.02 & -.00 \\
\hline 39. Family Support (T3) & $-.20 * *$ & $.18^{* *}$ & $-.12 *$ & $.15^{* *}$ & $-.18 * *$ & $.25^{* *}$ & $.17 * *$ & -.01 & $.12 *$ & $.45^{* *}$ & $.11 *$ & .09 & .01 \\
\hline 40. Supervisor Support (T3) & $-.15^{* *}$ & $.14^{*}$ & $-.27 * *$ & $.34 * *$ & $-.30 * *$ & $.35^{* *}$ & .04 & -.05 & -.04 & $.24 * *$ & .03 & -.03 & -.00 \\
\hline 41. Coworker Support (T3) & $-.14 * *$ & $.17 * *$ & $-.19 * *$ & $.27 * *$ & $-.24 * *$ & $.34 * *$ & $.19 * *$ & -.02 & -.01 & $.29 * *$ & .05 & -.03 & .03 \\
\hline 42. Financial Strain (T3) & $.63 * *$ & -.00 & $.31 * *$ & $-.19 * *$ & $.30 * *$ & -.10 & -.08 & .07 & -.09 & $-.32 * *$ & $.11 *$ & -.09 & -.09 \\
\hline 43. Safety Compliance (T3) & .05 & $.57 * *$ & -.08 & $.22 * *$ & $-.14^{*}$ & $.25^{* *}$ & .02 & -.09 & .03 & $.13 *$ & $.11^{*}$ & .01 & .03 \\
\hline 44. Job Search Beh. (T3) & $.23 * *$ & -.03 & $.61 * *$ & $-.29 * *$ & $.52 * *$ & $-.20 * *$ & .07 & .08 & .06 & $-.20 * *$ & -.03 & -.03 & -.03 \\
\hline 45. Job Satisfaction (T3) & $-.12 *$ & $.20 * *$ & $-.34 * *$ & $.59 * *$ & $-.44 * *$ & $.44 * *$ & -.01 & .00 & -.05 & $.32 * *$ & $.13 *$ & .03 & .02 \\
\hline 46. Turnover Intentions (T3) & $.16^{* *}$ & $-.12 *$ & $.49 * *$ & $-.39 * *$ & $.64 * *$ & $-.33 * *$ & .04 & .07 & .02 & $-.26^{* *}$ & -.10 & -.05 & .03 \\
\hline 47. Org. Commitment (T3) & $-.11 *$ & $.22 * *$ & $-.30 * *$ & $.52 * *$ & $-.44 * *$ & $.69 * *$ & .03 & -.03 & -.02 & $.34 * *$ & $.18^{* *}$ & .08 & .04 \\
\hline 48. Healthy Diet Beh. (T3) & $-.11 *$ & -.03 & .06 & .06 & -.05 & .03 & $.65 * *$ & -.04 & $.20 * *$ & $.22 * *$ & -.00 & -.05 & $-.10 *$ \\
\hline 49. Unhealthy Diet Beh. (T3) & .09 & -.03 & .06 & -.05 & .04 & -.04 & -.06 & $.61 * *$ & $-.15 * *$ & $-.15 * *$ & .04 & -.07 & .03 \\
\hline 50. Exercise Beh. (T3) & $-.14 * *$ & .00 & .03 & .03 & -.03 & -.05 & $.34 * *$ & -.04 & $.59 * *$ & $.17 * *$ & -.06 & .09 & -.04 \\
\hline 51. Life Satisfaction (T3) & $-.37 * *$ & $.12 *$ & $-.24 * *$ & $.34 * *$ & $-.31 * *$ & $.32 * *$ & $.20 * *$ & $-.14 * *$ & $.22 * *$ & $.76^{* *}$ & $.11 *$ & .09 & .08 \\
\hline
\end{tabular}


Table 2, Cont.

Means, Standard Deviations, and Intercorrelations of Study Variables

\begin{tabular}{|c|c|c|c|c|c|c|c|c|c|c|c|c|c|c|}
\hline Variable & 38 & 39 & 40 & 41 & 42 & 43 & 44 & 45 & 46 & 47 & 48 & 49 & 50 & 51 \\
\hline \multicolumn{15}{|l|}{ 26. Safety Compliance (T2) } \\
\hline \multicolumn{15}{|l|}{ 27. Job Search Beh. (T2) } \\
\hline \multicolumn{15}{|l|}{ 28. Job Satisfaction (T2) } \\
\hline \multicolumn{15}{|l|}{ 29. Turnover Intentions (T2) } \\
\hline \multicolumn{15}{|l|}{ 30. Org. Commitment (T2) } \\
\hline \multicolumn{15}{|l|}{ 31. Healthy Diet Beh. (T2) } \\
\hline \multicolumn{15}{|l|}{ 32. Unhealthy Diet Beh. (T2) } \\
\hline \multicolumn{15}{|l|}{ 33. Exercise Beh. (T2) } \\
\hline \multicolumn{15}{|l|}{ 34. Life Satisfaction (T2) } \\
\hline \multicolumn{15}{|l|}{ 35. Home Demands (T3) } \\
\hline \multicolumn{15}{|l|}{ 36. Total Work Hours (T3) } \\
\hline \multicolumn{15}{|l|}{ 37. Schedule Type (T3) } \\
\hline 38. Friends Support (T3) & $(.93)$ & & & & & & & & & & & & & \\
\hline 39. Family Support (T3) & $.36 * *$ & $(.90)$ & & & & & & & & & & & & \\
\hline 40. Supervisor Support (T3) & $.15 * *$ & $.18 * *$ & $(.70)$ & & & & & & & & & & & \\
\hline 41. Coworker Support (T3) & $.35 * *$ & $.29 * *$ & $.30 * *$ & $(.84)$ & & & & & & & & & & \\
\hline 42. Financial Strain (T3) & $-.21 * *$ & $-.18 * *$ & $-.15 * *$ & $-.14 * *$ & $(.84)$ & & & & & & & & & \\
\hline 43. Safety Compliance (T3) & $.19 * *$ & $.11 *$ & $.17 * *$ & $.20 * *$ & .01 & $(.96)$ & & & & & & & & \\
\hline 44. Job Search Beh. (T3) & $-.14 * *$ & $-.12 *$ & $-.39 * *$ & $-.23 * *$ & $.33 * *$ & -.03 & $(.85)$ & & & & & & & \\
\hline 45. Job Satisfaction (T3) & $.23 * *$ & $.13 *$ & $.41 * *$ & $.32 * *$ & $-.20 * *$ & $.24 * *$ & $-.51 * *$ & $(.89)$ & & & & & & \\
\hline 46. Turnover Intentions (T3) & $-.19 * *$ & $-.16^{* *}$ & $-.39 * *$ & $-.26 * *$ & $.25 * *$ & -.09 & $.71 * *$ & $-.61 * *$ & - & & & & & \\
\hline 47. Org. Commitment (T3) & $.28 * *$ & $.20 * *$ & $.45 * *$ & $.45 * *$ & $-.14 * *$ & $.22 * *$ & $-.35 * *$ & $.59 * *$ & $-.49 * *$ & $(.95)$ & & & & \\
\hline 48. Healthy Diet Beh. (T3) & $.19 * *$ & $.16^{* *}$ & -.01 & $.20 * *$ & -.10 & .03 & $.11^{*}$ & -.05 & .07 & .02 & $(.78)$ & & & \\
\hline 49. Unhealthy Diet Beh. (T3) & -.08 & -.03 & $-.11 *$ & .02 & .08 & $-.11 *$ & $.13 *$ & -.05 & .06 & -.08 & -.03 & $(.74)$ & & \\
\hline 50. Exercise Beh. (T3) & $.10 *$ & .09 & -.00 & -.05 & $-.14 * *$ & -.03 & .05 & -.00 & -.04 & .06 & $.33 * *$ & $-.12 *$ & $(.78)$ & \\
\hline 51. Life Satisfaction (T3) & $.44 * *$ & $.44 * *$ & $.28 * *$ & $.33 * *$ & $-.43 * *$ & $.18 * *$ & $-.27 * *$ & $.41 * *$ & $-.29 * *$ & $.35 * *$ & $.23 * *$ & $-.18 * *$ & $.22 * *$ & $(.91)$ \\
\hline
\end{tabular}

Note. ${ }^{*}$ indicates $p<.05 ; * *$ indicates $p<.01 . M$ and $S D$ are used to represent mean and standard deviation, respectively. Cronbach's alpha coefficients are presented on the diagonal for all measures with three items or more. Ns range from 298 to 509 due to missing data and attrition rates. Beh. $=$ Behaviors. Org. = Organizational. T1 = time 1 (i.e., baseline). T2 = time 2 (i.e., 3 months following baseline). T3= time 3 (i.e., 9 months following baseline). 
Table 3

Correlations of Financial Strain With Other Study Variables

\begin{tabular}{|c|c|c|c|}
\hline Variable & Financial Strain (T1) & Financial Strain (T2) & Financial Strain (T3) \\
\hline 1. Home Demands (T1) & $.14 * *$ & $.15 * *$ & $.15 * *$ \\
\hline 2. Home Demands (T2) & $.17 * *$ & $.15^{* *}$ & $.14 * *$ \\
\hline 3. Home Demands (T3) & $.18 * *$ & $.14 * *$ & $.11 *$ \\
\hline 4. Total Work Hours (T1) & -.06 & -.05 & -.01 \\
\hline 5. Total Work Hours (T2) & -.01 & -.01 & .07 \\
\hline 6. Total Work Hours (T3) & -.08 & -.06 & -.09 \\
\hline 7. Schedule Type (T1) & .04 & .05 & -.03 \\
\hline 8. Schedule Type (T2) & .00 & -.01 & -.02 \\
\hline 9. Schedule Type (T3) & -.01 & .03 & -.09 \\
\hline 10. Friends Support (T1) & $-.17 * *$ & $-.14 * *$ & $-.16^{* *}$ \\
\hline 11. Friends Support (T2) & $-.10^{*}$ & $-.17 * *$ & $-.13^{*}$ \\
\hline 12. Friends Support (T3) & $-.15^{* *}$ & $-.22 * *$ & $-.21 * *$ \\
\hline 13. Family Support (T1) & $-.24 * *$ & $-.19 * *$ & $-.20 * *$ \\
\hline 14. Family Support (T2) & $-.18 * *$ & $-.23 * *$ & $-.13^{*}$ \\
\hline 15. Family Support (T3) & $-.20 * *$ & $-.20 * *$ & $-.18 * *$ \\
\hline 16. Supervisor Support (T1) & $-.09 *$ & -.08 & $-.14 * *$ \\
\hline 17. Supervisor Support (T2) & -.08 & -.08 & $-.11 *$ \\
\hline 18. Supervisor Support (T3) & $-.19 * *$ & $-.15 * *$ & $-.15^{* *}$ \\
\hline 19. Coworker Support (T1) & $-.14 * *$ & -.09 & -.08 \\
\hline 20. Coworker Support (T2) & $-.11 *$ & $-.19 * *$ & $-.10 *$ \\
\hline 21. Coworker Support (T3) & $-.12 *$ & $-.14 * *$ & $-.14 * *$ \\
\hline 22. Safety Compliance (T1) & .02 & .03 & .04 \\
\hline 23. Safety Compliance (T2) & .03 & -.04 & -.00 \\
\hline 24. Safety Compliance (T3) & .05 & .05 & .01 \\
\hline 25. Job Search Beh. (T1) & $.25^{* *}$ & $.23^{* *}$ & $.28 * *$ \\
\hline 26. Job Search Beh. (T2) & $.25 * *$ & $.30 * *$ & $.31 * *$ \\
\hline 27. Job Search Beh. (T3) & $.29 * *$ & $.23 * *$ & $.33^{* *}$ \\
\hline 28. Job Satisfaction (T1) & $-.12 * *$ & $-.14 * *$ & $-.12 *$ \\
\hline 29. Job Satisfaction (T2) & $-.14 * *$ & $-.22 * *$ & $-.19 * *$ \\
\hline 30. Job Satisfaction (T3) & $-.14 * *$ & $-.12 *$ & $-.20 * *$ \\
\hline 31. Turnover Intentions (T1) & $.25^{* *}$ & $.24 * *$ & $.27 * *$ \\
\hline 32. Turnover Intentions (T2) & $.28^{* *}$ & $.33 * *$ & $.30 * *$ \\
\hline 33. Turnover Intentions (T3) & $.25^{* *}$ & $.16^{* *}$ & $.25 * *$ \\
\hline 34. Org. Commitment (T1) & $-.09^{*}$ & $-.11 *$ & $-.12 *$ \\
\hline 35. Org. Commitment (T2) & -.07 & $-.15 * *$ & -.10 \\
\hline 36. Org. Commitment (T3) & $-.10^{*}$ & $-.11 *$ & $-.14 * *$ \\
\hline 37. Healthy Diet Beh. (T1) & $-.12 * *$ & $-.16^{* *}$ & $-.13 * *$ \\
\hline 38. Healthy Diet Beh. (T2) & $-.12 *$ & $-.17 * *$ & -.08 \\
\hline 39. Healthy Diet Beh. (T3) & -.05 & $-.11^{*}$ & -.10 \\
\hline 40. Unhealthy Diet Beh. (T1) & $.13^{* *}$ & $.10^{*}$ & $.14 * *$ \\
\hline 41. Unhealthy Diet Beh. (T2) & $.10^{*}$ & $.10^{*}$ & .07 \\
\hline 42. Unhealthy Diet Beh. (T3) & $.13 * *$ & .09 & .08 \\
\hline 43. Exercise Beh. (T1) & $-.16^{* *}$ & $-.15^{* *}$ & -.09 \\
\hline 44. Exercise Beh. (T2) & -.07 & $-.11^{*}$ & -.09 \\
\hline 45. Exercise Beh. (T3) & -.03 & $-.14 * *$ & $-.14 * *$ \\
\hline 46. Life Satisfaction (T1) & $-.40 * *$ & $-.36 * *$ & $-.31 * *$ \\
\hline 47. Life Satisfaction (T2) & $-.35 * *$ & $-.41 * *$ & $-.32 * *$ \\
\hline 48. Life Satisfaction (T3) & $-.29 * *$ & $-.37 * *$ & $-.43 * *$ \\
\hline
\end{tabular}

Note. $*$ indicates $p<.05 ; * *$ indicates $p<.01 . N \mathrm{~s}$ range from 298 to 509 due to missing data and attrition rates. Beh. $=$ Behaviors. Org. $=$ Organizational. $\mathrm{T} 1=$ time 1 (i.e., baseline). $\mathrm{T} 2=$ time 2 (i.e., 3 months following baseline). T3 = time 3 (i.e., 9 months following baseline). 


\section{Figures}

Domain $1 \quad$ Individual Domain 2

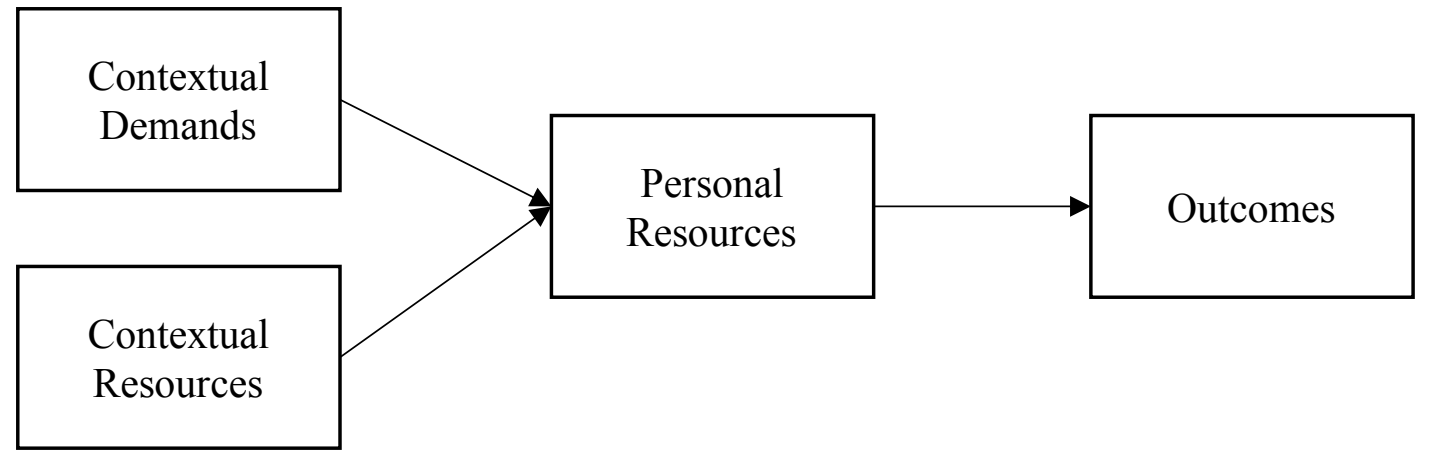

Figure 1. Conceptual model from the work-home resources model (ten Brummelhuis \& Bakker, 2012). 
Home

Individual

Work

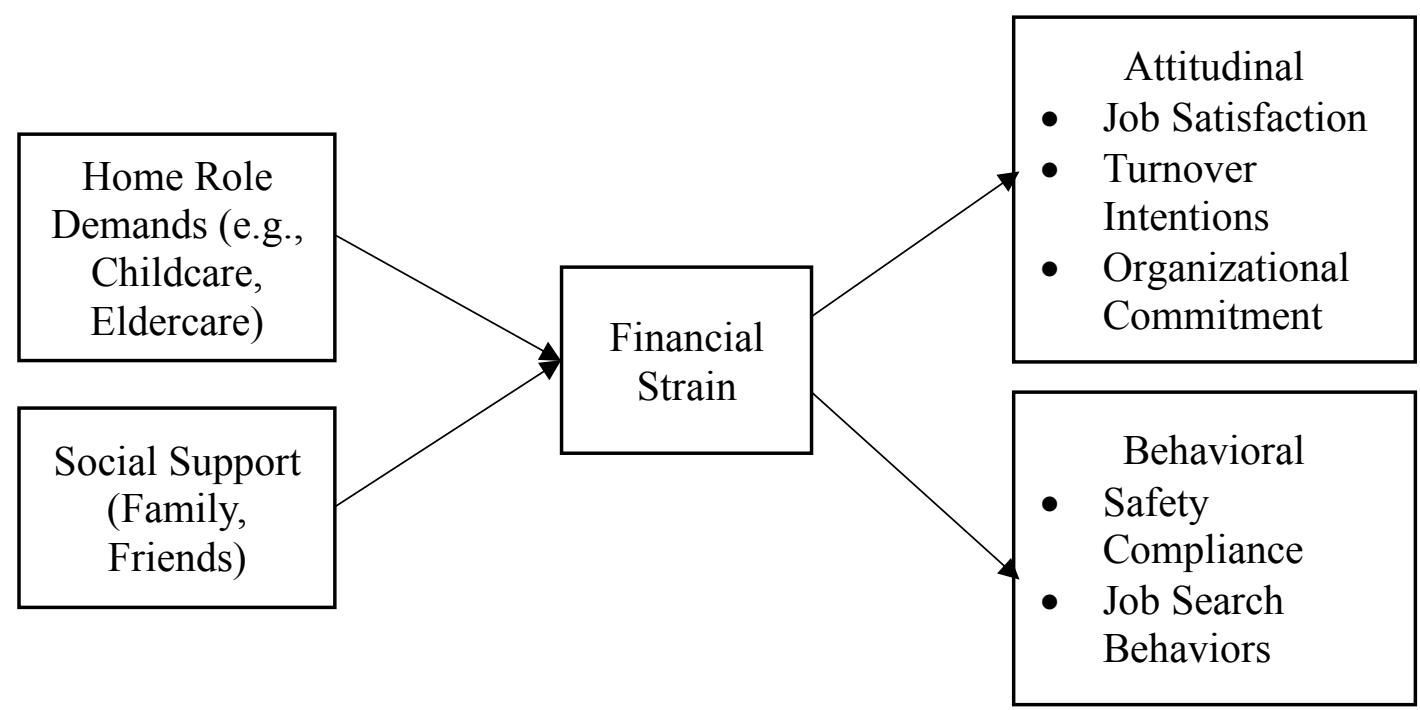

Figure 2. Hypothesized model of the home-to-work process. 
Work

Individual

Home

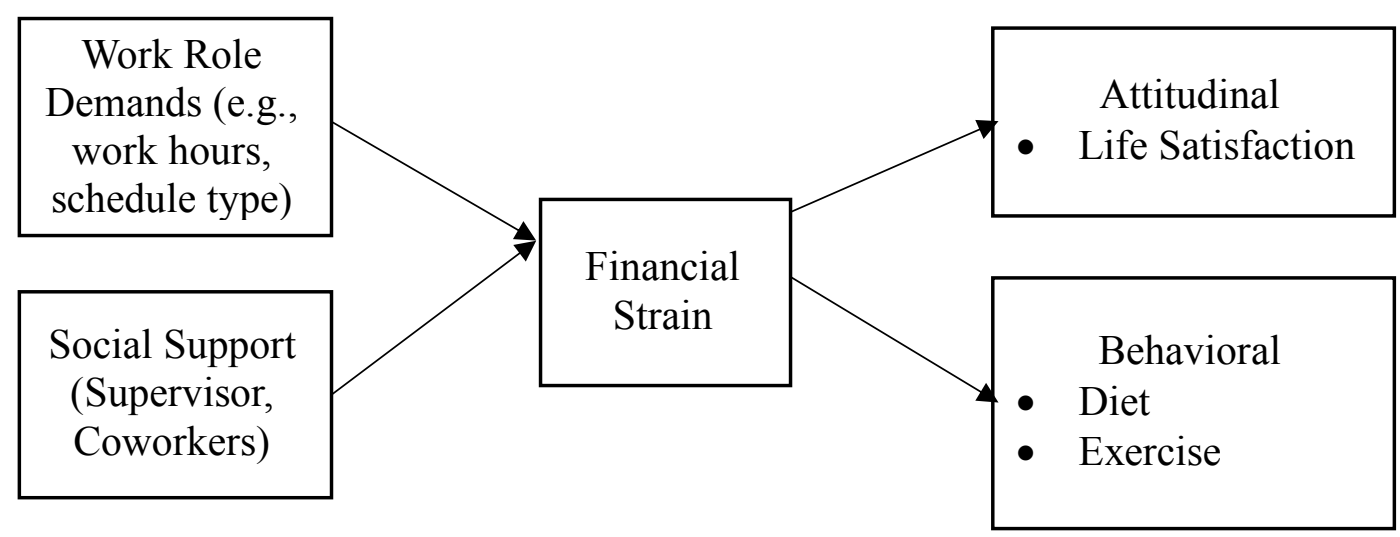

Figure 3. Hypothesized model of the work-to-home process. 
Figure 4. Participants and conditions for the Study for Employment Retention of Veterans (SERVe).

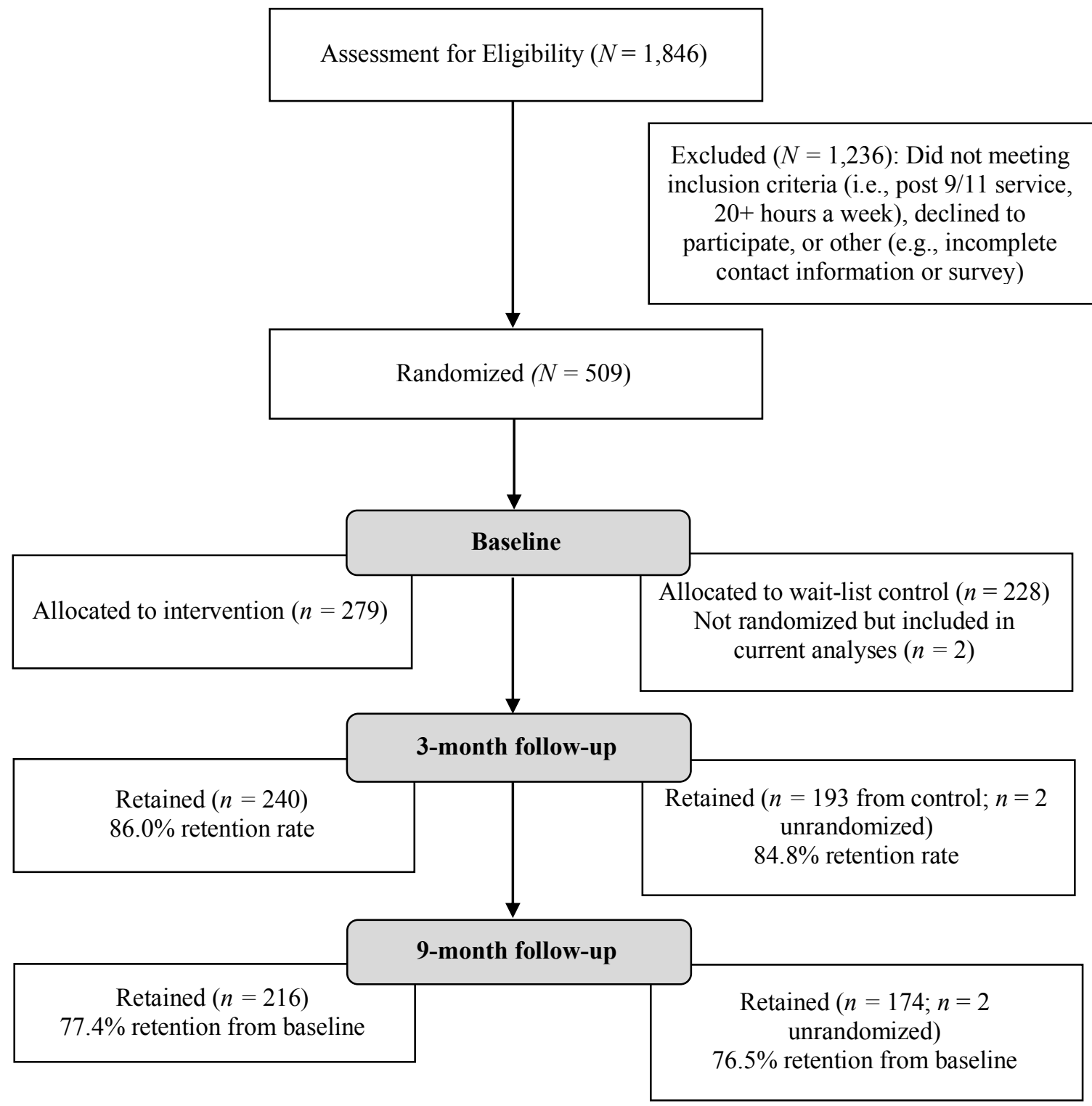


Time 1

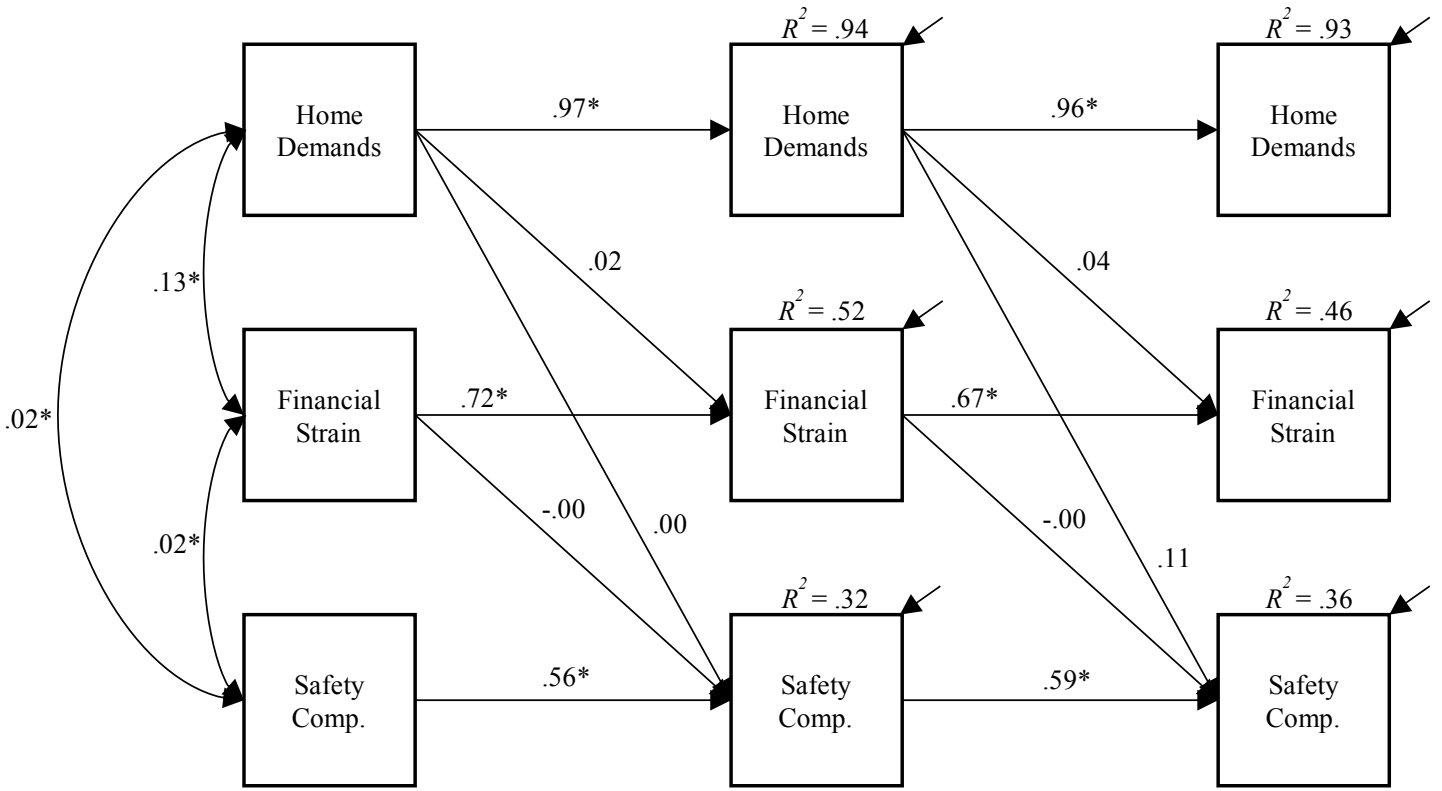

Figure 5. Standardized results for structural equation model 1. $N=509 .{ }^{*}=p<.05$. Standardized total indirect effect $=.05, n s$. Standardized specific indirect effect of time 1 demands at home on time 3 safety compliance through time 2 financial strain $=.00, n s$. Model includes intervention condition as a control variable. 
Time 1

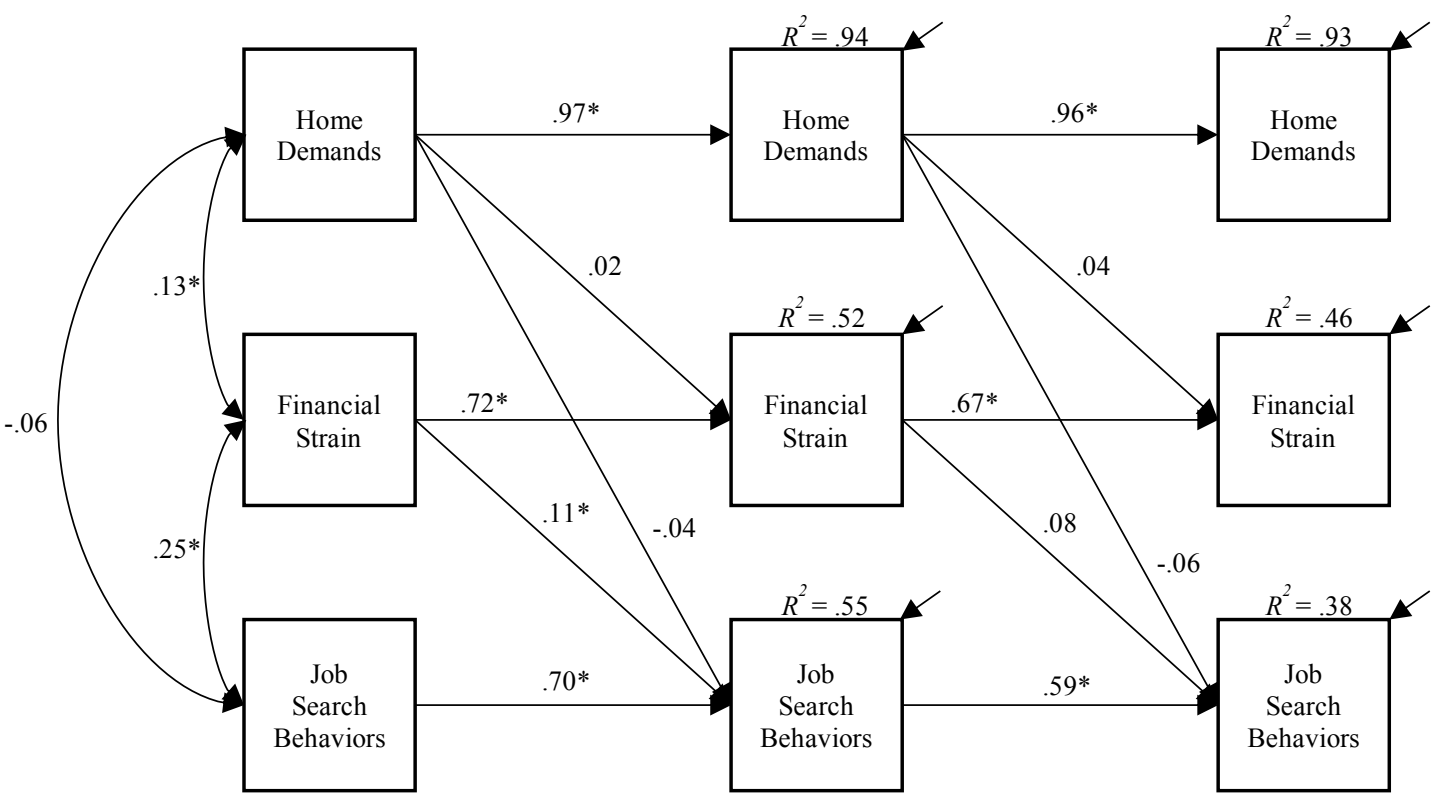

Figure 6. Standardized results for structural equation model 2. $N=509 . *=p<.05$. Standardized total indirect effect $=-.05, n s$. Standardized specific indirect effect of time 1 home demands on time 3 job search behaviors through time 2 financial strain $=.00, n s$. Model includes intervention condition as a control variable. 
Time 1

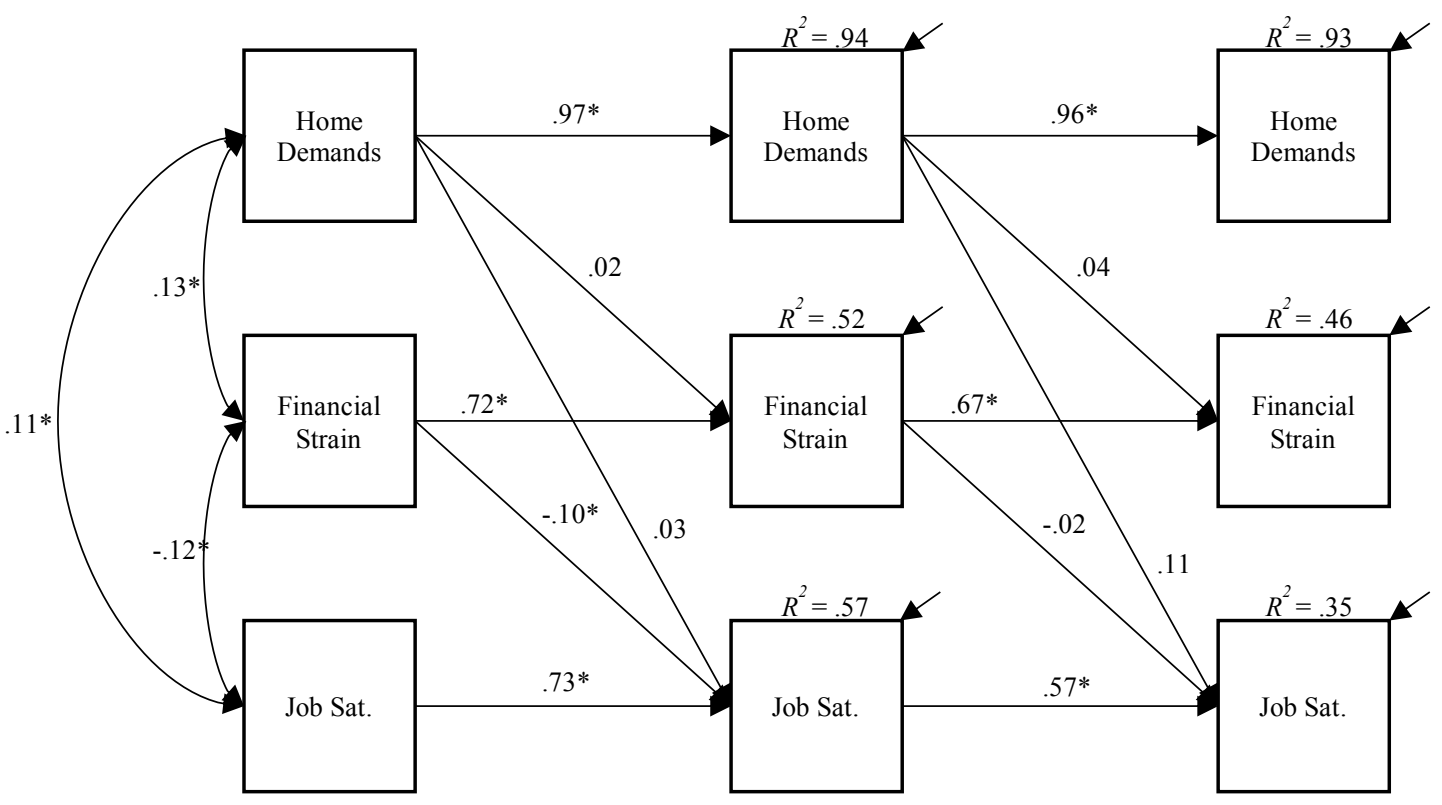

Figure 7. Standardized results for structural equation model 3. $N=509 . *=p<.05$. Standardized total indirect effect $=.08, n s$. Standardized specific indirect effect of time 1 home demands on time 3 job satisfaction through time 2 financial strain $=.00$, $n s$. Model includes intervention condition as a control variable. 
Time 1

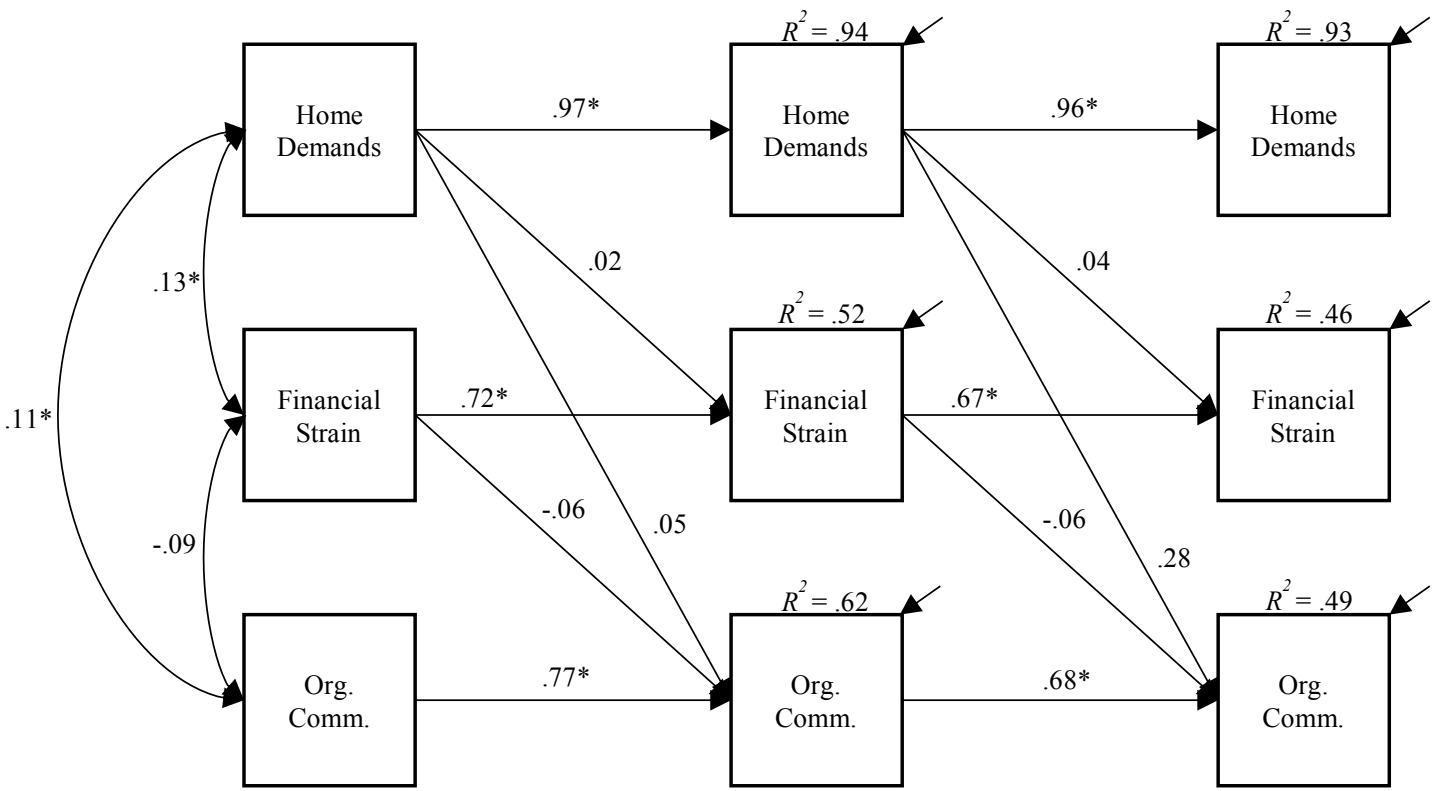

Figure 8. Standardized results for structural equation model 4. $N=509 . *=p<.05$. Standardized total indirect effect $=.23, n s$. Standardized specific indirect effect of time 1 home demands on time 3 organizational commitment through time 2 financial strain $=-.00, n s$. Model includes intervention condition as a control variable. 
Time 1

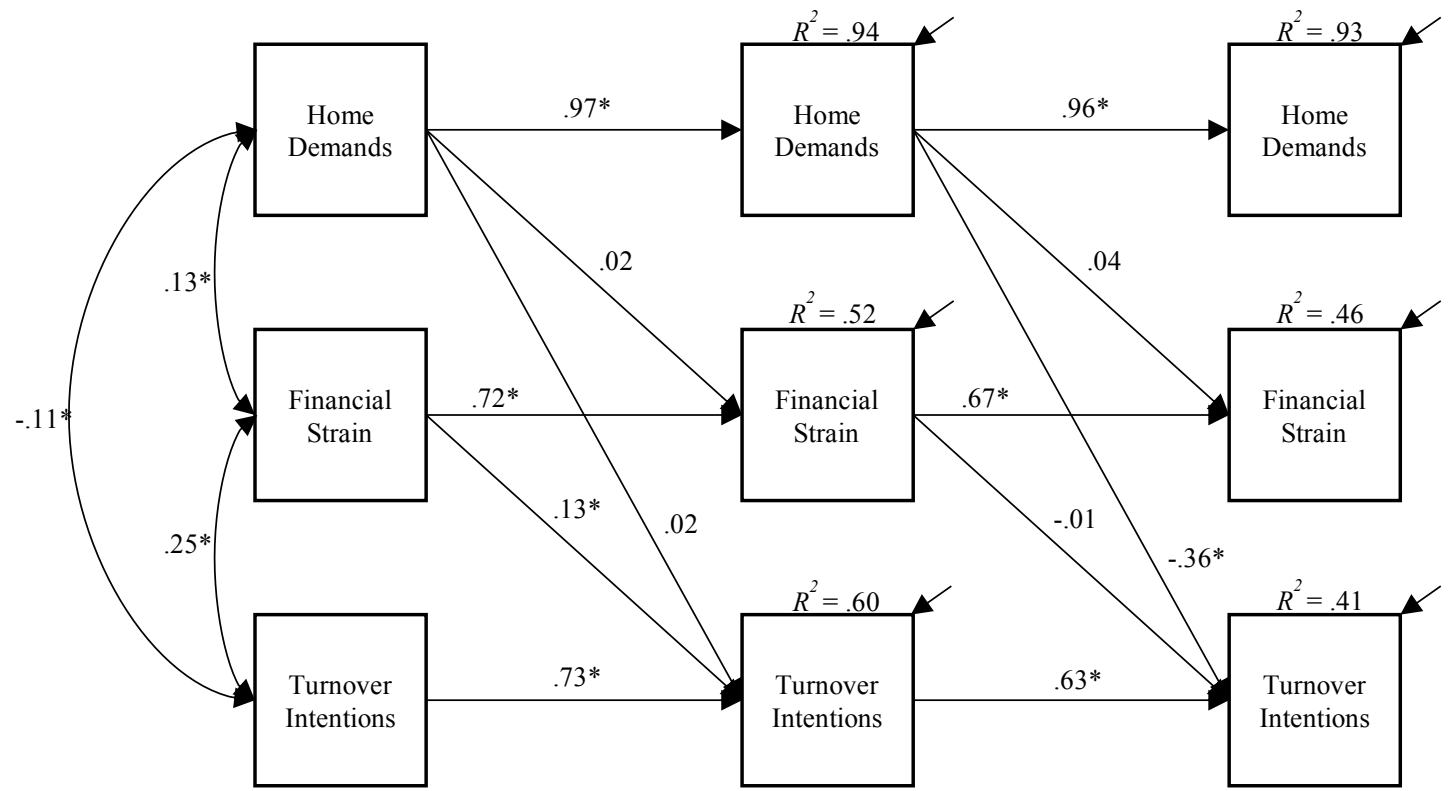

Figure 9. Standardized results for structural equation model 5. $N=509 .{ }^{*}=p<.05$. Standardized total indirect effect $=-.33, n s$. Standardized specific indirect effect of time 1 home demands on time 3 turnover intentions through time 2 financial strain $=$ $.00, n s$. Model includes intervention condition as a control variable. 
Time 1

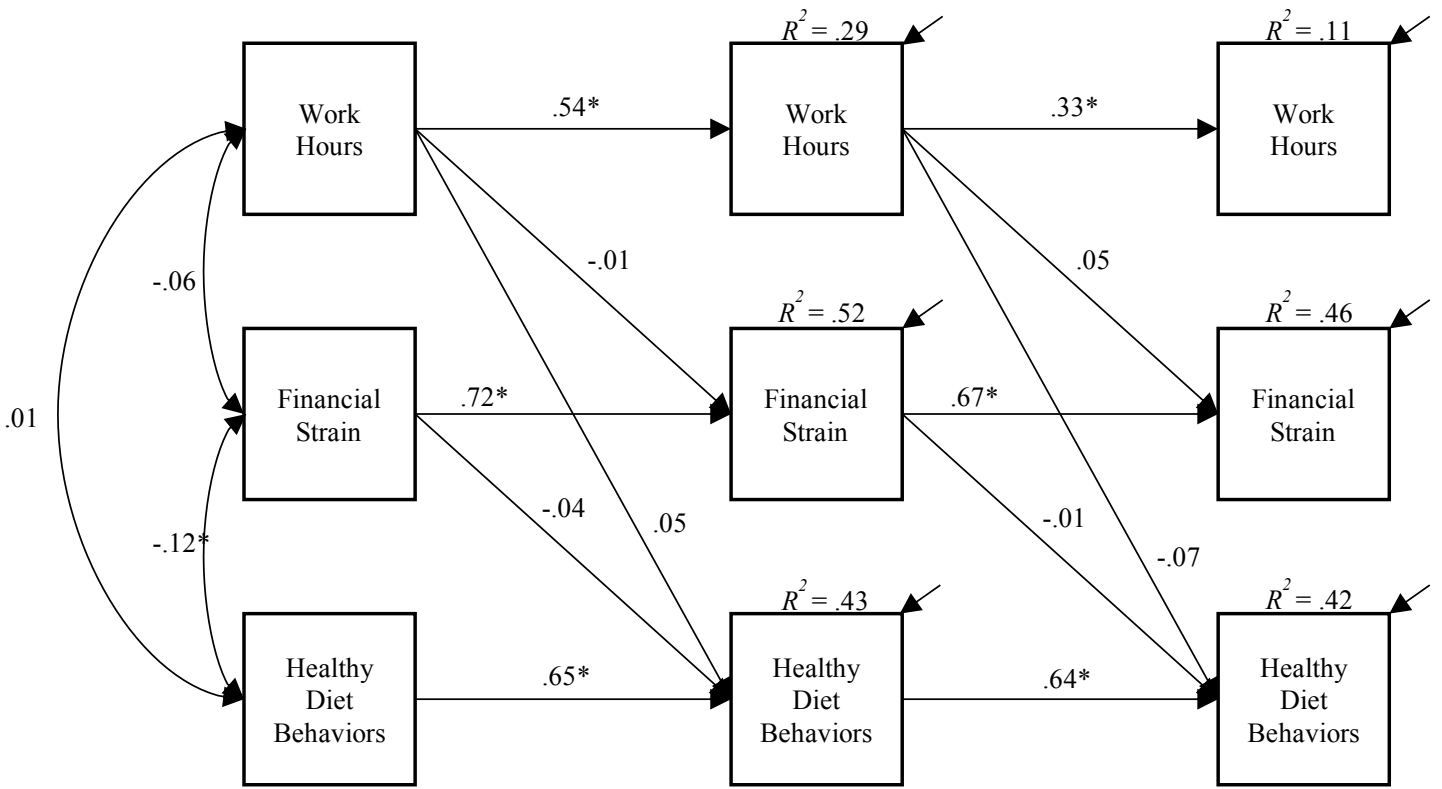

Figure 10. Standardized results for structural equation model 6. $N=509 .{ }^{*}=p<$ .05 . Standardized total indirect effect $=-.00, n s$. Standardized specific indirect effect of time 1 work hours on time 3 healthy diet behaviors through time 2 financial strain $=.00, n s$. Model includes intervention condition as a control variable. 
Time 1

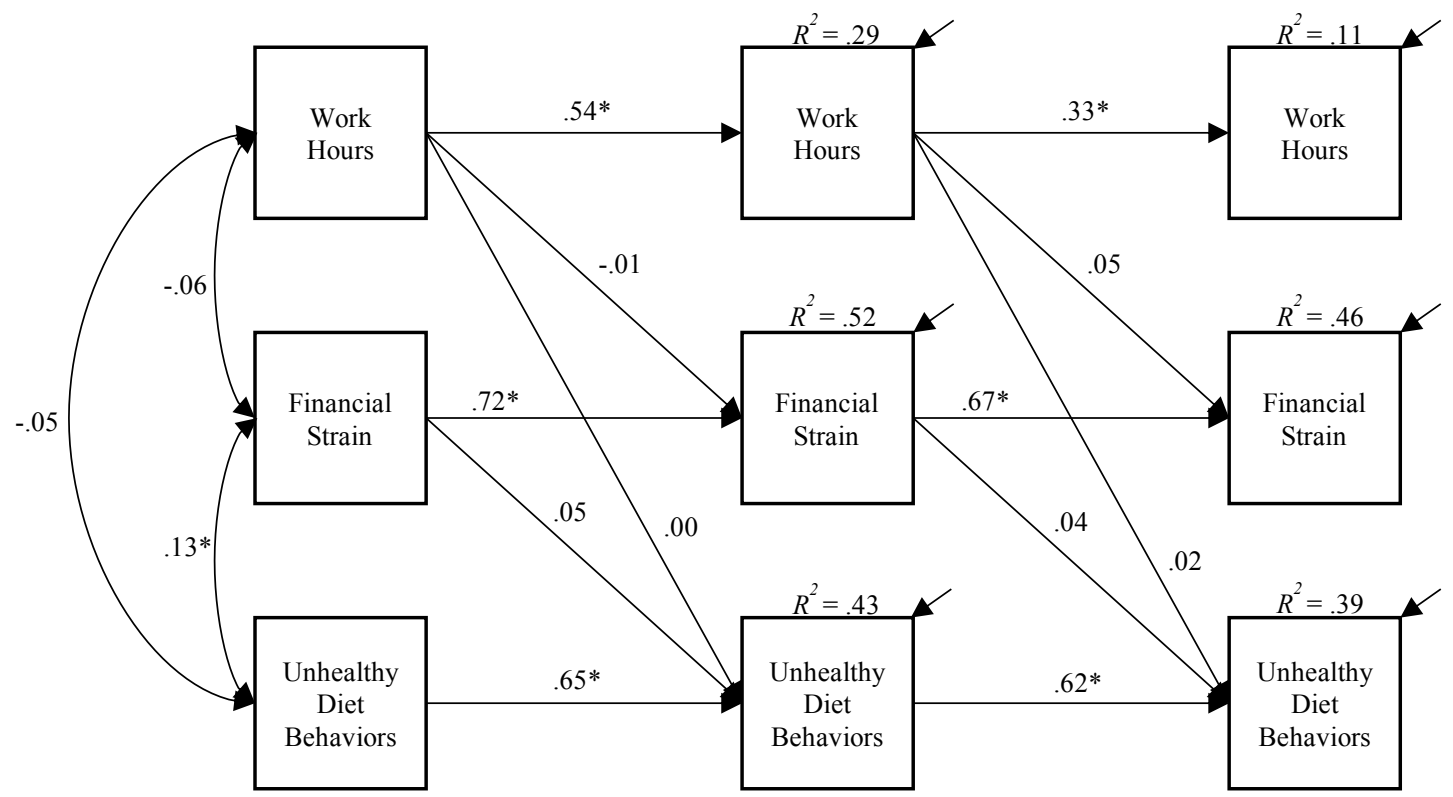

Figure 11. Standardized results for structural equation model 7. $N=509 . *=p<$ .05 . Standardized total indirect effect $=.00, n s$. Standardized specific indirect effect of time 1 work hours on time 3 unhealthy diet behaviors through time 2 financial strain $=.00, n s$. Model includes intervention condition as a control variable. 
Time 1

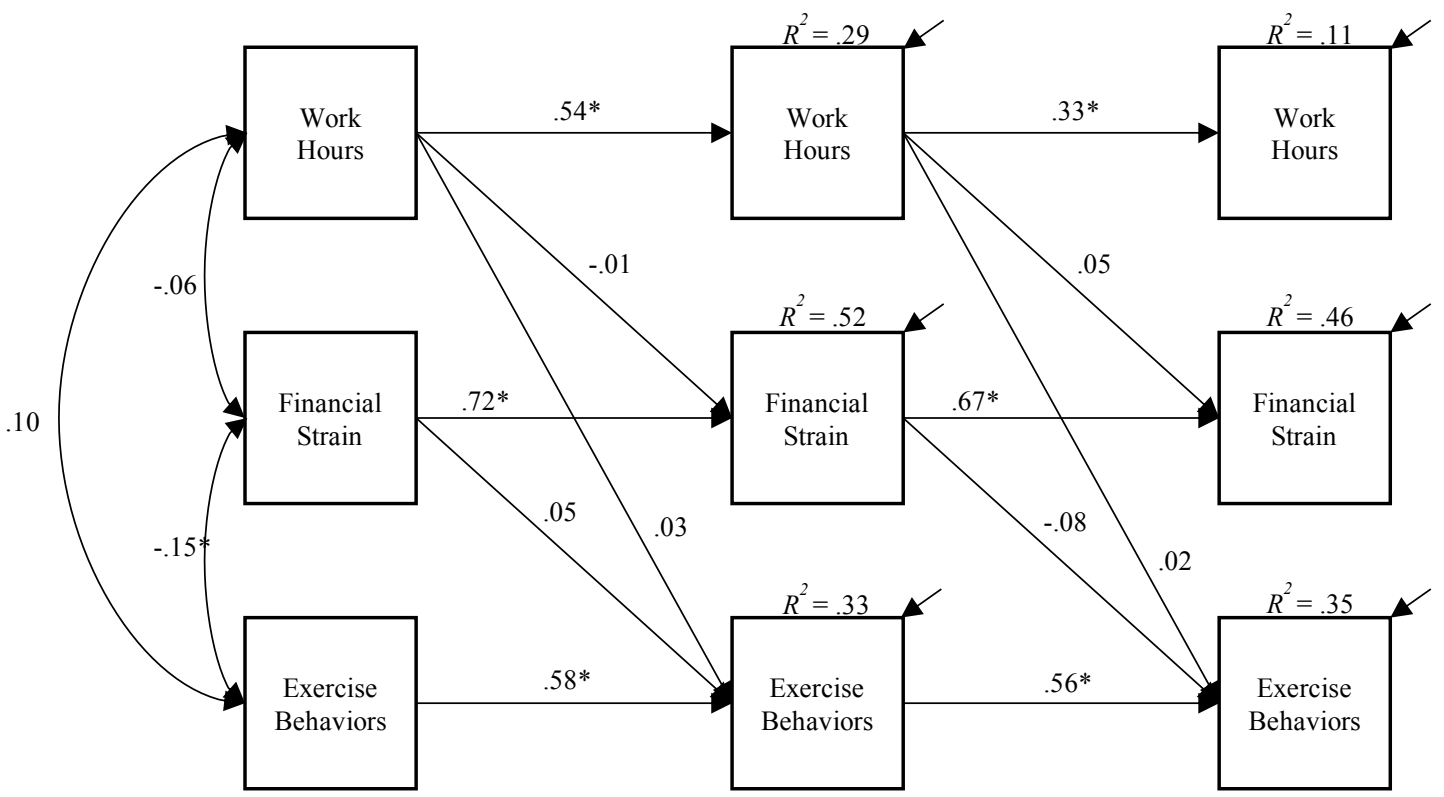

Figure 12. Standardized results for structural equation model 8. $N=509 .{ }^{*}=p<$ .05 . Standardized total indirect effect $=.03, n s$. Standardized specific indirect effect of time 1 work hours on time 3 exercise behaviors through time 2 financial strain = $.00, n s$. Model includes intervention condition as a control variable. 
Time 1

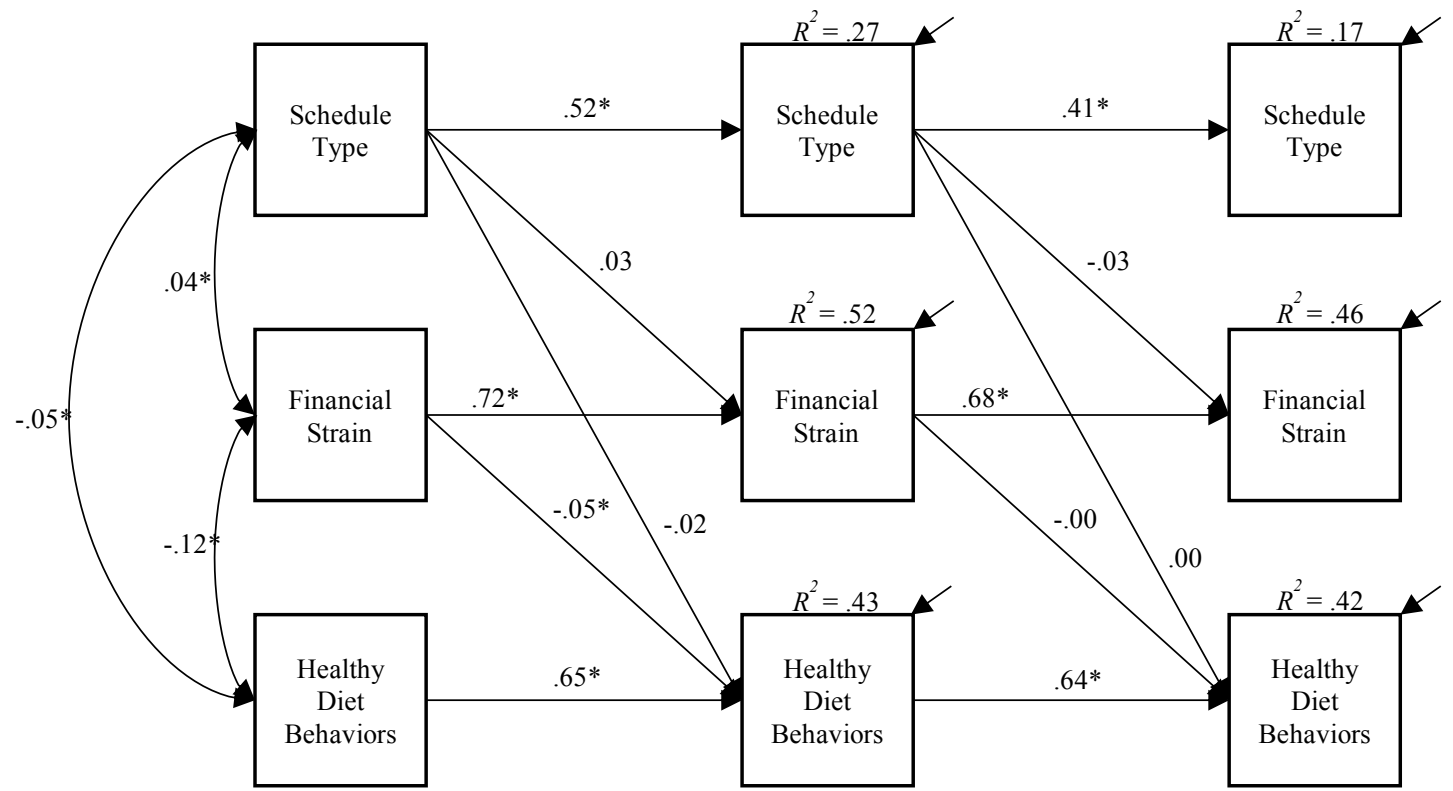

Figure 13. Standardized results for structural equation model 9. $N=509 .{ }^{*}=p<$ .05 . Standardized total indirect effect $=-.01, n s$. Standardized specific indirect effect of time 1 schedule type on time 3 healthy diet behaviors through time 2 financial strain $=.00, n s$. Model includes intervention condition as a control variable. 


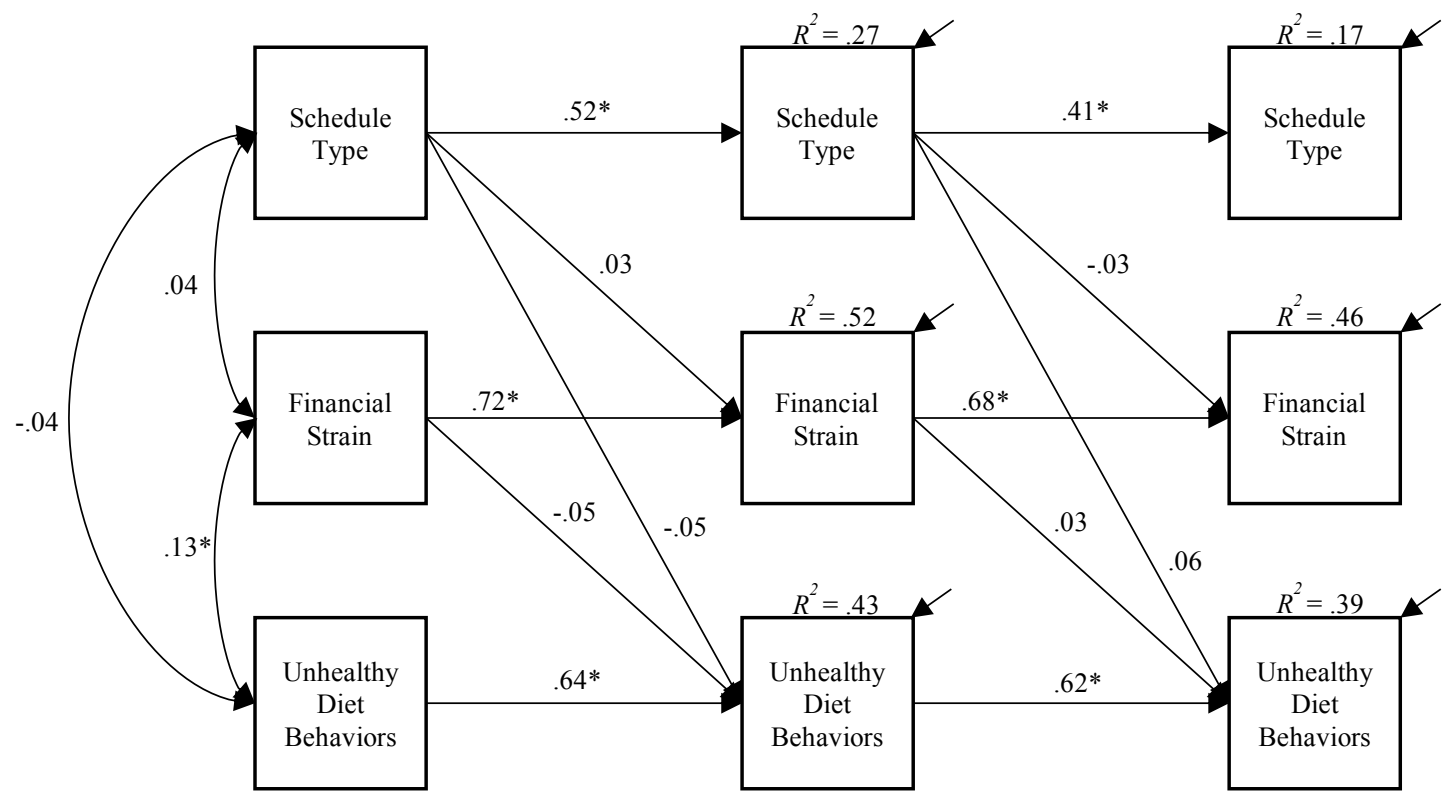

Figure 14. Standardized results for structural equation model 10. $N=509 . *=p<$ .05 . Standardized total indirect effect $=.00, n s$. Standardized specific indirect effect of time 1 schedule type on time 3 unhealthy diet behaviors through time 2 financial strain $=.00, n s$. Model includes intervention condition as a control variable. 
Time 1

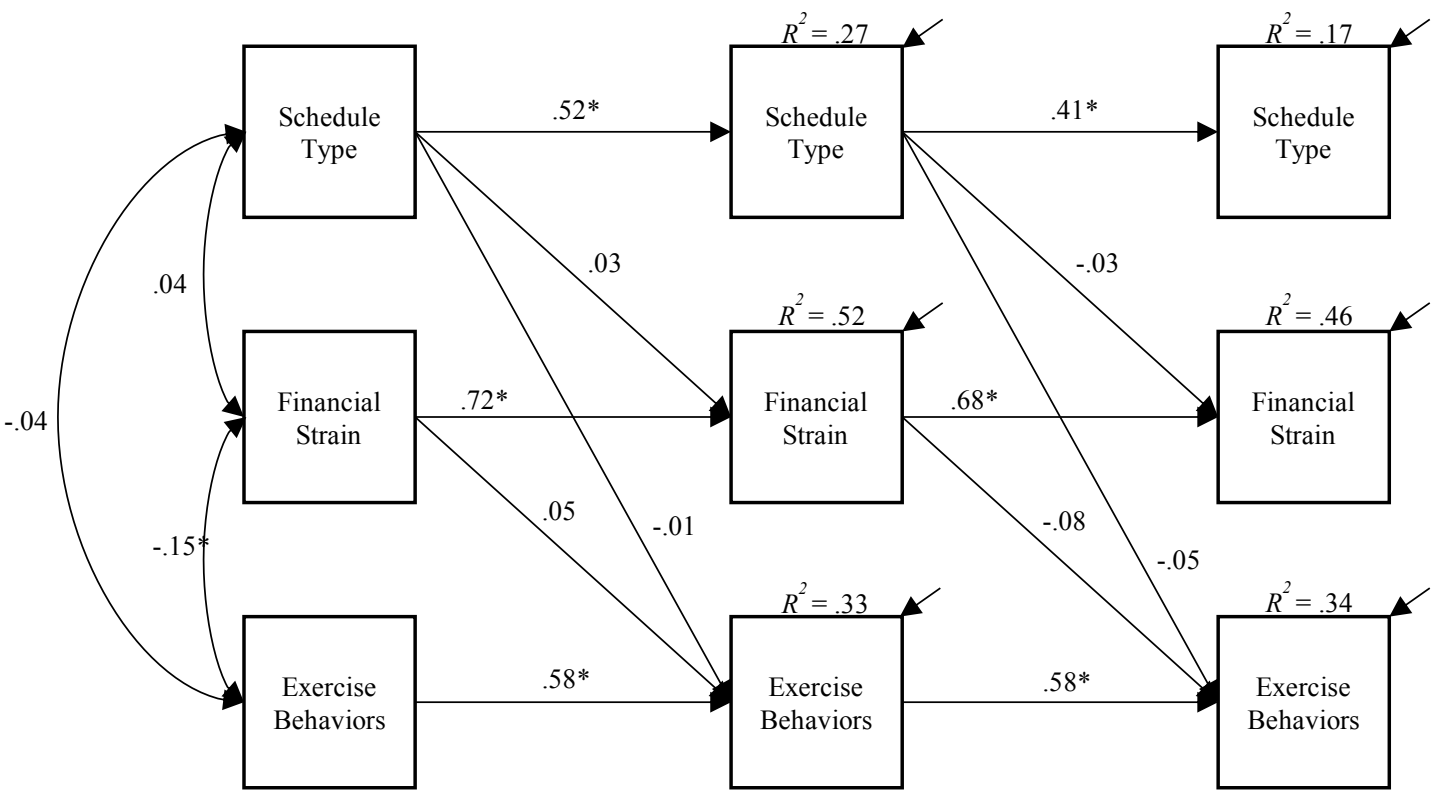

Figure 15. Standardized results for structural equation model 11. $N=509 . *=p<$ .05 . Standardized total indirect effect $=-.03, n s$. Standardized specific indirect effect of time 1 schedule type on time 3 exercise behaviors through time 2 financial strain $=-.00, n s$. Model includes intervention condition as a control variable. 
Time 1

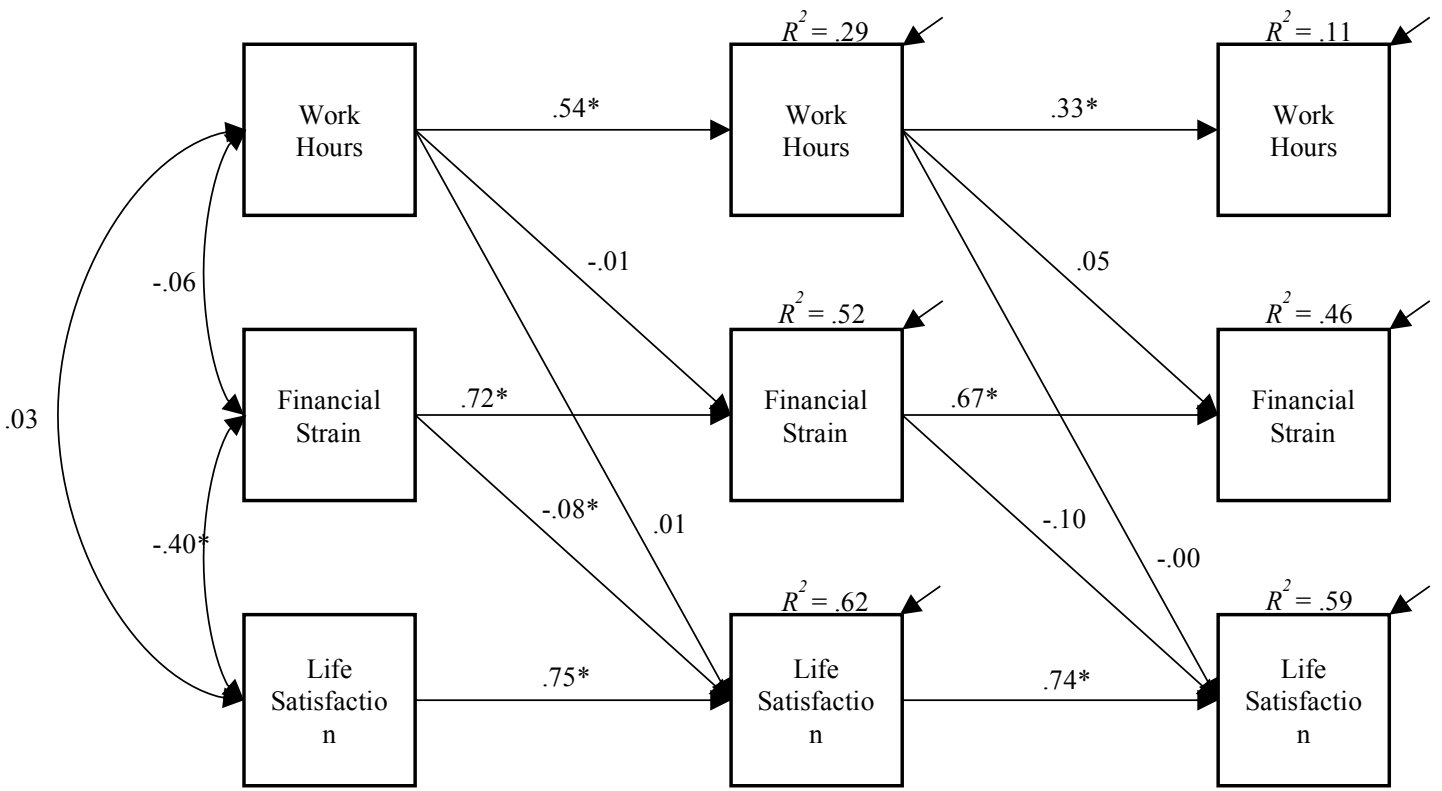

Figure 16. Standardized results for structural equation model 12. $N=509{ }^{*}=p<$ .05 . Standardized total indirect effect $=.01, n s$. Standardized specific indirect effect of time 1 work hours on time 3 life satisfaction through time 2 financial strain $=.00$, $n s$. Model includes intervention condition as a control variable. 
Time 1

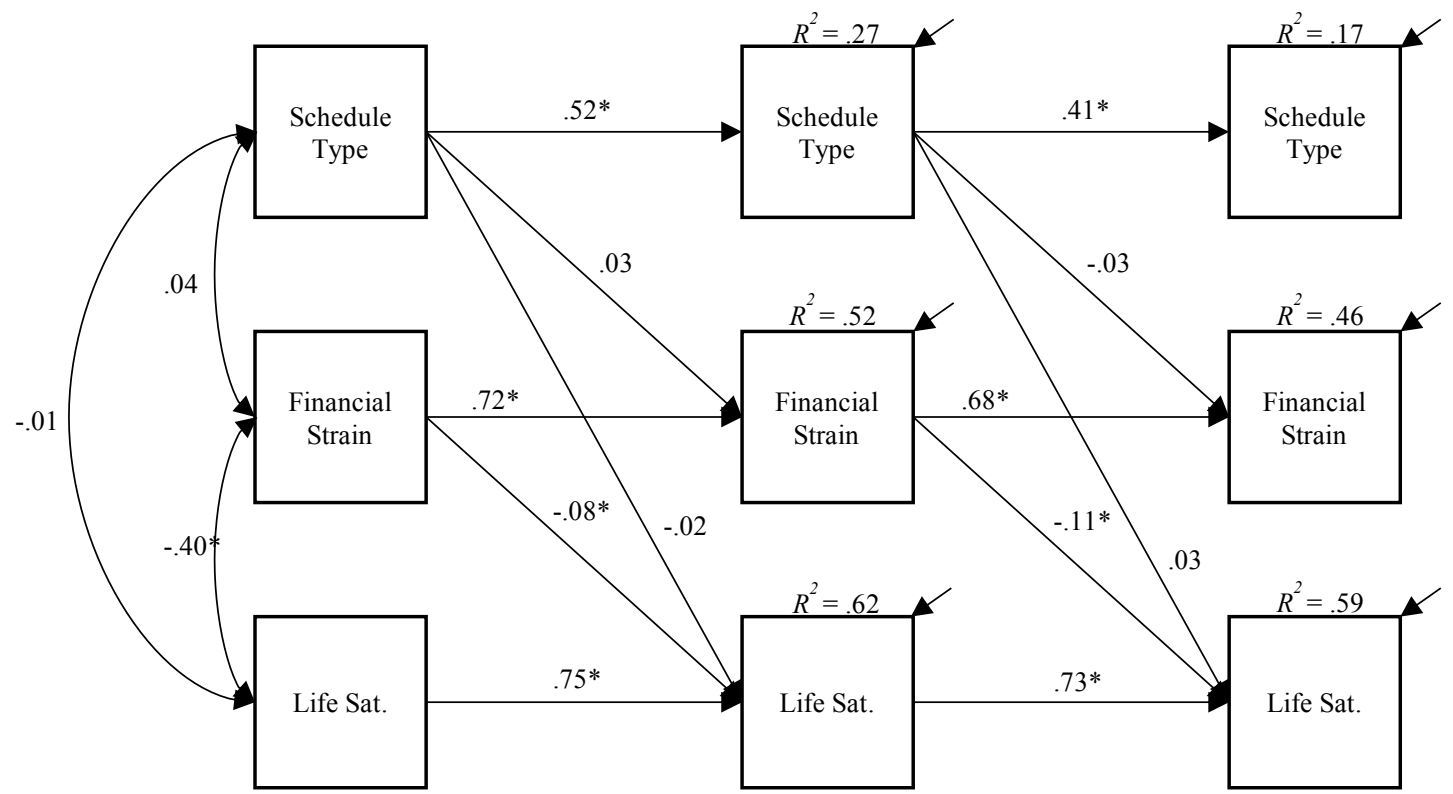

Figure 17. Standardized results for structural equation model 13. $N=509 . *=p<$ .05 . Standardized total indirect effect $=-.00, n s$. Standardized specific indirect effect of time 1 schedule type on time 3 life satisfaction through time 2 financial strain = $.00, n s$. Model includes intervention condition as a control variable. 
Time 1

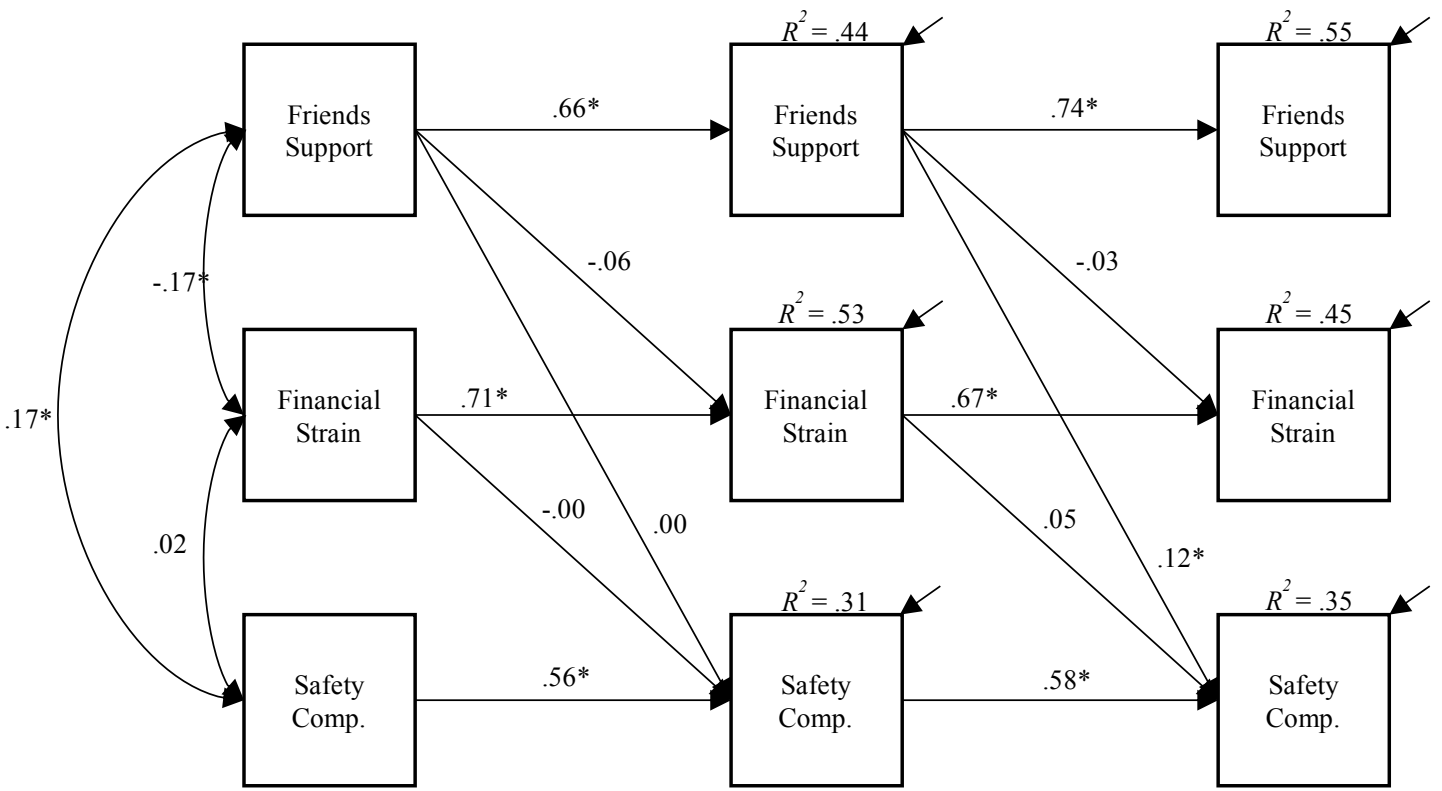

Figure 18. Standardized results for structural equation model 14. $N=509 . *=p<$ .05 . Standardized total indirect effect $=.08, n s$. Standardized specific indirect effect of time 1 support from friend on time 3 safety compliance through time 2 financial strain $=-.00, n s$. Model includes intervention condition as a control variable. 
Time 1

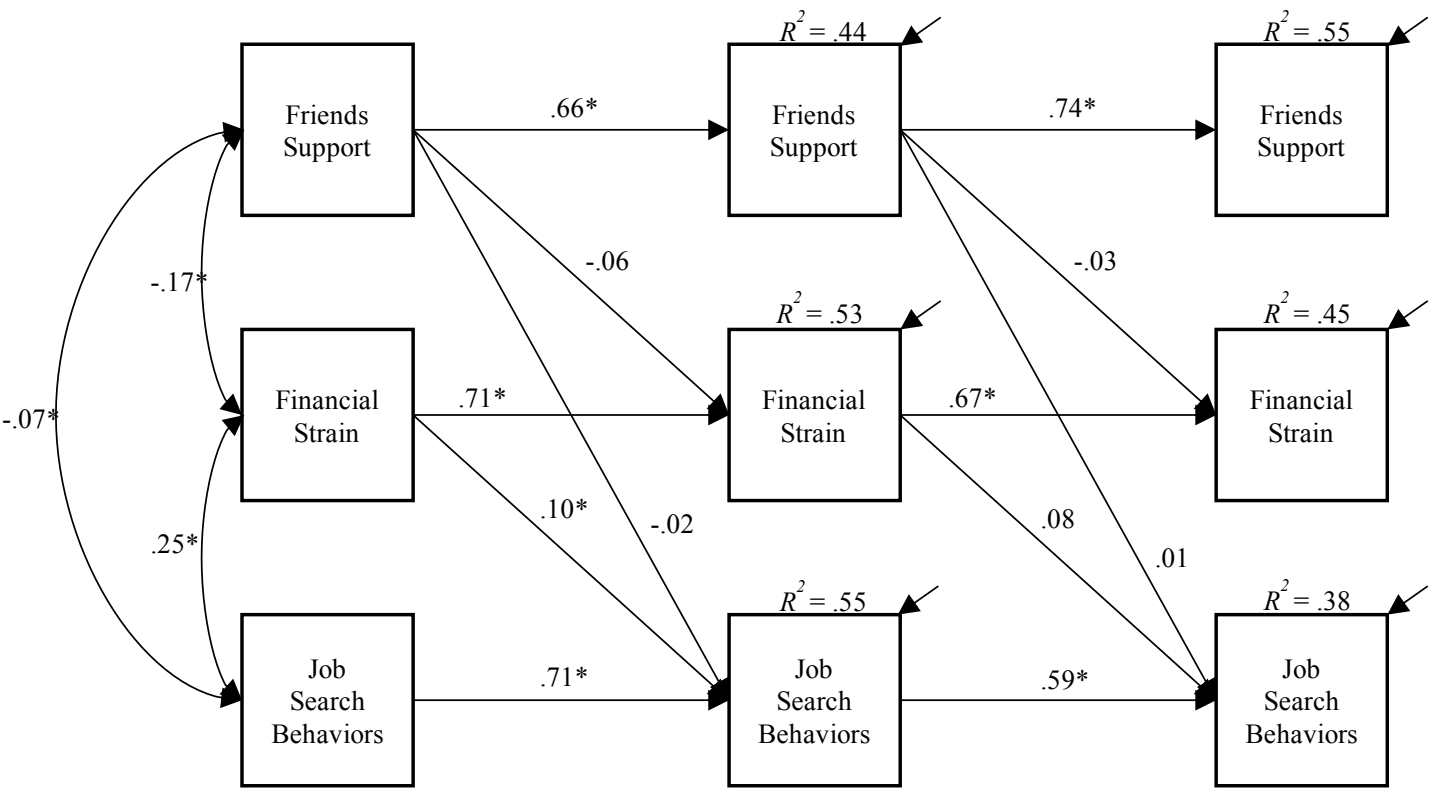

Figure 19. Standardized results for structural equation model 15. $N=509 . *=p<$ .05 . Standardized total indirect effect $=-.01, n s$. Standardized specific indirect effect of time 1 support from friends on time 3 job search behaviors through time 2 financial strain $=-.00, n s$. Model includes intervention condition as a control variable. 
Time 1

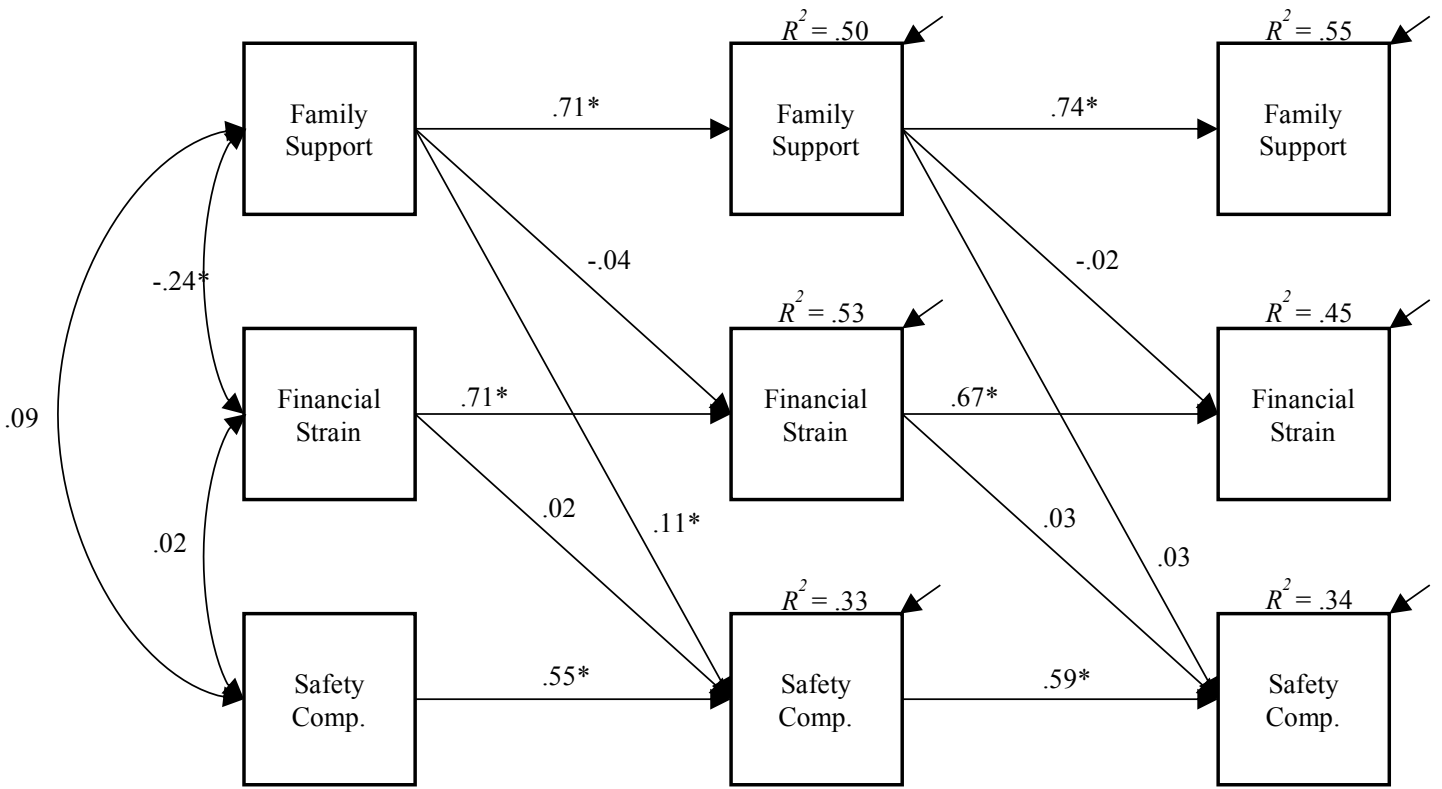

Figure 20. Standardized results for structural equation model 16. $N=509 .{ }^{*}=p<$ .05 . Standardized total indirect effect $=.09, n s$. Standardized specific indirect effect of time 1 support from family on time 3 safety compliance through time 2 financial strain $=-.00, n s$. Model includes intervention condition as a control variable. 
Time 1

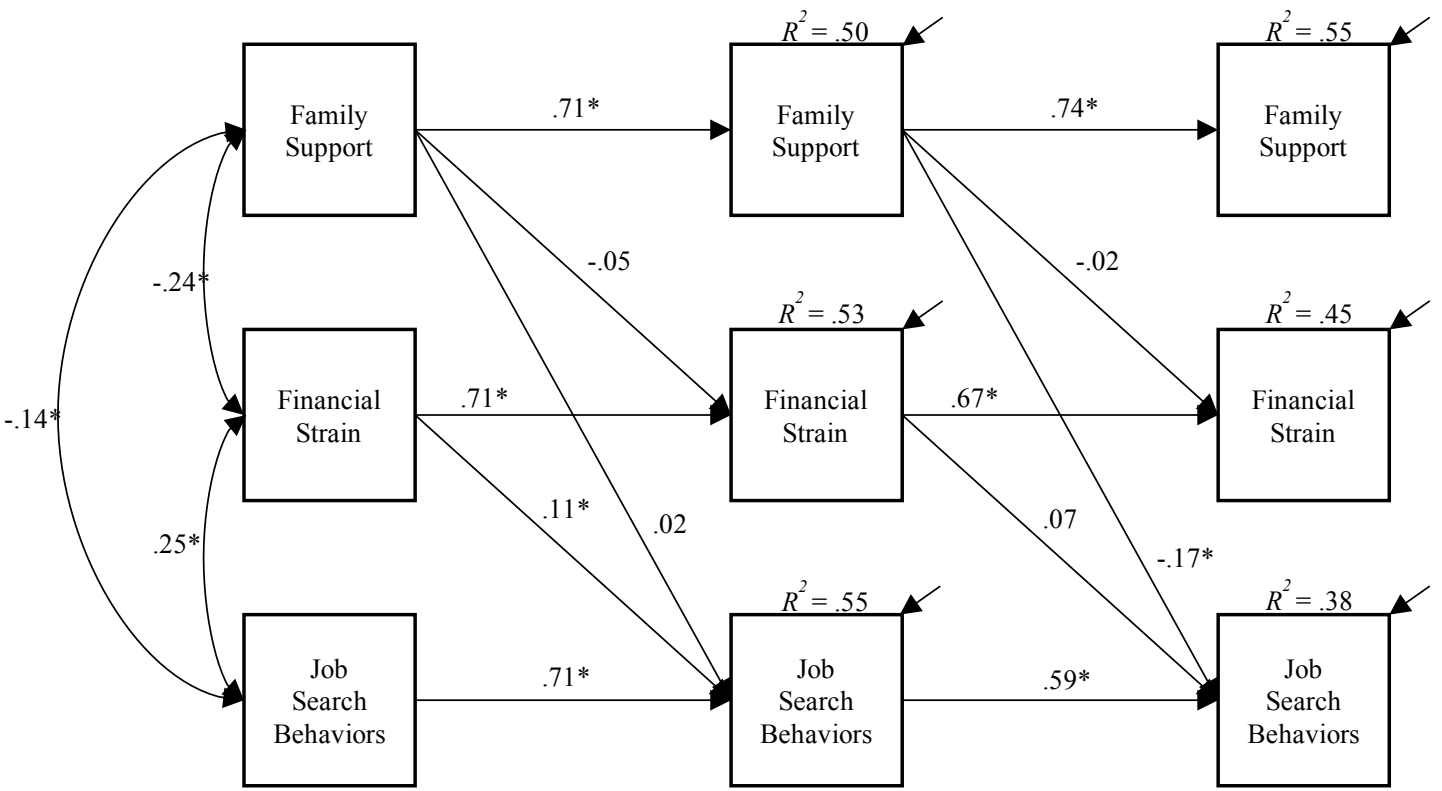

Figure 21. Standardized results for structural equation model 17. $N=509 . *=p<$ .05 . Standardized total indirect effect $=-.11, p<.05$. Standardized specific indirect effect of time 1 support from family on time 3 job search behaviors through time 2 financial strain $=-.00, n s$. Model includes intervention condition as a control variable. 
Time 1

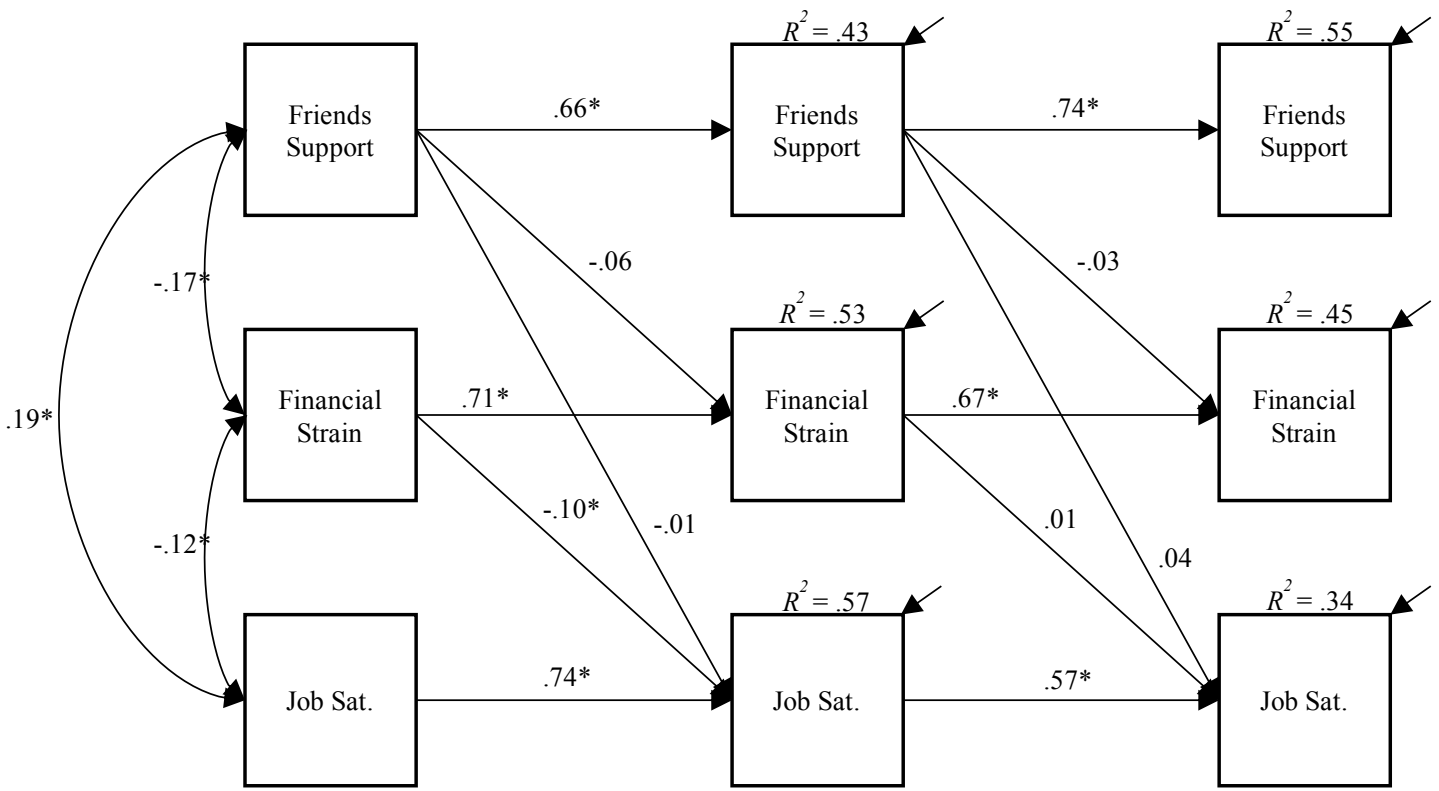

Figure 22. Standardized results for structural equation model 18. $N=509 . *=p<$ .05 . Standardized total indirect effect $=.02, n s$. Standardized specific indirect effect of time 1 support on time 3 job satisfaction through time 2 financial strain $=.03, n s$. Model includes intervention condition as a control variable. 
Time 1

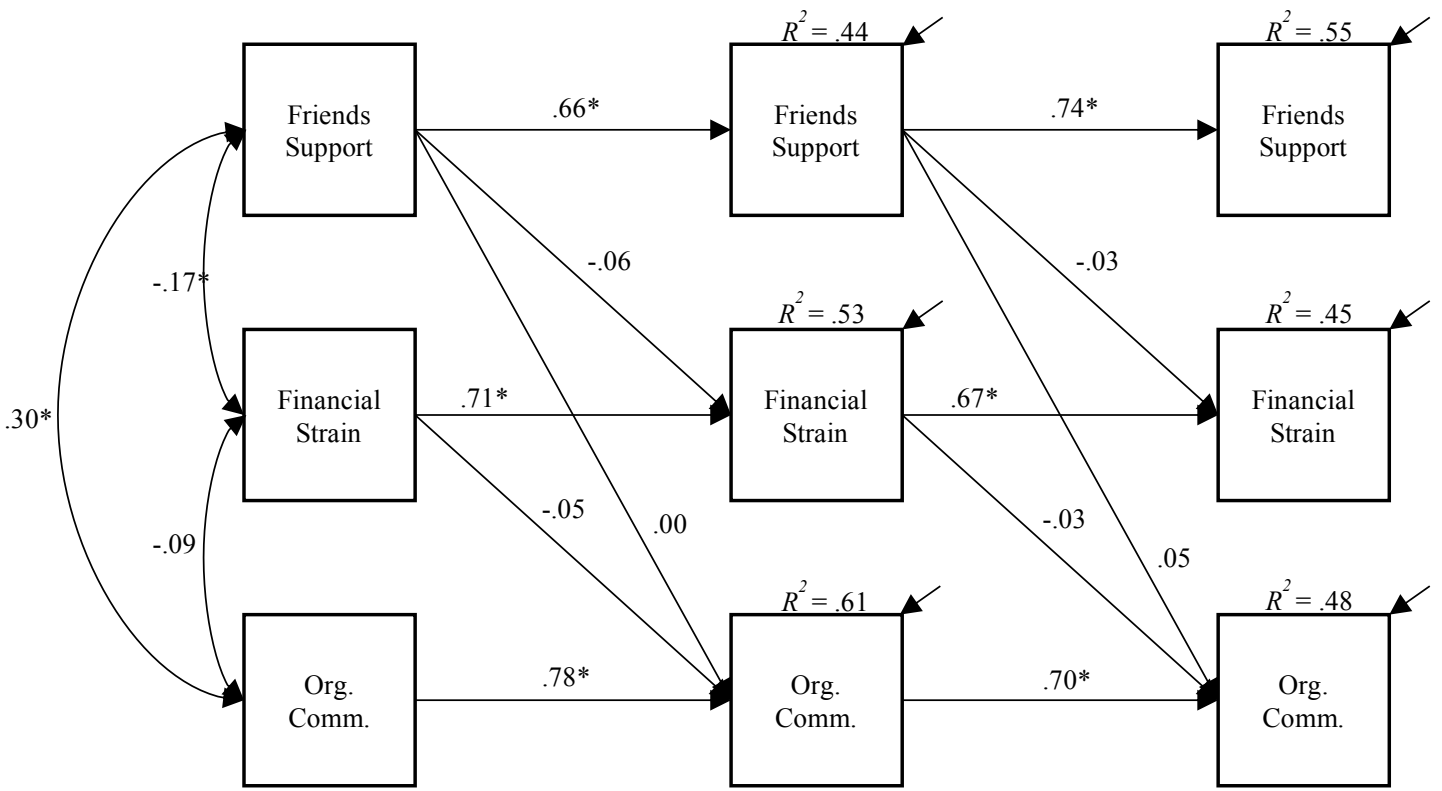

Figure 23. Standardized results for structural equation model 19. $N=509 .{ }^{*}=p<$ .05 . Standardized total indirect effect $=.04, n s$. Standardized specific indirect effect of time 1 support from friends on time 3 organizational commitment through time 2 financial strain $=.00, n s$. Model includes intervention condition as a control variable. 


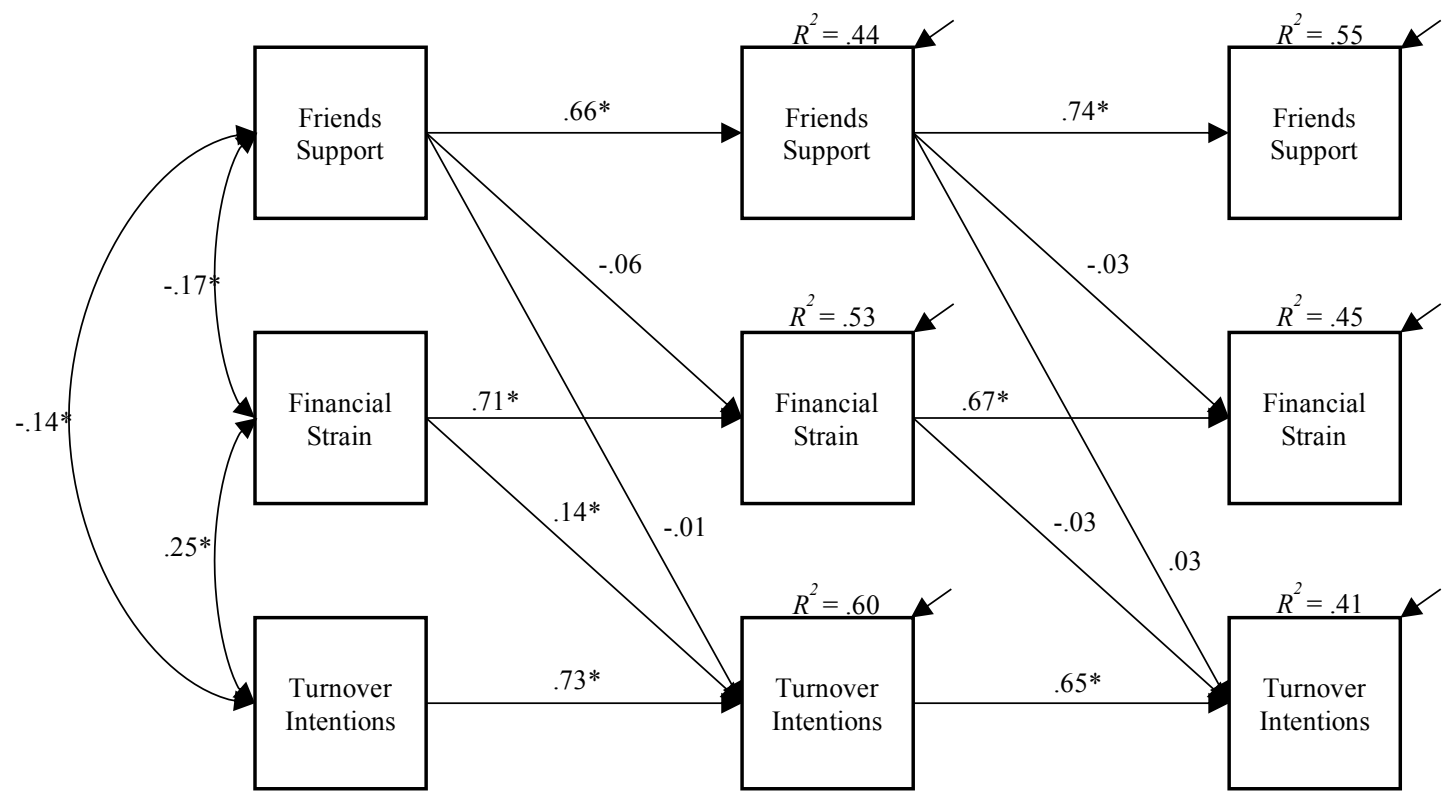

Figure 24. Standardized results for structural equation model 20. $N=509 . *=p<$ .05 . Standardized total indirect effect $=.02, n s$. Standardized specific indirect effect of time 1 support from friends on time 3 turnover intentions through time 2 financial strain $=.00, n s$. Model includes intervention condition as a control variable. 
Time 1

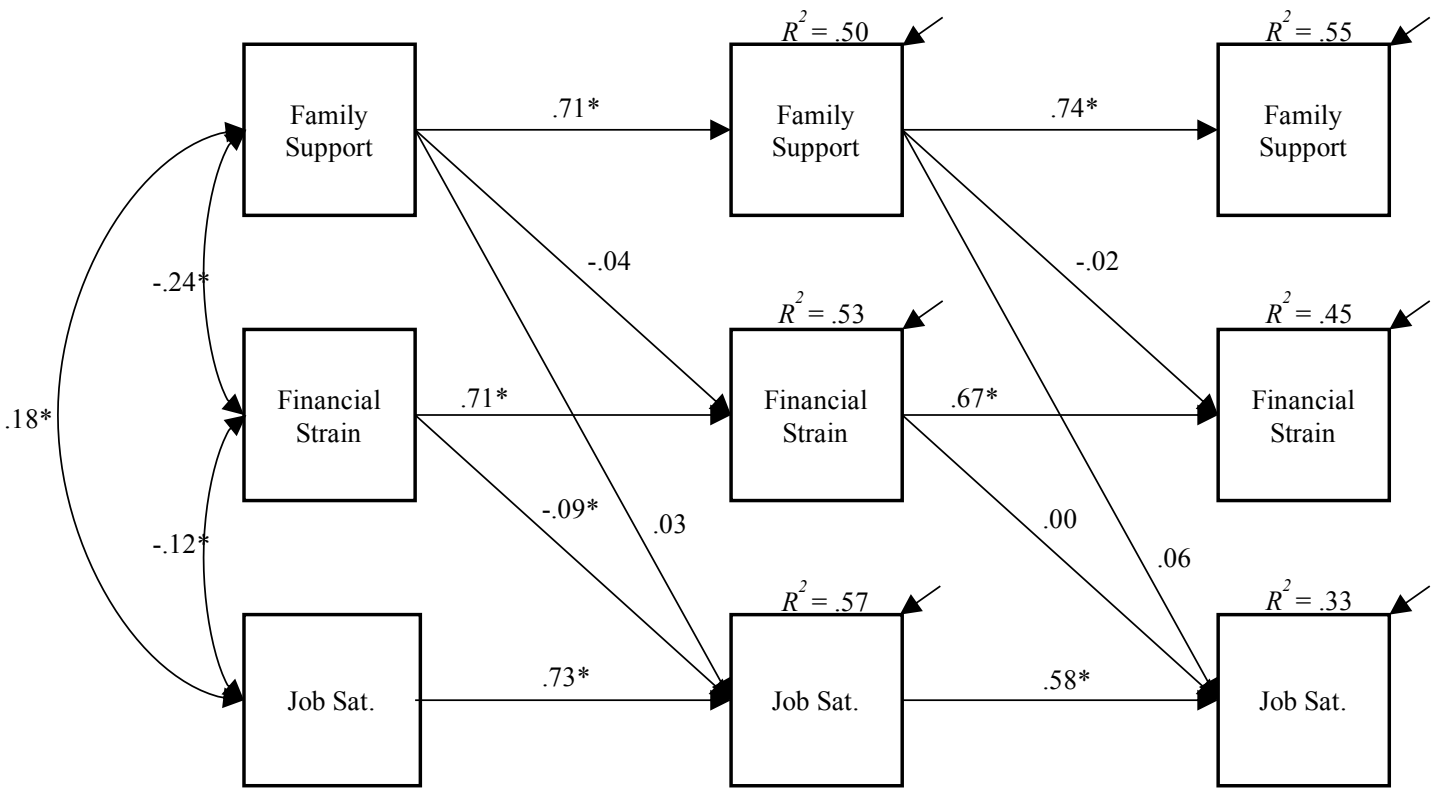

Figure 25. Standardized results for structural equation model 21. $N=509{ }^{*}=p<$ .05 . Standardized total indirect effect $=.06, n s$. Standardized specific indirect effect of time 1 support from family on time 3 job satisfaction through time 2 financial strain $=.00, n s$. Model includes intervention condition as a control variable. 
Time 1

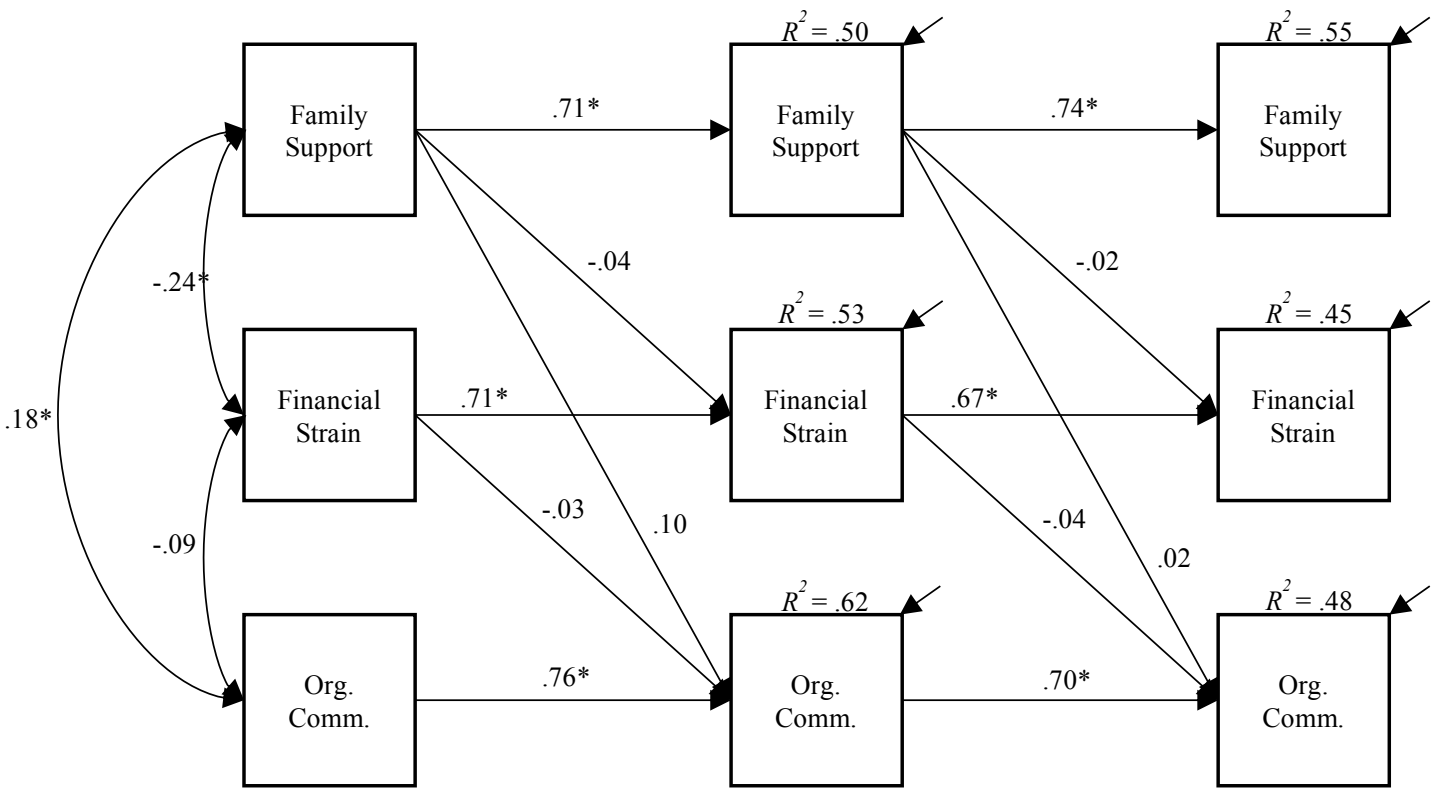

Figure 26. Standardized results for structural equation model 22. $N=509{ }^{*}=p<$ .05 . Standardized total indirect effect $=.09, n s$. Standardized specific indirect effect of time 1 support from family on time 3 organizational commitment through time 2 financial strain $=.00, n s$. Model includes intervention condition as a control variable. 
Time 1

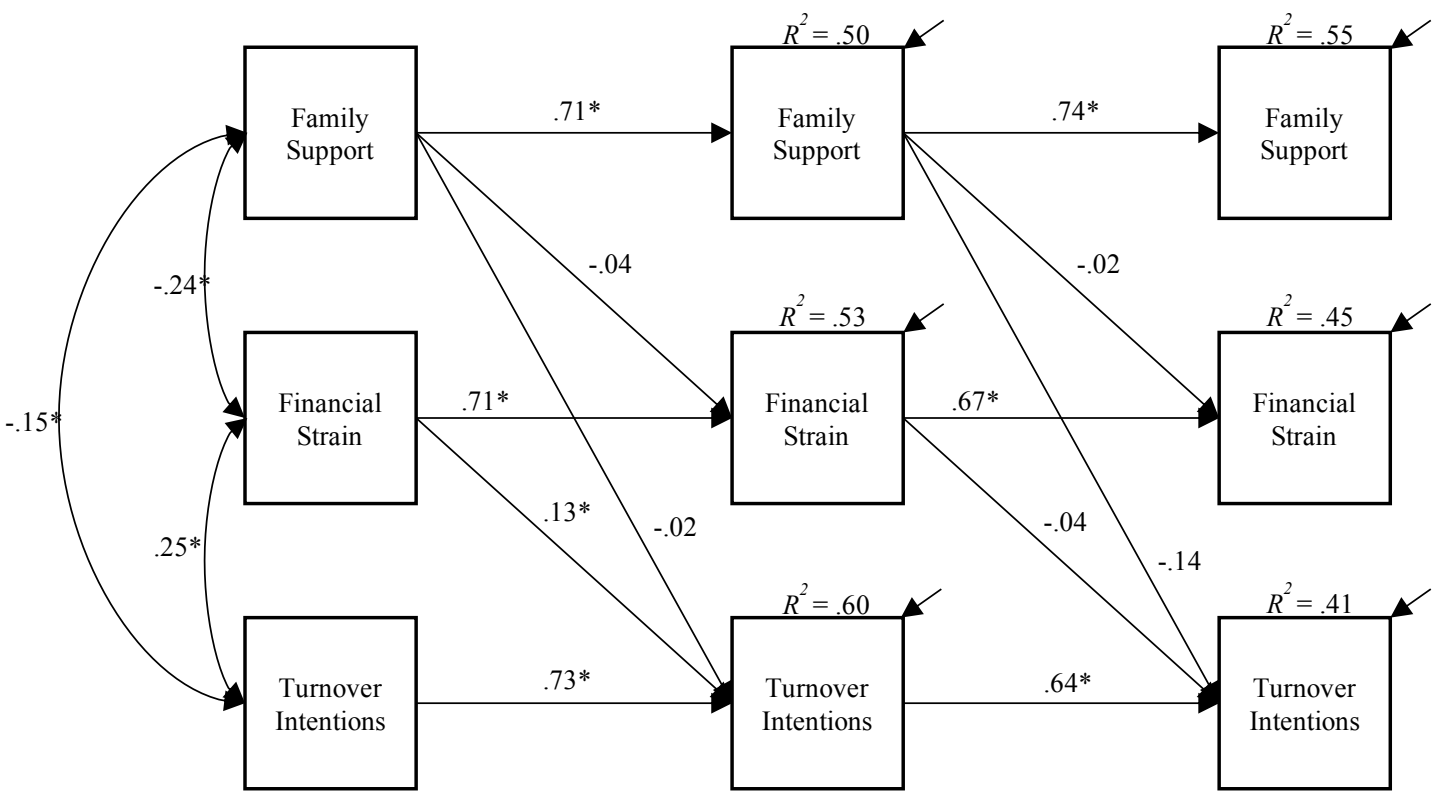

Figure 27. Standardized results for structural equation model 23. $N=509{ }^{*}=p<$ .05 . Standardized total indirect effect $=-.11, n s$. Standardized specific indirect effect of time 1 support from family on time 3 turnover intentions through time 2 financial strain $=.00, n s$. Model includes intervention condition as a control variable. 
Time 1

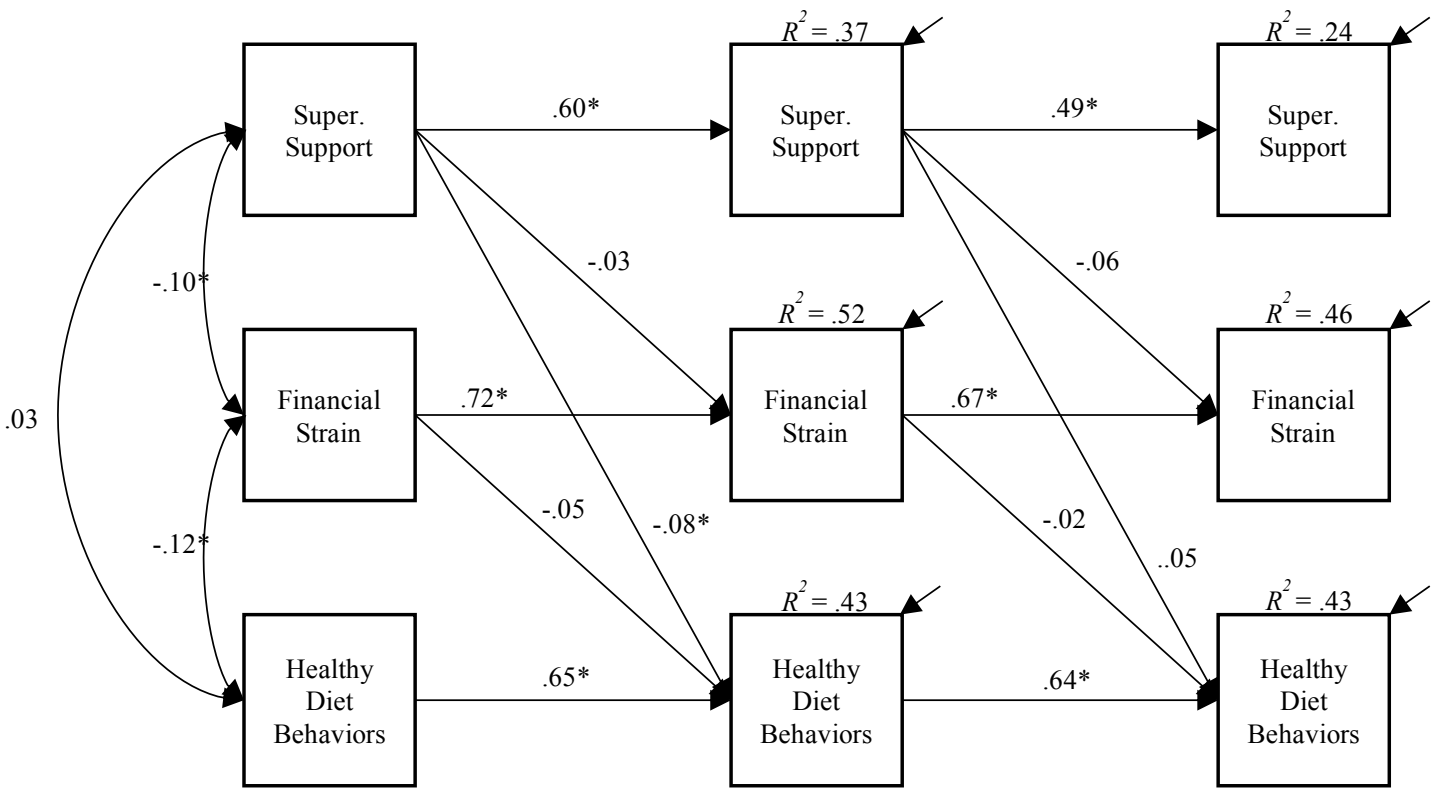

Figure 28. Standardized results for structural equation model 24. $N=509{ }^{*}=p<$ .05 . Standardized total indirect effect $=-.02$, $n s$. Standardized specific indirect effect of time 1 supervisor support on time 3 healthy diet behaviors through time 2 financial strain $=.00, n s$. Model includes intervention condition as a control variable. 
Time 1

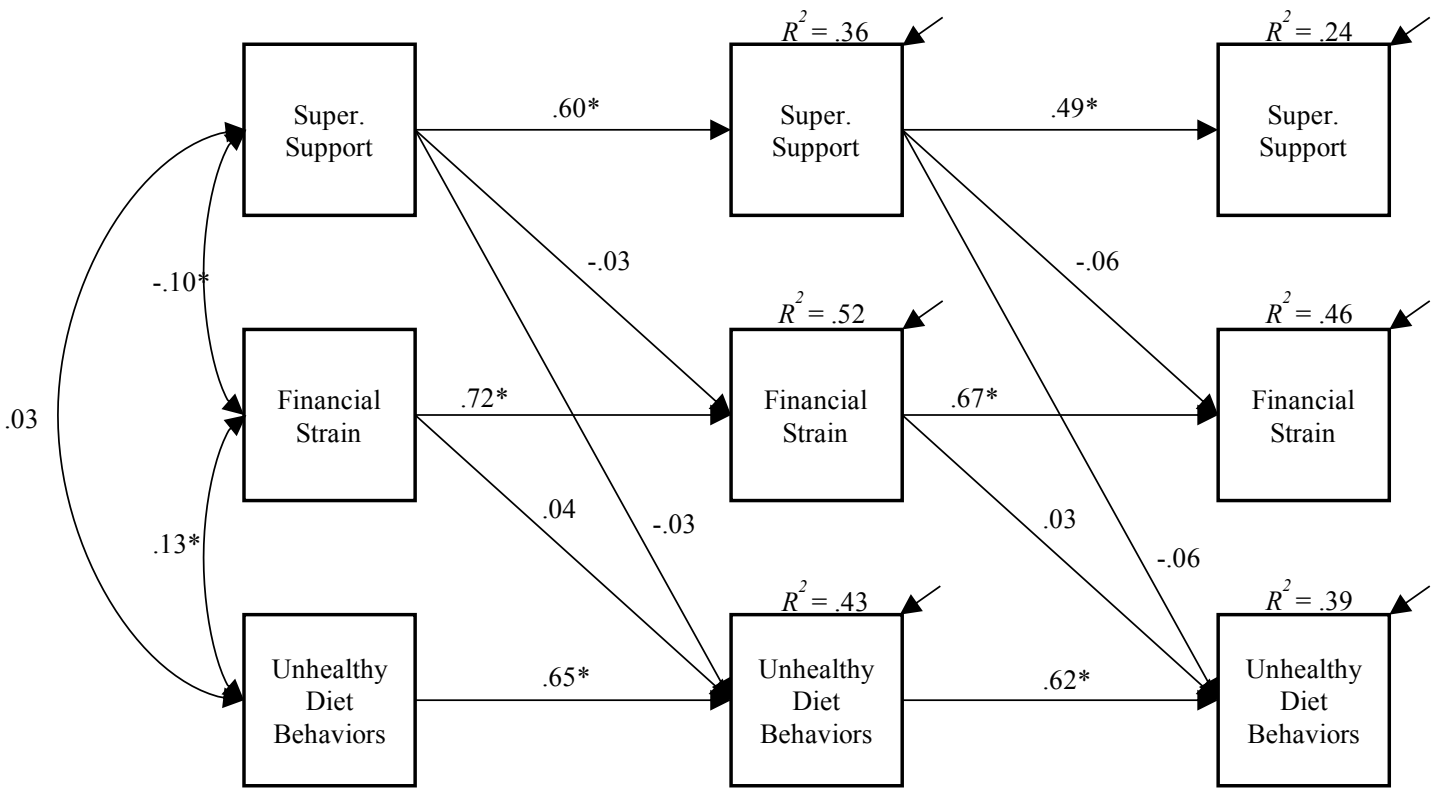

Figure 29. Standardized results for structural equation model 25. $N=509{ }^{*}=p<$ .05 . Standardized total indirect effect $=-.05, n s$. Standardized specific indirect effect of time 1 supervisor support on time 3 unhealthy diet behaviors through time 2 financial strain $=-.00, n s$. Model includes intervention condition as a control variable. 
Time 1

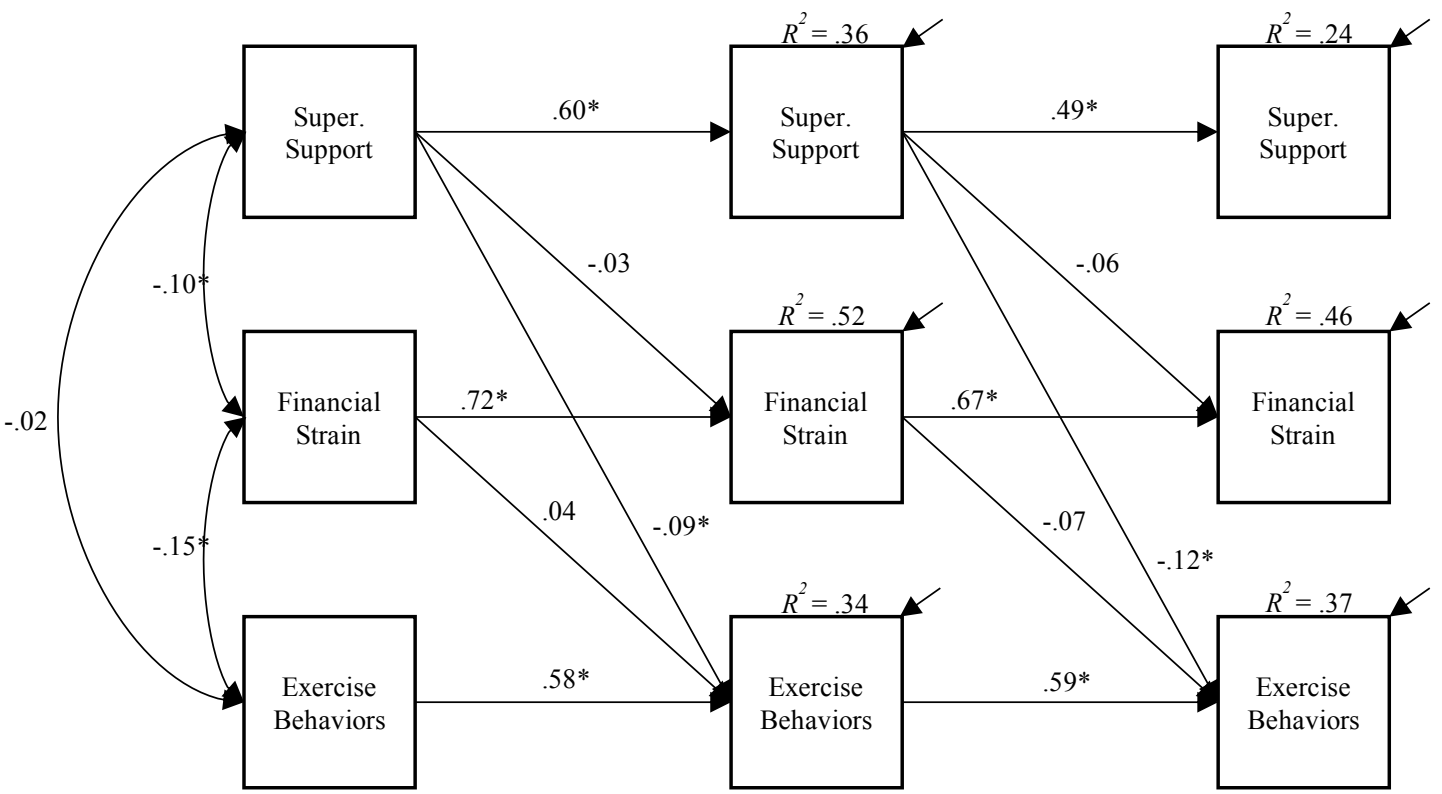

Figure 30. Standardized results for structural equation model 26. $N=509 . *=p<$ .05 . Standardized total indirect effect $=-.13, p<.01$. Standardized specific indirect effect of time 1 supervisor support on time 3 exercise behaviors through time 2 financial strain $=.00, n s$. Model includes intervention condition as a control variable. 
Time 1

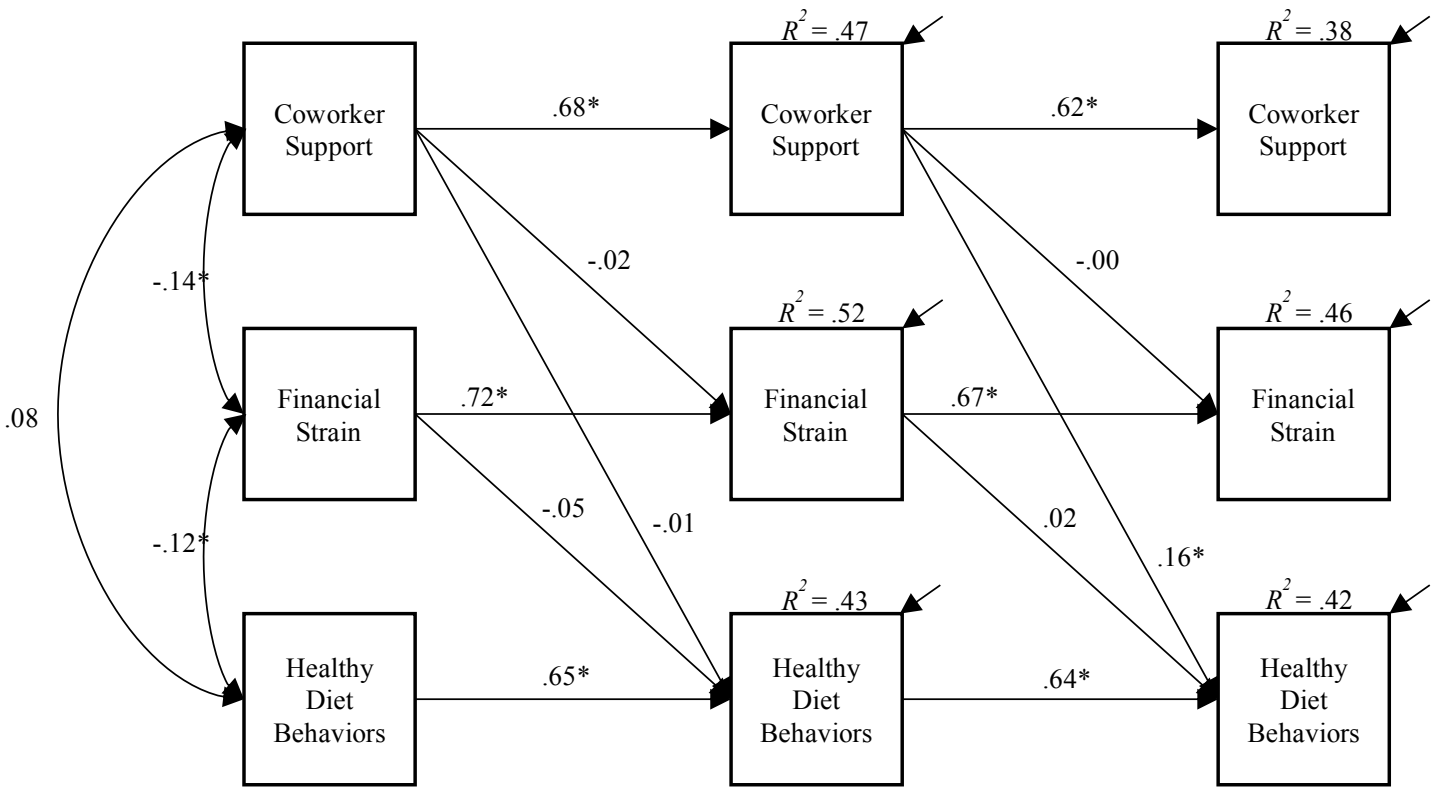

Figure 31. Standardized results for structural equation model 27. $N=509 . *=p<$ .05 . Standardized total indirect effect $=.10, p<.05$. Standardized specific indirect effect of time 1 coworker support on time 3 healthy diet behaviors through time 2 financial strain $=.00, n s$. Model includes intervention condition as a control variable. 
Time 1

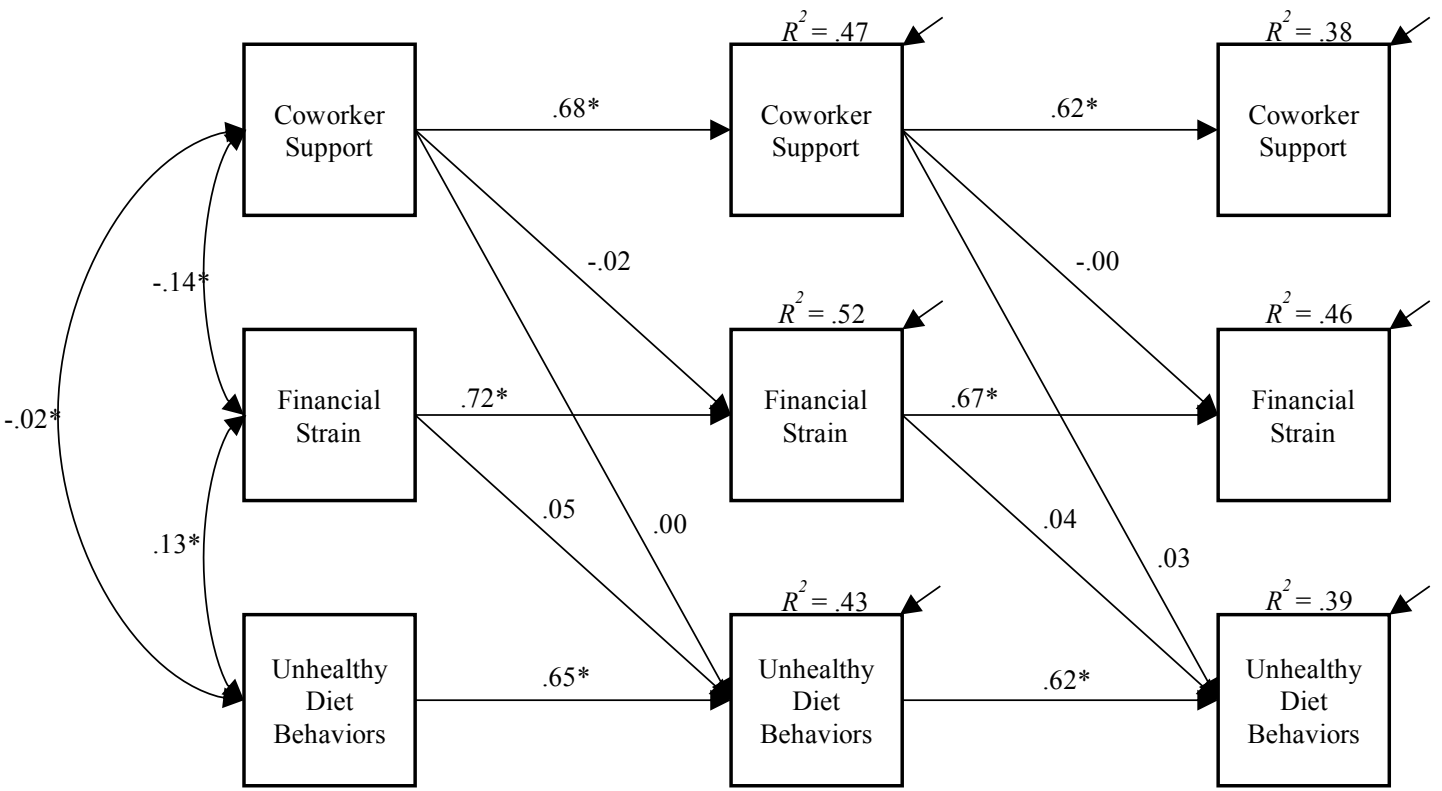

Figure 32. Standardized results for structural equation model 28. $N=509{ }^{*}=p<$ .05 . Standardized total indirect effect $=.02, n s$. Standardized specific indirect effect of time 1 coworker support on time 3 unhealthy diet behaviors through time 2 financial strain $=-.00, n s$. Model includes intervention condition as a control variable. 
Time 1

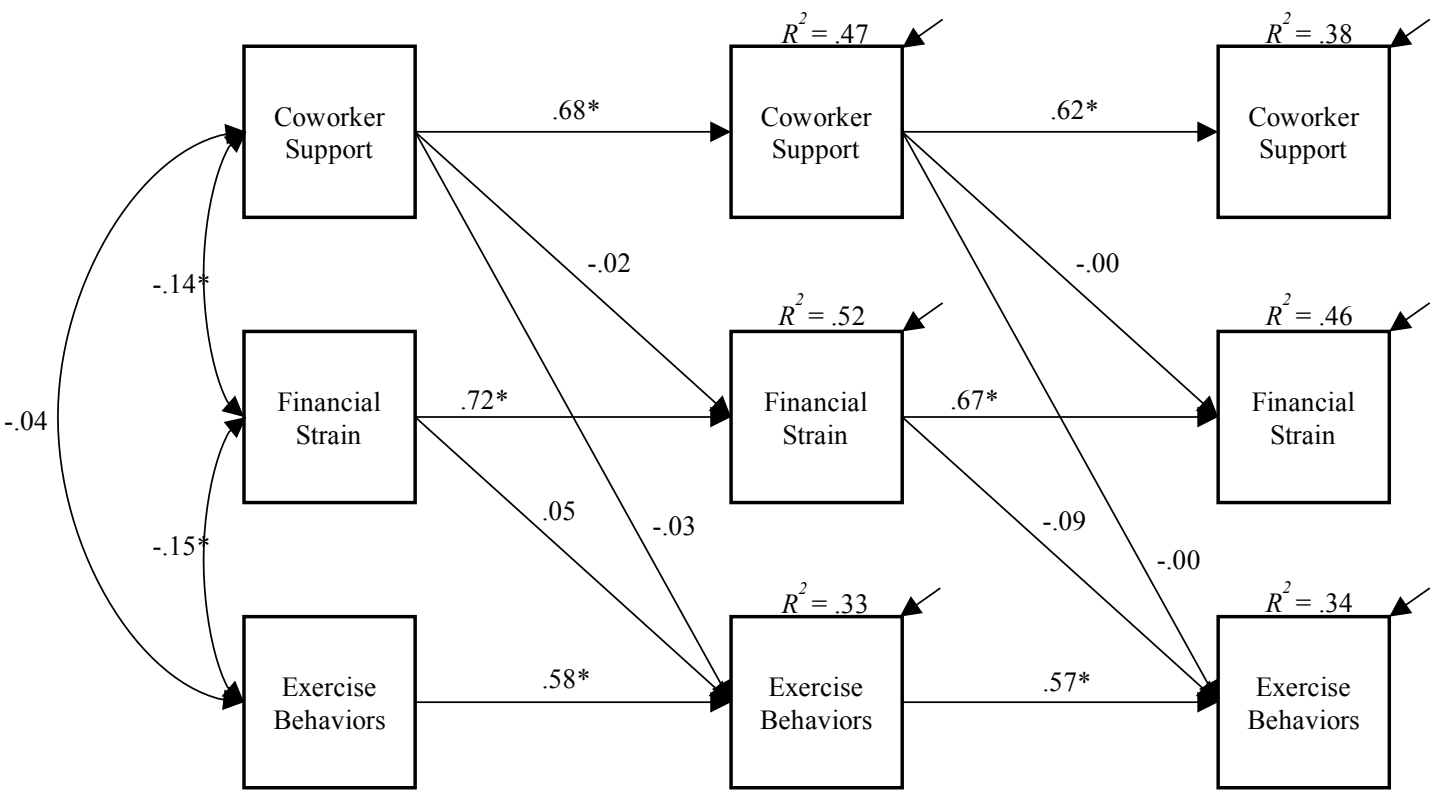

Figure 33. Standardized results for structural equation model 29. $N=509 . *=p<$ .05 . Standardized total indirect effect $=-.01, n s$. Standardized specific indirect effect of time 1 coworker support on time 3 exercise behaviors through time 2 financial strain $=.00, n s$. Model includes intervention condition as a control variable. 
Time 1

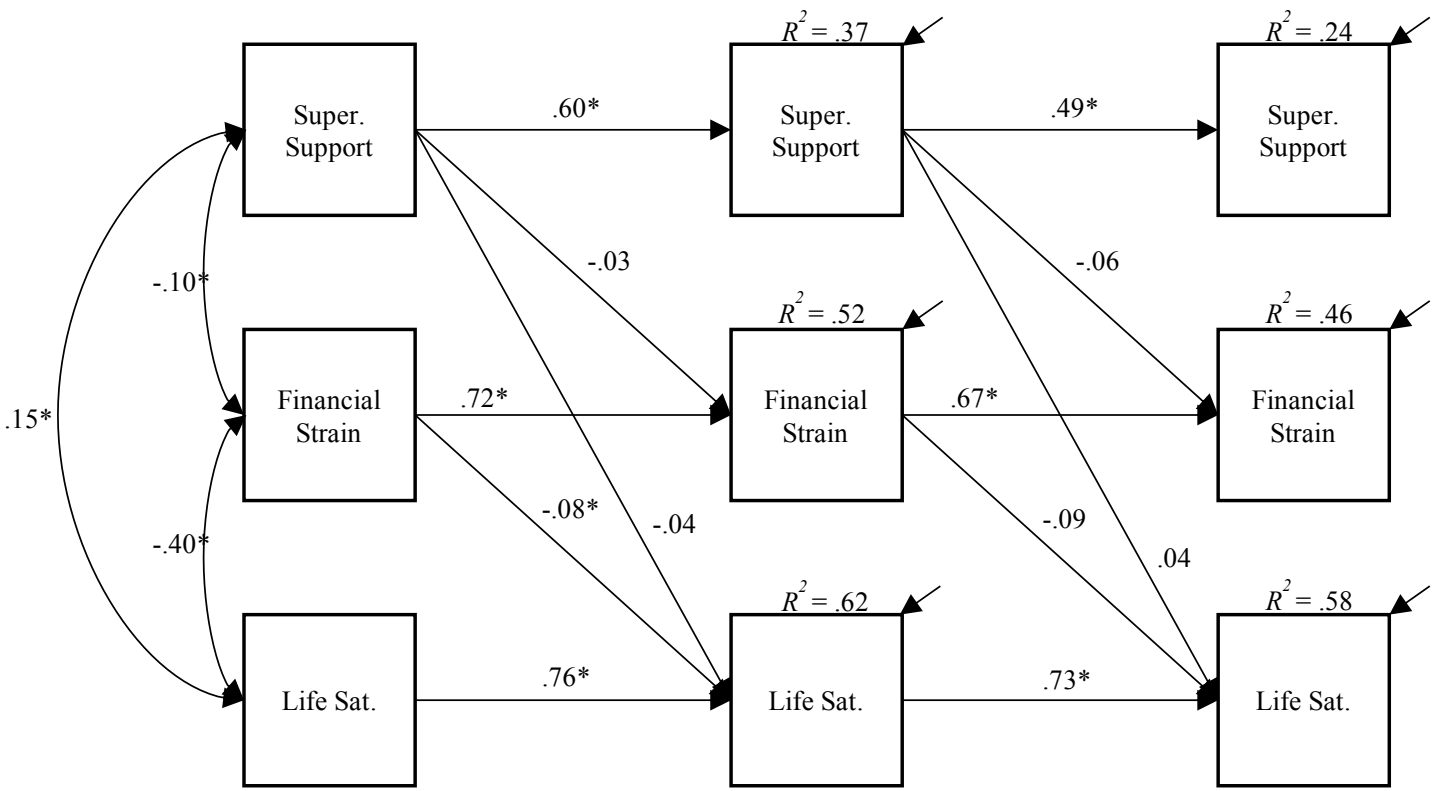

Figure 34. Standardized results for structural equation model 30. $N=509 . *=p<$ .05 . Standardized total indirect effect $=-.00, n s$. Standardized specific indirect effect of time 1 supervisor support on time 3 life satisfaction through time 2 financial strain $=.00, n s$. Model includes intervention condition as a control variable. 
Time 1

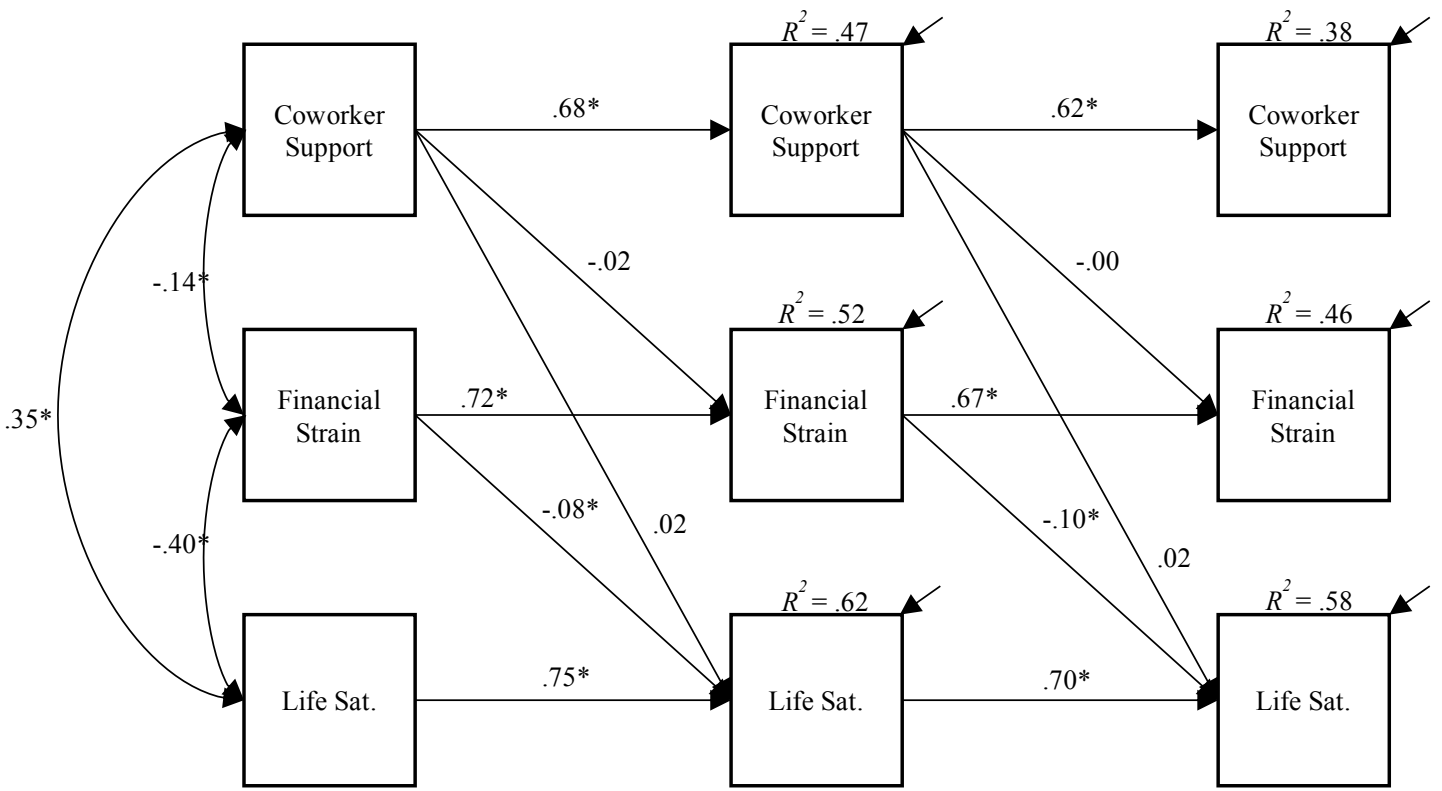

Figure 35. Standardized results for structural equation model 31. $N=509 .{ }^{*}=p<$ .05 . Standardized total indirect effect $=.04, n s$. Standardized specific indirect effect of time 1 coworker support on time 3 life satisfaction through time 2 financial strain $=.00, n s$. Model includes intervention condition as a control variable. 


\section{References}

Adler, D. A., Possemato, K., Mavandadi, S., Lerner, D., Chang, H., Klaus, J., ... \& Oslin, D. W. (2011). Psychiatric status and work performance of veterans of Operations Enduring Freedom and Iraqi Freedom. Psychiatric Services, 62, 39-46.

Allen, T. D., French, K. A., Dumani, S., \& Shockley, K. M. (2015). Meta-analysis of work-family conflict mean differences: Does national context matter?. Journal of Vocational Behavior, 90, 90-100.

Allen, T. D., Herst, D. E. L., Bruck, C. S., \& Sutton, M. (2000). Consequences associated with work-to-family conflict: A review and agenda for future research. Journal of Occupational Health Psychology, 5, 278-308.

Allen, T. D., Johnson, R. C., Kiburz, K. M., \& Shockley, K. M. (2013). Work-family conflict and flexible work arrangements: Deconstructing flexibility. Personnel Psychology, 66, 345-376.

American Psychological Association (2017). Stress in America: Coping with change. Stress in America Survey. Retrieved from http://www.apa.org/news/press/releases/stress/2016/coping-withchange.PDF

Amstad, F. T., Meier, L. L., Fasel, U., Elfering, A., \& Semmer, N. K. (2011). A metaanalysis of work-family conflict and various outcomes with a special emphasis on cross-domain versus matching-domain relations. Journal of Occupational Health Psychology, 16, 151-169. 
Angel, R. J., Frisco, M., Angel, J. L., \& Chiriboga, D. A. (2003). Financial strain and health among elderly Mexican-origin individuals. Journal of Health and Social Behavior, 44, 536-551.

Ashforth, B. E., Kreiner, G. E., \& Fugate, M. (2000). All in a day's work: Boundaries and micro role transitions. Academy of Management Review, 25, 472-491.

Baron, R. M., \& Kenny, D. A. (1986). The moderator-mediator variable distinction in social psychological research: Conceptual, strategic, and statistical considerations. Journal of Personality and Social Psychology, 51, 1173-1182.

Bentler, P.M., \& Wu, E.J.C. (2002). EQS for Windows user's guide. Encino, CA. Multivariate Software, Inc.

Berkman, L. F., Buxton, O., Ertel, K., \& Okechukwu, C. (2010). Managers' practices related to work-family balance predict employee cardiovascular risk and sleep duration in extended care settings. Journal of Occupational Health Psychology, 15, 316-329.

Beutell, N. J., \& Wittig-Berman, U. (1999). Predictors of work-family conflict and satisfaction with family, job, career, and life. Psychological Reports, 85, 893-903.

Blau, G. (1994). Testing a two-dimensional measure of job search behavior. Organizational Behavior and Human Decision Processes, 59, 288-312.

Bliese, P. D. (2000). Within-group agreement, non-independence, and reliability: Implications for data aggregation andanalysis. In K. J. Klein \& S. W. Kozlowski (Eds.), Multilevel theory, research, and methods in organizations (pp. 349 -381). San Francisco: Jossey-Bass. 
Bliese, P.D., \& Jex, S.M. (2002). Incorporating a mulitilevel perspective into occupational stress research: Theoretical, methodological, and practical implications. Journal of Occupational Health Psychology, 7, 265-276.

Boroff, K. E., \& Lewin, D. (1997). Loyalty, voice, and intent to exit a union firm: A conceptual and empirical analysis. ILR Review, 51, 50-63.

Boswell, W. R., \& Olson-Buchanan, J. B. (2007). The use of communication technologies after hours: The role of work attitudes and work-life conflict. Journal of Management, 33, 592-610.

Bradley, C. J., Grossman, D. C., Hubbard, R. A., Ortega, A. N., \& Curry, S. J. (2016). Integrated interventions for improving total worker health: A panel report from the National Institutes of Health Pathways to Prevention Workshop: Total Worker Health—what's work got to do with it? Integrated interventions for improving Total Worker Health. Annals of Internal Medicine, 165, 279-283.

Bronfenbrenner, U. (1977). Toward an experimental ecology of human development. American Psychologist, 32, 513-531.

Brown, T. A. (2006). Confirmatory Factor Analysis for Applied Research. New York: The Guilford Press.

Bureau of Labor Statistics (2017a). The employment situation-April 2017. Retrieved from https://www.bls.gov/news.release/pdf/empsit.pdf.

Bureau of Labor Statistics (2017b). Occupational employment and wages news release. Retrieved from https://www.bls.gov/news.release/ocwage.htm. Bureau of Labor Statistics (2017c). Employment situation of veterans summary. Retrieved from https://www.bls.gov/news.release/vet.nr0.htm 
Burke, R. J., \& Greenglass, E. R. (2001). Hospital restructuring, work-family conflict and psychological burnout among nursing staff. Psychology \& Health, 16, 583-594.

Butler, A. B. (2007). Job characteristics and college performance and attitudes: A model of work-school conflict and facilitation. Journal of Applied Psychology, 93, 500510.

Buxton, O. M., Quintiliani, L. M., Yang, M. H., Ebbeling, C. B., Stoddard, A. M., Pereira, L. K., \& Sorensen, G. (2009). Association of sleep adequacy with more healthful food choices and positive workplace experiences among motor freight workers. American Journal of Public Health, 99(S3), S636-S643.

Byron, K. (2005). A meta-analytic review of work-family conflict and its antecedents. Journal of Vocational Behavior, 67, 169-198.

Cammann, C., Fichman, M., Jenkins, G. D., Jr., \& Klesh, J. R. (1983). Assessing the attitudes and perceptions of organizational members. In S. E. Seashore, E. E. Lawler, III, P. Mirvis, \& C. Cammann (eds.), Assessing organizational change (pp. 71-138). New York: John Wiley and Sons.

Carlson, D. S., Grzywacz, J. G., \& Kacmar, K. M. (2010). The relationship of schedule flexibility and outcomes via the work-family interface. Journal of Managerial Psychology, 25, 330-355.

Carr, S. C., Parker, J., Arrowsmith, J., Watters, P., \& Jones, H. (2016). Can a 'living wage' springboard human capability? An exploratory study from New Zealand. Labour \& Industry, 26, 24-39. 
Catalano, R., Dooley, D., Wilson, G., \& Hough, R. (1993). Job loss and alcohol abuse: a test using data from the Epidemiologic Catchment Area project. Journal of Health and Social Behavior, 34, 215-225.

Chandra, A., Martin, L. T., Hawkins, S. A., \& Richardson, A. (2010). The impact of parental deployment on child social and emotional functioning: Perspectives of school staff. Journal of Adolescent Health, 46, 218-223.

Clark, S. C. (2000). Work/family border theory: A new theory of work/family balance. Human Relations, 53, 747-770.

Cohen, S. (1988). Psychosocial models of the role of social support in the etiology of physical disease. Health Psychology, 7, 269-297.

Cohen, S. G., \& Bailey, D. E. (1997). What makes teams work: Group effectiveness research from the shop floor to the executive suite. Journal of Management, 23, 239-290.

Cole, D. A., \& Maxwell, S. E. (2003). Testing mediation models with longitudinal data: Questions and tips in the use of structural equation modeling. Journal of Abnormal Psychology, 112, 558-577.

Conger, R. D., Ge, X., Elder, G. H., Lorenz, F. O., \& Simons, R. L. (1994). Economic stress, coercive family process, and developmental problems of adolescents. Child Development, 65, 541-561.

Crain, T. L., \& Hammer, L. B. (2013). Work-family enrichment: A systematic review of antecedents, outcomes, and mechanisms. In A. B. Bakker (Ed.), Advances in positive organizational psychology (Vol. 1, pp. 303-328). Bingley, England: Emerald. 
Creed, P. A., Muller, J., \& Machin, M. A. (2001). The role of satisfaction with occupational status, neuroticism, financial strain and categories of experience in predicting mental health in the unemployed. Personality and Individual Differences, 30, 435-447.

Cullen, J. C., \& Hammer, L. B. (2007). Developing and testing a theoretical model linking work-family conflict to employee safety. Journal of Occupational Health Psychology, 12, 266-278.

DeCarlo, L. T. (1997). On the meaning and use of kurtosis. Psychological Methods, 2 , 292-307.

Demerouti, E., Bakker, A. B., Nachreiner, F., \& Schaufeli, W. B. (2001). The job demands-resources model of burnout. Journal of Applied Psychology, 86, 499512.

Department of Defense (2011). Health-related behaviors survey of active duty military personnel. Retrieved fromhttp://www.murray.senate.gov/public/_cache/files/889efd07-2475-40eeb3b0-508947957a0f/final-2011-hrb-active-duty-survey-report.pdf

Department of Veteran Affairs (2015). National Survey of Veterans (NSV). Retrieved from http://www.va.gov/vetdata/docs/SurveysAndStudies/AppendixAQuestionnai res.pdf.

Diener, E. D., Emmons, R. A., Larsen, R. J., \& Griffin, S. (1985). The satisfaction with life scale. Journal of Personality Assessment, 49, 71-75. 
Dolan, P., Peasgood, T., \& White, M. (2008). Do we really know what makes us happy? A review of the economic literature on the factors associated with subjective wellbeing. Journal of Economic Psychology, 29, 94-122.

Doran, L. I., Stone, V. K., Brief, A. P., \& George, J. M. (1991). Behavioral intentions as predictors of job attitudes: The role of economic choice. Journal of Applied Psychology, 76, 40-45.

Dooley, D., Prause, J., \& Ham-Rowbottom, K. A. (2000). Underemployment and depression: longitudinal relationships. Journal of Health and Social Behavior, 41, 421-436.

Eber, S., Barth, S., Kang, H., Mahan, C., Dursa, E., \& Schneiderman, A. (2013). The National Health Study for a New Generation of United States Veterans: Methods for a large-scale study on the health of recent veterans. Military Medicine, 178, 966-969.

Edwards, J. R., \& Rothbard, N. P. (2000). Mechanisms linking work and family: Clarifying the relationship between work and family constructs. Academy of Management Review, 25, 178-199.

Elbogen, E. B., Johnson, S. C., Wagner, H. R., Newton, V. M., \& Beckham, J. C. (2012). Financial well-being and post-deployment adjustment among Iraq and Afghanistan war veterans. Military Medicine, 177, 669-675.

Elbogen, E. B., Sullivan, C. P., Wolfe, J., Wagner, H. R., \& Beckham, J. C. (2013). Homelessness and money mismanagement in Iraq and Afghanistan veterans. American Journal of Public Health, 103(S2), S248-S254. 
Faber, A. J., Willerton, E., Clymer, S. R., MacDermid, S. M., \& Weiss, H. M. (2008). Ambiguous absence, ambiguous presence: a qualitative study of military reserve families in wartime. Journal of Family Psychology, 22, 222-230.

Ford, M. T., Heinen, B. A., \& Langkamer, K. L. (2007). Work and family satisfaction and conflict: A meta-analysis of cross-domain relations. Journal of Applied Psychology, 92, 57-80.

Frone, M. R., Russell, M., \& Cooper, M. L. (1992). Antecedents and outcomes of workfamily conflict: Testing a model of the work-family interface. Journal of Applied Psychology, 77, 65-78.

George, J. M., \& Brief, A. P. (1990). The economic instrumentality of work: An examination of the moderating effects of financial requirements and sex on the pay-life satisfaction relationship. Journal of Vocational Behavior, 37 357-368.

Graham, J. W., \& Hofer, S. M. (2000). Multiple imputation in multivariate research. In T. D. Little, K. U. Schnabel, \& J. Baumert (Eds.), Modeling longitudinal and multiple-group data: Practical issues, applied approaches, and specific examples (pp. 201-218). Hillsdale, NJ: Erlbaum.

Greenhaus, J. H., \& Beutell, N. J. (1985). Sources of conflict between work and family roles. Academy of Management Review, 10, 76-88.

Grzywacz, J. G., \& Marks, N. F. (2000). Reconceptualizing the work-family interface: An ecological perspective on the correlates of positive and negative spillover between work and family. Journal of Occupational Health Psychology, 5, 111126. 
Halbesleben, J. R., Neveu, J. P., Paustian-Underdahl, S. C., \& Westman, M. (2014). Getting to the "COR": Understanding the role of resources in conservation of resources theory. Journal of Management, 40, 1334-1364.

Hall, D. T., \& Richter, J. (1988). Balancing work life and home life: What can organizations do to help?. The Academy of Management Executive, 2, 213-223.

Hammer, L. B., Cullen, J. C., Neal, M. B., Sinclair, R. R., \& Shafiro, M. V. (2005). The longitudinal effects of work-family conflict and positive spillover on depressive symptoms among dual-earner couples. Journal of Occupational Health Psychology, 10, 138-154.

Hammer, L. B., Cullen, J. C., \& Shafiro, M. (2006). Work-family best practices. In F. Jones, R. Burke, \& M. Westman (Eds.) Work-life balance: A psychological perspective (pp. 261-275). East Sussex, England: Psychology Press.

Hammer, L. B., Demsky, C., Kossek, E. E., \& Bray, J. (2016). Work-family intervention research. In T. D. Allen \& L. T. Eby (Eds.), Handbook of work and family. Oxford, England: Oxford University Press.

Hammer, L. B., Johnson, R. C., Crain, T. L., Bodner, T., Kossek, E. E., Davis, K. D., ... \& Berkman, L. (2016). Intervention effects on safety compliance and citizenship behaviors: Evidence from the Work, Family, and Health Study. Journal of Applied Psychology, 101, 190-208.

Hammer, L. B., Kossek, E. E., Yragui, N. L., Bodner, T. E., \& Hanson, G. C. (2009). Development and validation of a multidimensional measure of family supportive supervisor behaviors (FSSB). Journal of Management, 35, 837-856. 
Hammer, L. B., Van Dyck, S., \& Ellis, A. (2013). Organizational policies supportive of work-life integration. In D. A. Major \& R. Burke (Eds.), Handbook of work-life integration among professionals: Challenges and opportunities (pp. 288-309). Northampton, MA: Edward Elgar.

Hammer, L. B., \& Zimmerman, K. L. (2011). Quality of work life. In S. Zedeck (Ed.), American Psychological Association handbook of industrial and organizational psychology (pp. 399-431). Washington, DC: American Psychological Association.

Healthways (2015). Gallup-Healthways Well-Being 5: Actionable data for improved well-being. Retrieved from http://info.healthways.com/hs-fs/hub/162029/file743424751-pdf/Fact_Sheet/Well-Being_Five_Fact_Sheet.pdf?t=1503698120941

Hellerstedt, W. L., \& Jeffery, R. W. (1997). The association of job strain and health behaviours in men and women. International Journal of Epidemiology, 26, 575583.

Heymann, J. \& McNeill, K. (2012). Families at work: What we know about conditions globally. Policy brief prepared for the United Nations Department of Economic and Social Affairs, Division for Social Policy and Development, United Nations Expert Group Meeting Session: "Good Practices in Family Policy Making.”

Hobfoll, S. E. (1988). The ecology of stress. Washington, DC: Hemisphere.

Hobfoll, S.E. (1989). Conservation of resources: A new attempt at conceptualizing stress. American Psychologist, 44, 513-524.

Hobfoll, S. E. (2002). Social and psychological resources and adaptation. Review of General Psychology, 6, 307-324. 
Hu, L., \& Bentler, P. M. (1999). Cutoff criteria for fit indexes in covariance structure analysis: Conventional criteria versus new alternatives. Structural Equation Modeling, 6, 1-55.

Innstrand, S. T., Langballe E. M., Espnes, G.A., Falkum E., Aasland, O.G. (2008). Positive and negative work-family interaction and burnout: a longitudinal study of reciprocal relations. Work Stress, 22, 1-15.

Kahn, J. R., \& Pearlin, L. I. (2006). Financial strain over the life course and health among older adults. Journal of Health and Social Behavior, 47, 17-31.

Kahn, R.L., Wolfe, D.M., Quinn, R.P., \& Snoek, J. D. (1964). Organizational stress: Studies in role conflict and ambiguity. New York: Wiley.

Kanfer, R., Wanberg, C. R., \& Kantrowitz, T. M. (2001). Job search and employment: A personality-motivational analysis and meta-analytic review. Journal of Applied Psychology, 86, 837-855.

Katz, D. \& Kahn, R. L. (1978). The social psychology of organizations (2nd ed.). New York, NY: Wiley.

Kenny, D. A. (1979). Correlation and Causality. New York: Wiley.

Kleykamp, M. (2013). Unemployment, earnings and enrollment among post-9/11 veterans. Social Science Research, 42, 836-851.

Kline, R. B. (2011). Principles and practice of structural equation modeling, 3rd ed. New York: The Guilford Press.

Koeske, G. F., \& Koeske, R. D. (1993). A preliminary test of a stress-strain-outcome model for reconceptualizing the burnout phenomenon. Journal of Social Service Research, 17, 107-135. 
Kopelman, R. E., Rovenpor, J. L., \& Millsap, R. E. (1992). Rationale and construct validity evidence for the Job Search Behavior Index: Because intentions (and New Year's resolutions) often come to naught. Journal of Vocational Behavior, 40, 269-287.

Kossek, E. E., \& Lautsch, B. A. (2012). Work-family boundary management styles in organizations: A cross-level model. Organizational Psychology Review, 2, 152171.

Kossek, E. E., \& Ozeki, C. (1998). Work-family conflict, policies, and the job-life satisfaction relationship: A review and directions for organizational behaviorhuman resources research. Journal of Applied Psychology, 83, 139-149.

Kossek, E. E., Pichler, S., Bodner, T., \& Hammer, L. B. (2011). Workplace social support and work-family conflict: A meta-analysis clarifying the influence of general and work-family-specific supervisor and organizational support. Personnel Psychology, 64, 289-313.

Krause, N. (1991). Stress and isolation from close ties in later life. Journal of Gerontology, 46, S183-S194.

Kreiner, G. E. (2006). Consequences of work-home segmentation or integration: A person-environment fit perspective. Journal of Organizational Behavior, 27, 485507.

Kreiner, G. E., Hollensbe, E. C., \& Sheep, M. L. (2009). Balancing borders and bridges: Negotiating the work-home interface via boundary work tactics. Academy of management journal, 52, 704-730. 
Kwan, H. K., \& Mao, Y. (2011). The role of citizenship behavior in personal learning and work-family enrichment. Frontiers of Business Research in China, 5, 96-120.

Lazarus, R. S., \& Folkman, S. (1984). Stress, appraisal, and coping. New York: Springer.

Lynch, J., \& Kaplan, G. (2000). Socioeconomic position. In L. F. Berkman \& I. Kawachi (Eds.), Social epidemiology (pp. 13-35). New York: Oxford University Press.

MacDermid Wadsworth, S., \& Southwell, K. (2011). Military families: Extreme work and extreme "work-family". The Annals of the American Academy of Political and Social Science, 638, 163-183.

MacKinnon, D. P. (2008). Introduction to statistical mediation analysis. New York: Lawrence Erlbaum Associates.

Mandel, B. R., \& Seydl, J. (2016). Credit conditions and economic growth: Recent evidence from US banks. Economics Letters, 147, 63-67.

Martin, M., Grüendahl, M., Martin, P. (2001). Age differences in stress, social resources, and well-being in middle and older age. Journal of Gerontology: Psychological Sciences, 56B, 214-222.

Matthews, R. A., Wayne, J. H., \& McKersie, S. J. (2016). Theoretical approaches to the study of work and family: Avoiding stagnation via effective theory borrowing. In T. D. Allen \& L. T. Eby (Eds.), Handbook of work and family. Oxford, England: Oxford University Press.

Mattsson, M., Topor, A., Cullberg, J., \& Forsell, Y. (2008). Association between financial strain, social network and five-year recovery from first episode psychosis. Social Psychiatry and Psychiatric Epidemiology, 43, 947-952. 
McNall, L. A., Nicklin, J. M., \& Masuda, A. D. (2010). A meta-analytic review of the consequences associated with work-family enrichment. Journal of Business and Psychology, 25, 381-396.

Meyer, J. P., Allen, N. J., \& Smith, C. A. (1993). Commitment to organizations and occupations: Extension and test of a three-component conceptualization. Journal of Applied Psychology, 78, 538-551.

Michel, J. S., Clark, M. A., \& Jaramillo, D. (2011a). The role of the Five Factor Model of personality in the perceptions of negative and positive forms of work-nonwork spillover: A meta-analytic review. Journal of Vocational Behavior, 79, 191-203.

Michel, J. S., Kotrba, L. M., Mitchelson, J. K., Clark, M. A., \& Baltes, B. B. (2011b). Antecedents of work-family conflict: A meta-analytic review. Journal of Organizational Behavior, 32, 689-725.

Mirowsky, J., \& Ross, C. E. (1999). Economic hardship across the life course. American Sociological Review, 64, 548-569.

Mirowsky, J., \& Ross, C. E. (2003). Social causes of psychological distress. Hawthorne, NY: Aldine de Gruyter.

Morra, D. J., Regehr, G., \& Ginsburg, S. (2008). Anticipated debt and financial stress in medical students. Medical Teacher, 30, 313-315.

Mowday, R. T., Steers, R. M., \& Porter, L. W. (1979). The measurement of organizational commitment. Journal of Vocational Behavior, 14, 224-247.

Muthén, L. K. and Muthén, B. O. (2012). Mplus User's Guide, Seventh Edition. Los Angeles, CA: Muthén \& Muthén. 
Nahrgang, J. D., Morgeson, F. P., \& Hofmann, D. A. (2011). Safety at work: a metaanalytic investigation of the link between job demands, job resources, burnout, engagement, and safety outcomes. Journal of Applied Psychology, 96, 71-94.

National Center for Veterans Analysis and Statistics (2015). Veterans by period of service and by children in or not in the household as of 9/30/2015. Retrieved from https://www.va.gov/vetdata/docs/Quickfacts/Veterans_by_POS_and_by_Ch ildren.pdf

National Center for Veterans Analysis and Statistics (2016). Profile of post-9/11 veterans: 2014. Retrieved from https://www.va.gov/vetdata/docs/SpecialReports/Post_911_Veterans_Profile 2014.pdf

Neal, A., Griffin, M. A., \& Hart, P. M. (2000). The impact of organizational climate on safety climate and individual behavior. Safety Science, 34, 99-109.

Neal, M.B. \& Hammer, L.B. (2007). Working couples caring for children and aging parents: Effects on work and well-being. Mahwah, NJ: Lawrence Erlbaum.

Ng, T. W., \& Sorensen, K. L. (2008). Toward a further understanding of the relationships between perceptions of support and work attitudes: A meta-analysis. Group \& Organization Management, 33, 243-268.

Nippert-Eng, C. E. (1996). Home and work: Negotiating boundaries through everyday life. Chicago, IL: University of Chicago Press.

Nohe, C., Meier, L. L., Sonntag, K., \& Michel, A. (2015). The chicken or the egg? A meta-analysis of panel studies of the relationship between work-family conflict and strain. Journal of Applied Psychology, 100, 522-536. 
Oron, A. (2006). Easy prey: Evidence for race and military related targeting in the distribution of pay-day loan branches in Washington state. Consulting Report, Department of Statistics, University of Washington.

Paiva, C. E., Barroso, E. M., Carneseca, E. C., de Pádua Souza, C., dos Santos, F. T., López, R. V. M., \& Paiva, S. B. R. (2014). A critical analysis of test-retest reliability in instrument validation studies of cancer patients under palliative care: A systematic review. BMC Medical Research Methodology, 14.

Park, J., Kitayama, S., Karasawa, M., Curhan, K., Markus, H. R., Kawakami, N., ... \& Ryff, C. D. (2013). Clarifying the links between social support and health: Culture, stress, and neuroticism matter. Journal of Health Psychology, 18, 226235.

Payne, N., Jones, F., \& Harris, P. (2002). The impact of working life on health behavior: The effect of job strain on the cognitive predictors of exercise. Journal of Occupational Health Psychology, 7, 342-353.

Pearlin, L. I., Menaghan, E. G., Lieberman, M. A., \& Mullan, J. T. (1981). The stress process. Journal of Health and Social Behavior, 22, 337-356.

Probst, T. (2005). Economic stressors. In J. Barling, E. Kelloway, \& M. Frone (Eds.), Handbook of Work Stress (pp. 267-297). Thousand Oaks, CA: Sage.

Probst, T. M. (2010). Multi-level models of stress and well-being. Stress and Health, 26, 95-97.

Probst, T.M., \& Brubaker, T.L. (2001). The effect of job insecurity on employee safety outcomes: Cross sectional and longitudinal explorations. Journal of Occupational Health Psychology, 6, 139-159. 
Procidano, M.E., \& Heller, K. (1983). Measures of perceived social support from friends and family: Three validation studies. American Journal of Community Psychology, 11, 1-24.

Rosenblatt, Z., Talmud, I., \& Ruvio, A. (1999). A gender-based framework of the experience of job insecurity and its effects on work attitudes. European Journal of Work and Organizational Psychology, 8, 197-217.

Ross, C. E., \& Huber, J. (1985). Hardship and depression. Journal of Health and Social Behavior, 26, 312-327.

Shaw, J. D., \& Gupta, N. (2001). Pay fairness and employee outcomes: Exacerbation and attenuation effects of financial need. Journal of Occupational and Organizational Psychology, 74, 299-320.

Sheppard, S. C., Malatras, J. W., \& Israel, A. C. (2010). The impact of deployment on US military families. American Psychologist, 65, 599-609.

Shockley, K. M., \& Singla, N. (2011). Reconsidering work-family interactions and satisfaction: A meta-analysis. Journal of Management, 97, 1077-1096.

Sinclair, R. R., \& Cheung, J. H. (2016). Money matters: Recommendations for financial stress research in occupational health psychology. Stress and Health, 32, 181-193.

Sinclair, R. R., Sears, L. E., Probst, T. M., \& Zajack, M. (2010). A multilevel model of economic stress and employee well-being. In J. Houdmont \& S. Leka (Eds.), Contemporary Occupational Health Psychology: Global Perspectives on Research and Practice: v1 (pp. 1-20). Hoboken, NJ: Wiley-Blackwell. 
Smith, T. D., \& DeJoy, D. M. (2012). Occupational injury in America: An analysis of risk factors using data from the General Social Survey (GSS). Journal of Safety Research, 43, 67-74.

Son, J., \& Wilson, J. (2015). The psycho-social processes linking income and volunteering: Chronic financial strain and well-being. In Sociological Forum, 30, 1059-1081.

Sparks, K., Cooper, C., Fried, Y., \& Shirom, A. (1997). The effects of hours of work on health: a meta-analytic review. Journal of Occupational and Organizational Psychology, 70, 391-408.

Spector, P. E., Cooper, C. L., Poelmans, S., Allen, T. D., O’Driscoll, M., Sanchez, J. I., ... \& Lu, L. (2004). A cross-national comparative study of work-family stressors, working hours, and well-being: China and Latin America versus the Anglo world. Personnel Psychology, 57, 119-142.

Stevens, D. P., Minnotte, K. L., Mannon, S. E., \& Kiger, G. (2007). Examining the "neglected side of the work-family interface": Antecedents of positive and negative family-to-work spillover. Journal of Family Issues, 28, 242-262.

Sverke, M., Hellgren, J., \& Näswall, K. (2002). No security: a meta-analysis and review of job insecurity and its consequences. Journal of occupational health psychology, 7, 242-264.

Swanberg, J. E. (2005). Job-family role strain among low-wage workers. Journal of Family and Economic Issues, 26, 143-158.

Tabachnick, B. G., \& Fidell, L. S. (2007). Using multivariate statistics (5th ed.). Boston, MA: Pearson Education. 
ten Brummelhuis, L. L., \& Bakker, A. B. (2012). A resource perspective on the workhome interface: The work-home resources model. American Psychologist, 67, $545-556$.

Thoits, P. A. (1983). Multiple identities and psychological well-being: A reformulation and test of the social isolation hypothesis. American Sociological Review, $48,174-187$.

Thoits, P. A. (1986). Social support as coping assistance. Journal of Consulting and Clinical Psychology, 54, 416-423.

Thoits, P. A. (2010). Stress and health major findings and policy implications. Journal of Health and Social Behavior, 51, S41-S53.

Thompson, M. S., \& Cooper, C. L. (2001). A rose by any other name...: A commentary on Hobfoll's conservation of resources theory. Applied Psychology: An International Review, 50, 408-418.

Toker, S., Shirom, A., Melamed, S., \& Armon, G. (2012). Work characteristics as predictors of diabetes incidence among apparently healthy employees. Journal of Occupational Health Psychology, 17, 259-267.

Ullah, P. (1990). The association between income, financial strain and psychological well-being among unemployed youths. Journal of Occupational Psychology, 63, 317-330.

United States Census Bureau (2017). QuickFacts Oregon. Retrieved from https://www.census.gov/quickfacts/OR

Vinokur, A. D., Pierce, P. F., Lewandowski-Romps, L., Hobfoll, S. E., \& Galea, S. (2011). Effects of war exposure on air force personnel's mental health, job 
burnout and other organizational related outcomes. Journal of Occupational Health Psychology, 16, 3-17.

Vinokur, A. D., Price, R. H., \& Caplan, R. D. (1996). Hard times and hurtful partners: How financial strain affects depression and relationship satisfaction of unemployed persons and their spouses. Journal of Personality and Social Psychology, 71, 166-179.

Veal, A. J. (2004). A brief history of work and its relationship to leisure. In J. T. Haworth \& A. J. Veal (Eds.), Work and leisure (pp. 15-33). New York, NY: Routledge.

Viswesvaran, C., Sanchez, J. I., \& Fisher, J. (1999). The role of social support in the process of work stress: A meta-analysis. Journal of Vocational Behavior, 54, 314334.

Voydanoff, P. (1990). Economic distress and family relations: A review of the eighties. Journal of Marriage and the Family, 52, 1099-1115.

Watson, S. J., Barber, B. L., \& Dziurawiec, S. (2015). The role of economizing and financial strain in Australian university students' psychological wellbeing. Journal of Family and Economic Issues, 36, 421-433.

Wayne, J. H., Casper, W. J., Matthews, R. A., \& Allen, T. D. (2013). Family-supportive organization perceptions and organizational commitment: The mediating role of work-family conflict and enrichment and partner attitudes. Journal of Applied Psychology, 98, 606-622.

West, S. G., Finch, J. F., \& Curran, P. J. (1995). Structural equation models with nonnormal variables: Problems and remedies. In H Hoyle (Ed). Structural 
equation modeling: Concepts, issues, and applications (pp. 56-75). Thousand Oaks, CA: Sage.

Williams, M. L., McDaniel, M. A., \& Nguyen, N. T. (2006). A meta-analysis of the antecedents and consequences of pay level satisfaction. Journal of Applied Psychology, 91, 392-413.

Wilson, K. S., \& Baumann, H. M. (2015). Capturing a more complete view of employees' lives outside of work: The introduction and development of new interrole conflict constructs. Personnel Psychology, 68, 235-282.

Winston, P. (2014). Work-family supports for low-income families: Key research findings and policy trends. Retrieved from U.S. Department of Health and Human Services, http://aspe.hhs.gov/hsp/14/WorkFamily/rpt_workfamily.cfm

Yoon, J., \& Lim, J. 1999. Organizational support in the workplace: The case of Korean hospital employees. Human Relations, 82, 923-945.

Young, M., \& Schieman, S. (2012). When hard times take a toll: The distressing consequences of economic hardship and life events within the family-work interface. Journal of Health and Social Behavior, 53, 84-98.

Zerubavel, E. (1991). The fine line. New York, NY: Free Press. 